UNIVERSIDADE DE SÃO PAULO

FACULDADE DE MEDICINA DE RIBEIRÃO PRETO

DAIANE LEITE DA ROZA

Padrões espaço-temporais da incidência da tuberculose em Ribeirão Preto, SP: uso de um modelo bayesiano autoregressivo condicional 


\title{
Padrões espaço-temporais da incidência da tuberculose em Ribeirão Preto, SP: uso de um modelo bayesiano auto- regressivo condicional
}

\author{
VERSÃO CORRIGIDA \\ O original encontra-se disponível na unidade que aloja o Programa de Pós-Graduação em \\ Saúde na Comunidade
}

Dissertação apresentada à Faculdade de Medicina de Ribeirão Preto da Universidade de São Paulo para a obtenção do título de Mestre.

Área de Concentração: Saúde na Comunidade

Linha de Pesquisa: Métodos Quantitativos em Saúde

Orientador: Prof. Dr. Edson Zangiacomi Martinez

Ribeirão Preto - SP

2011 
AUTORIZO A REPRODUÇÃO E DIVULGAÇÃO TOTAL E PARCIAL DESTE TRABALHO, POR QUALQUER MEIO CONVENCIONAL OU ELETRÔNICO, PARA FINS DE ESTUDO E PESQUISA, DESDE QUE CITADA A FONTE.

\section{Ficha Catalográfica}

Roza, Daiane Leite da

Padrões espaço-temporais da incidência da tuberculose em Ribeirão Preto, SP: uso de um modelo bayesiano auto-regressivo condicional, 2011

115 p.:il.; $30 \mathrm{~cm}$

Dissertação de Mestrado apresentada à Faculdade de Medicina de Ribeirão Preto - USP. Área de concentração: Saúde na Comunidade.

Orientador: Martinez, Edson Zangiacomi

1. Estudo Ecológico. 2. Métodos Bayesianos. 3. Tuberculose. 


\section{FOLHA DE APROVAÇÃO}

Roza, Daiane Leite da

Padrões espaço-temporais da incidência da tuberculose em Ribeirão Preto, SP: uso de um modelo bayesiano auto-regressivo condicional.

Dissertação apresentada à Faculdade de Medicina de Ribeirão Preto da Universidade de São Paulo para obtenção do título de Mestre.

Área de Concentração: Saúde na Comunidade.

Aprovado em:

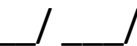

\section{Banca Examinadora}

Prof.(a) Dr.(a) Instituição:

Julgamento: Assinatura:

Prof.(a) Dr.(a) Instituição:

Julgamento: Assinatura:

Prof.(a) Dr(a). Instituição: Assinatura: 


\section{DEDICATÓRIA}

\section{À minha mãe}

"O amor de mãe é o combustível que permite a um ser humano fazer o impossível"

Marion C. Garretty 


\section{AGRADECIMENTO ESPECIAL}

Meu agradecimento especial é para meu admirável orientador

Prof. Dr. Edson Zangiacomi Martinez

Ser humano de caráter extraordinário, profissional de extrema competência, digno de imensa admiração. Obrigada pela confiança depositada em meu trabalho, pelo saber transmitido em toda trajetória, pela orientação segura, pelo incentivo de meus acertos e pela paciência e compreensão de meus erros, pela simples palavra de carinho e conforto no momento certo.

Obrigada por me ajudar a levantar em todos os momentos nos quais eu pensei em desistir, obrigada por não ter me deixado desistir, por me encorajar e principalmente por dizer sempre, fique calma tudo vai dar certo! Obrigada por ter me transmitido muito mais que ensinamentos acadêmicos, aprendi com seu exemplo de caráter, honestidade, humildade, solidariedade e principalmente a sabedoria, intrínsecos somente aos verdadeiros mestres. 


\section{AGRADECIMENTOS}

Foram muitos que me ajudaram nesta dissertação, tenho certeza que não conseguirei agradecer a todos, mas algumas pessoas marcaram mais, sendo assim...

Agradeço aos Professores Altacílio, Maria do Carmo, Jorge e Edson que tão gentilmente dividiram sua sala comigo para que fosse possível a redação desta dissertação.

Agradeço as contribuições valiosas dos professores Aparecida Doniseti, Laércio e Maria do Carmo em minha banca de qualificação.

Agradeço ao carinho, compreensão e amizade de todos os meus amigos que passaram e aos que estão no CEMEQ.

Agradeço a todos do Departamento de Medicina Social que tanto me ajudaram.

Agradeço aos coordenadores das unidades básicas de saúde que tão gentilmente me receberam e me ajudaram no mapeamento de cada região.

Agradeço a divisão epidemiológica do município de Ríbeirão Preto que permitiu a utilização dos dados, em especial as enfermeiras Maria Elvira e Luzia Márcia.

Agradeço à Coordenação de Aperfeiçoamento de Pessoal de Nível Superior CAPES pela concessão da bolsa de mestrado.

Agradeço à Fundação de Apoio ao Ensino, Pesquisa e Assistência do Hospital das Clínicas da Faculdade de Medicina de Ribeirão Preto - FAEPA pelo auxílio financeiro.

E a todos que acreditaram na relevância deste estudo. 
"A paciência é uma virtude." 


\section{RESUMO}

ROZA, D. L. Padrões espaço-temporais da incidência da tuberculose em Ribeirão Preto: uso de um modelo auto-regressivo condicional. 2011. 115p. Dissertação (Mestrado) Faculdade de Medicina de Ribeirão Preto, Universidade de São Paulo, Ribeirão Preto, 2011.

Neste trabalho foram utilizados modelos de regressão espaço-temporais bayesianos para estimar a incidência de TB em Ribeirão Preto (anos de 2006 a 2009) por área de abrangência de unidades de saúde, associando-a a covariáveis de interesse (IPVS, Renda e Educação predominantes naquelas áreas). O método baseia-se em simulações MCMC para estimar as distribuições a posteriori das incidências de TB em Ribeirão Preto. Como resultado, temos mapas que mostram mais claramente um padrão espacial, com estimativas mais suavizadas e com menos flutuações aleatórias. Observamos que as áreas com as mais altas taxas de incidência também possuem índice de vulnerabilidade social médio e alto. Em relação à renda, a faixa salarial predominante dos responsáveis pelo domicílio nestas regiões é entre 0 e 3 salários mínimos e o nível de escolaridade predominante dos chefes do domicílio nestas regiões é o ensino fundamental. Os resultados dos modelos bayesianos analisados nos evidenciam que com o aumento da vulnerabilidade social aumentamos significativamente a incidência de TB em Ribeirão Preto. Nas áreas onde a vulnerabilidade é alta a incidência de TB chega a quase 15 vezes a incidência das áreas sem vulnerabilidade. Houve um aumento significativo em relação à incidência de tuberculose em Ribeirão Preto durante os anos estudados, sendo as maiores incidências registradas no ano de 2009. O uso de mapas facilitou a visualização de áreas que merecem uma atenção especial no controle da TB, além disso, a associação da doença com renda, escolaridade e vulnerabilidade social trazem subsídios para que os gestores responsáveis pelo planejamento do município planejem intervenções com uma atenção especial a estas áreas, reunindo esforços para a redução da pobreza e da desigualdade social, alternativas para uma melhor distribuição de renda e melhorar o acesso ao saneamento básico dentre outras prioridades.

Palavras chave: estudo ecológico, análise espacial, métodos bayesianos e tuberculose. 


\section{ABSTRACT}

ROZA, D. L. Spatio-temporal patterns of tuberculosis incidence in Ribeirão Preto: using a conditional autoregressive model. 2011. 115p. Dissertation (Master degree) - Faculty of Medicine of Ribeirão Preto, University de São Paulo, Ribeirão Preto, 2011.

In this study we used Bayesian space-temporal regression models to estimate the incidence of TB in Ribeirão Preto, SP (years 2006 to 2009) by the coverage area of health units, associating it with the covariates of interest (IPVS, Income and Education predominant those areas). The method is based on MCMC simulations for estimate the posterior distributions of TB incidence in Ribeirão Preto. As a result, we have maps that show a spatial pattern more clearly, with estimates smoother and less random fluctuations. We observed that the areas with the highest incidence rates also have medium and high social vulnerability index. Concerning income, the prevailing salary range of household heads in these regions is between 0 and 3 minimum wages and the prevailing level of education of household heads in these regions is the elementary school. The results of the models in Bayesian analysis show that with increasing social vulnerability significantly increased the incidence of TB in Ribeirao Preto. In areas where vulnerability is high incidence of TB is nearly 15 times the incidence of areas without vulnerability. There was a significant increase in the incidence of tuberculosis in Ribeirão Preto during the years studied, the highest incidence recorded in 2009. The use of maps improved visualization of areas that deserve special attention for TB control, in addition, the association of disease with income, education and social vulnerability that bring benefits to the managers responsible for planning the municipality to plan interventions with special attention these areas, uniting efforts to reduce poverty and social inequality, alternatives to improve income distribution and improve access to basic sanitation among other priorities.

Keywords: ecological study, spatial analysis, bayesian methods and tuberculosis. 


\section{LISTA DE ILUSTRAÇÕES}

Figura 1.1 - Coeficiente de Incidência de TB em Ribeirão Preto nos anos de 1998 a 2009

Figura 3.1 - Localização do Município de Ribeirão Preto no Estado de São

Paulo. 32

Figura 3.2 - Divisão da área urbana do Município de Ribeirão Preto em 44 delimitações geográficas e em verde a área rural. 35

Figura 3.3 - Divisão da área urbana do Município de Ribeirão Preto em 44 delimitações geográficas, sobrepostas aos 651 setores censitários definidos pelo IBGE para

o Censo Demográfico de 2000. 36

Figura 3.4 - Mapa dos distritos de saúde de Ribeirão Preto, SP 37

Figura 3.5 - Mapa da distribuição da população (número de habitantes) por setor censitário e por áreas de saúde.

Figura 3.6 - Mapa da distribuição do IPVS por setor censitário e por áreas de saúde, respectivamente.

Figura 3.7 - Mapa da distribuição da Renda por setor censitário e por áreas de saúde, respectivamente.

Figura 3.8 - Mapa da distribuição da Educação por setor censitário e por áreas de saúde, respectivamente.

Figura 4.1 - Ajuste do modelo 3.2 em relação aos dados brutos. Os pontos sólidos em vermelho representam os valores brutos registrados da incidência de TB (100 mil habitantes) em cada ano. Os círculos pretos correspondem a estimativa média da incidência de casos de TB (100 mil habitantes), e as linhas pontilhadas correspondem ao intervalo de credibilidade com $95 \%$ 62

Figura 4.2 - Mapas das taxas de incidência de TB Bruto (A) e Ajustado (B) para os anos: 2006, 2007, 2008 e 2009. As legendas referem-se ao número de novos casos de TB a cada 100 mil habitantes. 


\section{LISTA DE TABELAS}

Tabela 3.1 - Áreas em estudo. Em negrito, destaca-se a UBDS de cada distrito.

Tabela 3.2 - Estimativas do número populacional para o município de Ribeirão Preto, SP.

Tabela 4.1 - Casos confirmados de TB segundo ano de diagnóstico, indivíduos residentes em Ribeirão Preto, SP. 59

Tabela 4.2 - Modelos espaço-temporais propostos. 60

Tabela 4.3 - Modelos espaço-temporais propostos com o modelo 3.2. 60

Tabela 4.4 - Coeficientes de incidência de tuberculose, segundo características das regiões de saúde do município de Ribeirão Preto, SP.

Tabela 4.5 - Razão entre os coeficientes de incidência de tuberculose, segundo características das regiões de saúde do município de Ribeirão Preto, SP.

Tabela 4.6 - Coeficientes de incidência de tuberculose, segundo características das regiões de saúde do município de Ribeirão Preto,

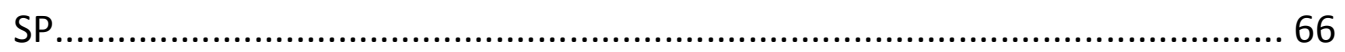

Tabela 4.7 - Razão entre os coeficientes de incidência de tuberculose, segundo características das regiões de saúde do município de Ribeirão Preto, SP.

Tabela 4.8 - Coeficientes de incidência de tuberculose, segundo características das regiões de saúde do município de Ribeirão Preto, SP. 68

Tabela 4.9 - Razão entre os coeficientes de incidência de tuberculose, segundo características das regiões de saúde do município de Ribeirão Preto, SP. 69 


\section{LISTA DE SIGLAS}

AIC

AIDS

CAR

CAPES

DIC

DOTS

FAPESP

IBGE

INPE

IPVS

MCMC

OMS

SEADE

SINAN

TB

UBDS

UBS

USF
Akaike's Information Criterion

Síndrome da Imunodeficiência Adquirida

Conditional Autoregressive

Coordenação de Aperfeiçoamento de Pessoal de Nível Superior

Deviance Information Criterion

Directly Observed Therapy Short-course

Fundação de Amparo á Pesquisa do Estado de São Paulo

Instituto Brasileiro de Geografia e Estatística

Instituto Nacional de Pesquisas Espaciais

Índice Paulista de Vulnerabilidade Social

Monte Carlo em Cadeia de Markov

Organização Mundial da Saúde

Sistema Estadual de Análise de Dados

Sistema de Informações de Agravos e Notificações

Tuberculose

Unidades Básicas Distritais de Saúde

Unidades Básicas de Saúde

Unidade Saúde da Família 


\section{SUMÁRIO}

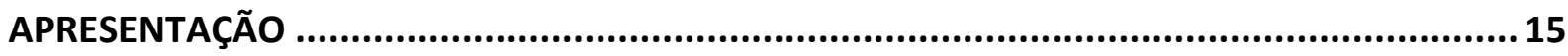

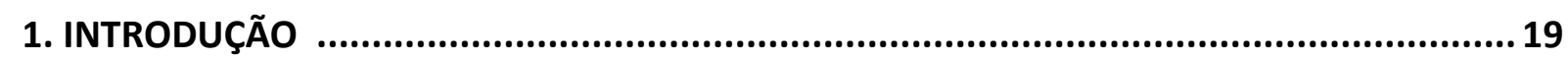

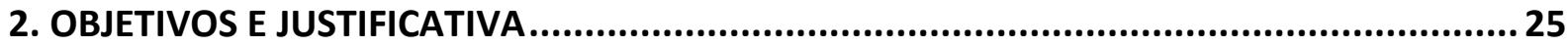

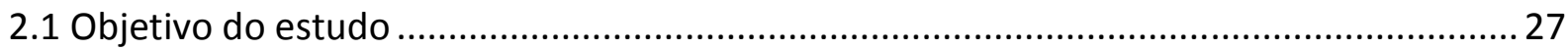

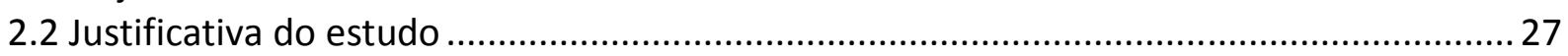

3. METODOLOGIA

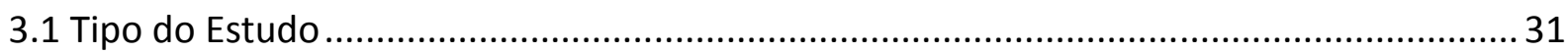

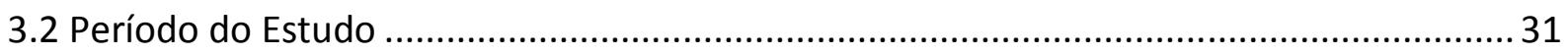

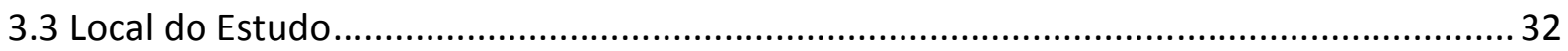

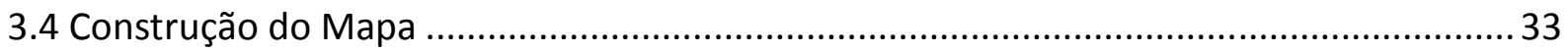

3.5 Critérios de Inclusão e Exclusão da população em estudo ............................................. 39

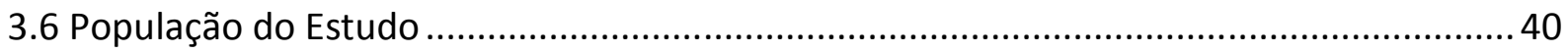

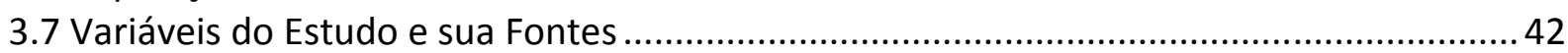

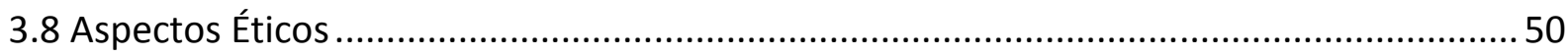

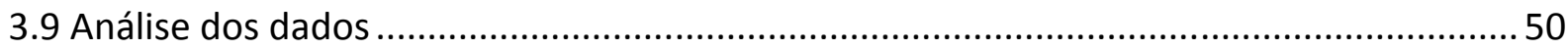

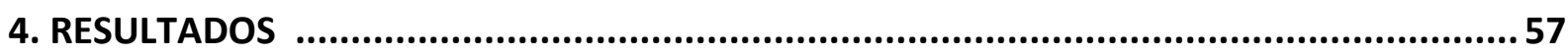

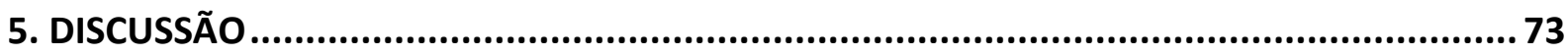

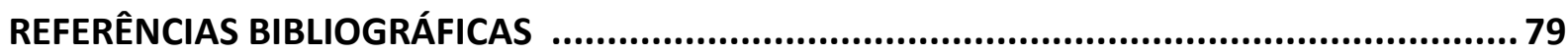

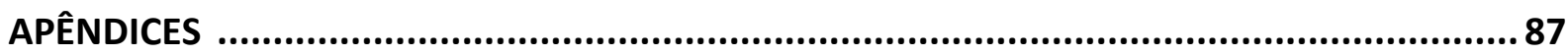

Apêndice A - Sumário a posteriori assumindo o modelo com efeito espacial e covariável IPVS

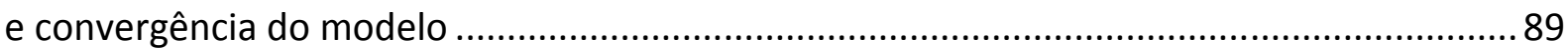

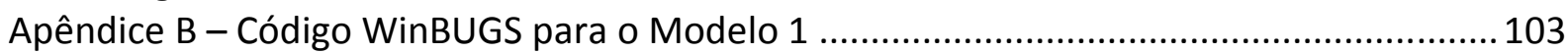

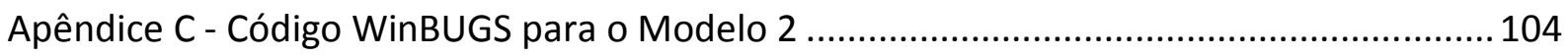

Apêndice D - Código WinBUGS para o Modelo 3.1 e 3.2 ..................................................... 105

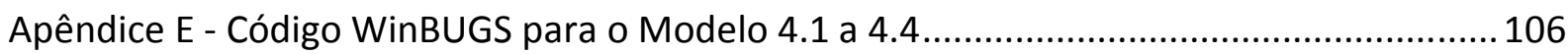

Apêndice F - Código WinBUGS para o Modelo 5................................................................. 107

Apêndice G - Tabela da incidência de casos de TB em Ribeirão Preto nos anos de 2006 a

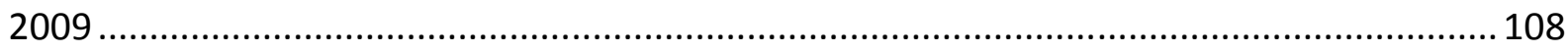

Apêndice $\mathrm{H}$ - Tabela da média ajustada da incidência de casos de TB pelo melhor modelo para Ribeirão Preto nos anos de 2006 a 2009 ................................................................. 110

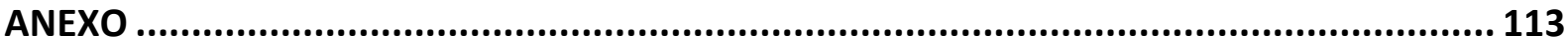

Anexo A - Aprovação do Comitê de Ética em Pesquisa.......................................................... 115 
APRESENTAÇÃO 

O interesse por estudos que envolvem análise espacial me acompanha desde o terceiro ano do curso de graduação em Estatística, em 2005. Durante o curso tive a oportunidade de participar de um projeto de pesquisa, cujo foco foi a região do Pontal do Paranapanema (oeste do estado de São Paulo), nesse Grupo de estudos o SIG-PONTAL da Faculdade de Ciência e Tecnologia da Universidade Estadual Paulista - UNESP, tive um projeto de Iniciação Científica financiado pela Fundação de Amparo à Pesquisa do Estado de São Paulo - FAPESP (2006-2007) com o título "Avaliação da Eficácia de Símbolos Cartográficos em Atlas Interativos do Pontal do Paranapanema". Essa experiência possibilitou desenvolver atividades de pesquisa em colaboração com outros pesquisadores do Grupo e, por se tratar de um projeto temático e multidisciplinar, cursei algumas disciplinas do curso de graduação em Engenharia Cartográfica. Essas atividades me permitiram conhecer melhor a análise espacial.

Com esse conhecimento adquirido resolvi continuar meus estudos nesta área, porém, com técnicas estatísticas agregadas a análise espacial. Desta forma, em 2007 desenvolvi o projeto de pesquisa Análise de Agrupamentos Espaciais como trabalho de conclusão de curso.

Na busca em aprofundar meu conhecimento e aproximar-me do contexto da bioestatística, após a graduação vim estagiar no CEMEQ (Centro de Métodos Quantitativos) da FMRP/USP, aonde aprendi muito sobre análise de dados clínicos e onde tive a oportunidade de conhecer e trabalhar com os professores Edson e Jorge. As atividades desenvolvidas junto ao CEMEQ me trouxeram grandes conhecimentos sobre pesquisa. E meu trabalho realizado junto a este centro envolve mais que análises estatísticas, mas trouxe-me a oportunidade de conhecimento em diversas áreas da saúde bem como ministrar cursos e aulas a um público com interesse em estatística. Assim, meu interesse em continuar nesta área só aumentou e, em meados de 2008, comecei a preparação deste projeto de mestrado. Preparei-me e no final de 2008 fui aprovada no processo seletivo do mestrado em saúde na comunidade do Departamento de Medicina Social da FMRP/USP e meu projeto recebeu financiamento pela CAPES - Coordenação de Aperfeiçoamento de Pessoal de Nível Superior.

Após aprovação no processo seletivo, no primeiro semestre de 2009 cursei 41 créditos, dos 30 obrigatórios para o curso de Mestrado. Os créditos cursados ofereceram 
subsídios para ajustes do projeto e ampliação da revisão da literatura. No segundo semestre após aprovação do projeto de pesquisa pelo Comitê de Ética em Pesquisa da FMRP/USP, protocolo 11304/2009, realizei a coleta de dados junto à divisão epidemiológica da Prefeitura Municipal de Ribeirão Preto referente aos casos de tuberculose no município nos anos de 2006 a 2009. Assim com os dados em mãos iniciei a elaboração dos modelos bayesianos com efeito espaço-temporal.

No final de 2010 fui convidada a lecionar aulas de estatística em uma faculdade particular de Ribeirão Preto, e atualmente tenho colocado em prática o aprendizado adquirido durante o curso de mestrado, principalmente o conhecimento adquirido com a preparação pedagógica e o estágio PAE - Programa de Aperfeiçoamento de Ensino.

No primeiro semestre de 2011 iniciei a preparação de um projeto de doutorado, preparei-me e em junho fui aprovada no processo seletivo para o doutoramento, no qual inicio logo após a defesa dessa dissertação.

Diante do exposto apresento a pesquisa desenvolvida contemplando a introdução, objetivos, metodologia, resultados e conclusão do estudo. Programas computacionais e resultados secundários estão no Apêndice. 
Capítulo 1 

Muitos autores (Pethe et al, 2001, Gandy \& Zumla, 2002 e Burgos \& Pym, 2002) têm afirmado que a tuberculose (TB) continua sendo a principal causa mundial de morte por um único agente infeccioso, o Mycobacterium tuberculosis, com cerca de 3 milhões de óbitos e 10 milhões de novos casos estimados a cada ano (Pethe et al, 2001). Estima-se que uma em cada três pessoas em todo o mundo receberiam um resultado positivo em um teste cutâneo para a infecção, ou seja, seriam portadoras da bactéria (Russel, 2010). A TB está fortemente associada com a pobreza (Spence et al, 1993), à má distribuição de renda, urbanização, ao crescimento dos casos da Síndrome da Imunodeficiência Adquirida (AIDS) (Vendramini et al, 2005) e determinantes socioeconômicos tais como a desnutrição e deficiências de micronutrientes (Koyanagi et al, 2004).

Diante disso, a Organização Mundial da Saúde (OMS) vem criando estratégias para o controle e erradicação da TB. Em 1993, a OMS declarou a situação da TB como estado de emergência mundial, apresentando um conjunto de medidas denominado Stop TB (Raviglione e Uplekar, 2006), com o cumprimento de metas que contemplam a redução da incidência e redução em $50 \%$ da prevalência e mortalidade por TB, e, até 2050, eliminar a TB como problema de saúde pública (Teixeira, 2006). Em 1998 foi estabelecido uma estratégia para o cumprimento do Plano Stop TB (WHO, 2006) a estratégia Directly Observed Therapy Short-course (DOTS) (WHO, 1999), um tratamento diretamente observado que visa favorecer a adesão do doente e assegurar a conclusão do tratamento (Cardozo Gonzáles et al, 2008). Esta estratégia tem como objetivos: detecção de casos pela microscopia; regime de tratamento padronizado de, no mínimo, seis a oito meses para todos os casos confirmados a partir de testes positivos de secreção, com tratamento diretamente observado pelo menos nos dois primeiros meses; provisão regular de todos os medicamentos antituberculostáticos; sistema padronizado e eficiente de registro e notificação de dados; e compromisso político no suporte financeiro na detecção de casos e atividades de controle da doença (Organização Panamericana de Saúde, 1997; Rodrigues et al, 2008).

No Brasil, a TB é um importante problema de saúde pública com aproximadamente 90.000 casos relatados anualmente (Dalcomo, 1996). Integra o grupo dos 22 países que concentram $80 \%$ dos casos de tuberculose registrados no mundo (Borgdorff, 2010), ocupando a 15a posição. Em 2004, o coeficiente de incidência de TB era de 41 novos casos para cada 100.000 habitantes (Bierrenbach et al, 2007), sendo esta incidência muito 
alta em áreas urbanas tais como os estados do Rio de Janeiro (120/100.000) e São Paulo (80/100.000) (Spindola et al, 2001). Em 1995, Ribeirão Preto foi incluída entre os 25 municípios prioritários para o controle da tuberculose no estado de São Paulo (Muniz \& Villa, 2002). Neste mesmo ano, o coeficiente anual médio da incidência de TB foi de 57,19 para cada 100.000 pessoas (Muniz \& Villa, 2002). Depois da implantação de ações como a estratégia DOTS (Vendramini et al, 2005), o coeficiente de incidência de TB em Ribeirão Preto diminuiu para 39,68, 35,73, 30,23 e 28,73 casos por 100.000 habitantes, respectivamente, para os anos de 2001, 2002, 2003 e 2004 segundo dados do SINAN (Sistema de Informações de Agravos e Notificações).

A implantação da estratégia DOTS em Ribeirão Preto aconteceu em 1998. Desde então as incidências de TB, segundo dados do SINAN, foram decrescendo ano a ano. Porém, as incidências vêm aumentando desde 2005, conforme Figura 1.1.

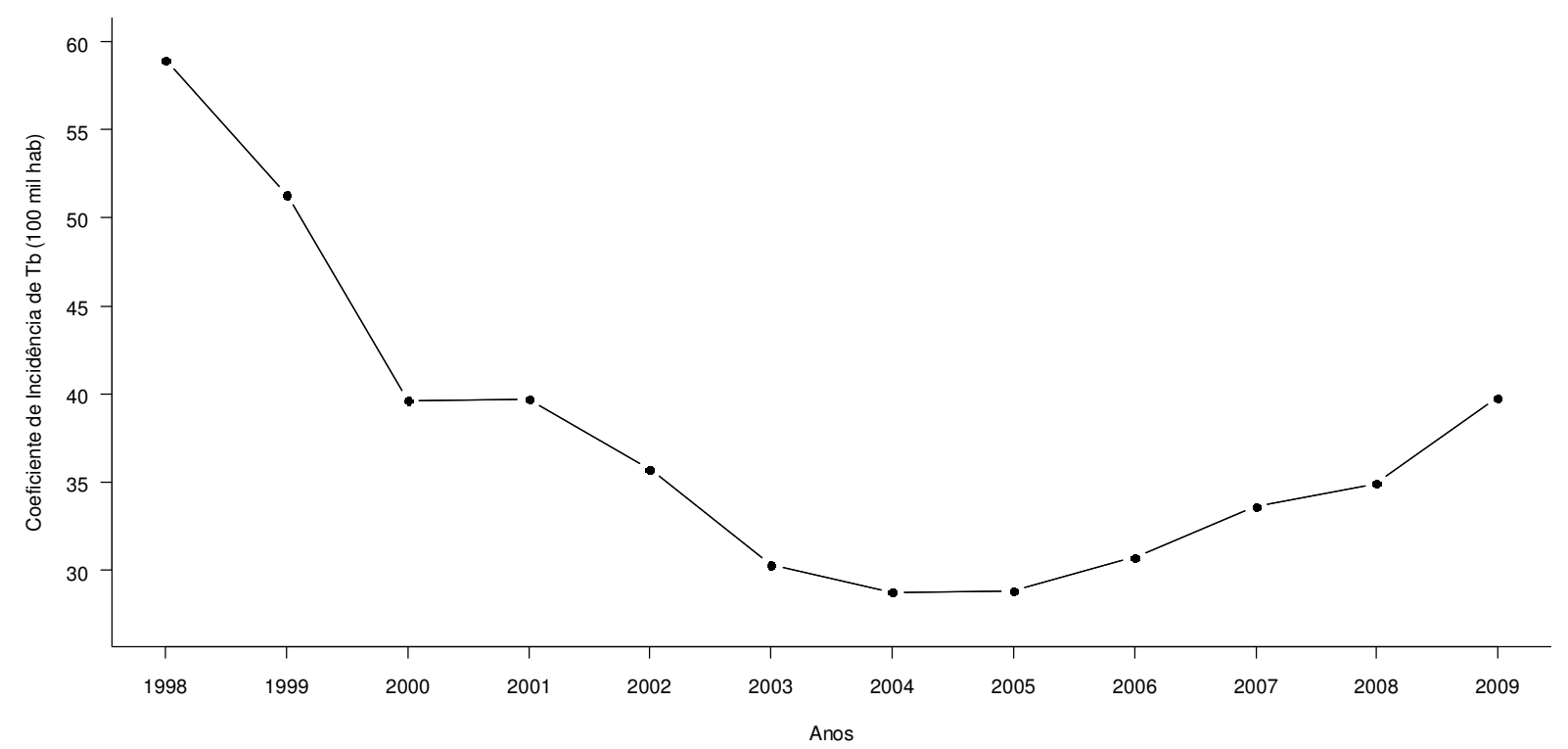

Figura 1.1. Coeficiente de Incidência de TB em Ribeirão Preto nos anos de 1998 a 2009. Fonte: SINAN e IBGE.

O uso de técnicas de análise espacial (Gesler, 1986) para o mapeamento geográfico da distribuição de casos de TB tem sido considerado por muitos autores (AlvarezHernández et al, 2010 , Touray et al, 2010 e Maciel et al, 2010). Os métodos de análise espacial na saúde pública vêm sendo usados principalmente em estudos ecológicos, com o intuito de detectar conglomerados espaciais ou espaço-temporais, na avaliação e no monitoramento ambiental aplicados no planejamento e na avaliação de uso de serviços de 
saúde (Elliot et al, 2004; Bailey, 2001). Nestes estudos, ao modelar dados de natureza espacial sobre a incidência de TB, verificou-se que os casos da doença tendem a se reunir em determinados locais (Munch et al, 2003). Assim, a identificação de áreas com diferentes riscos para a TB permite que o sistema público de saúde trabalhe com as características de cada região e priorize as que apresentam maior incidência da doença (Vendramini et al, 2005).

Estudos ecológicos da ocorrência de TB em Ribeirão Preto foram conduzidos por Brunello et al (2011), Hino et al (2011), Hino et al (2007), Hino et al (2005a e 2005b), Santos et al (2004) e Santos et al (2002). Estes estudos mostraram que existe grande variação nos locais de ocorrência dos casos da doença no município, algumas concentrações dos casos na faixa noroeste do município e grandes concentrações de casos em áreas supostamente com níveis socioeconômicos menos favorecidos.

A demora no diagnóstico da TB pode resultar em graves manifestações da doença e maior mortalidade, pois doentes não tratados continuam a transmitir a infecção a outras pessoas, sustentando a disseminação do Microbacterium tuberculosis na comunidade (Huong et al, 2007). O uso de um modelo ecológico no estudo da tuberculose tem por objetivo estudar as condições regionais, socioeconômicas e de responsabilidade social do município, ajudando administradores de saúde pública com informações sobre a dinâmica do problema da tuberculose.

Neste contexto, o presente estudo utilizou modelos estatísticos bayesianos com estrutura espaço-temporal para buscar um entendimento da distribuição geográfica dos casos de tuberculose em Ribeirão Preto, SP. Além disso, a inserção de covariáveis (renda, educação e IPVS) nestes modelos pode descrever melhor a ocorrência da doença. Este estudo difere dos trabalhos de Santos et al (2004) e Hino et al (2005) por: (a) mapear a incidência da TB em Ribeirão Preto por áreas relacionadas à abrangência de serviços públicos de saúde, e não apenas identificar pontualmente alguns locais com maior concentração de casos, e por (b) buscar associações via modelos de regressão entre a ocorrência de TB e variáveis relacionadas ao contexto de vulnerabilidade, renda e educação predominante entre os responsáveis pelos domicílios destas áreas. 

Capítulo 2

\section{OBJETIVOS E JUSTIFICATIVA}





\subsection{OBJETIVOS DO ESTUDO}

Avaliar a distribuição espaço-temporal da incidência da tuberculose em Ribeirão Preto, SP, entre os anos de 2006 a 2009 e a relação entre a ocorrência de novos casos da doença e variáveis como a vulnerabilidade social, a distribuição da renda e educação.

Como objetivo secundário, construir um mapa composto por limites geográficos inseridos na área urbana do município de Ribeirão Preto, que atendesse aos propósitos do presente estudo, baseado nas áreas de abrangência das UBS (Unidades Básicas de Saúde), UBDS (Unidades Básicas Distritais de Saúde) e USF (Unidade Saúde da Família).

\subsection{JUSTIFICATIVA DO ESTUDO}

O mapeamento e o estudo dos casos de TB pode ajudar os gestores da área pública de saúde a tomar medidas de prevenção e tratamento, adotando políticas mais eficientes e centradas nos locais com maior incidência e riscos mais elevados da doença. 

Capítulo 3

METODOLOGIA 



\subsection{TIPO DE ESTUDO}

Trata-se de um estudo epidemiológico ecológico, onde é conduzida uma análise espacial e temporal em saúde.

Um estudo ecológico tem como foco a comparação entre grupos, ao invés de indivíduos (Morgenstern, 1998). Os estudos ecológicos procuram avaliar como os contextos social e ambiental podem afetar a saúde de grupos populacionais (Medronho, 2002). Os objetivos principais de um estudo ecológico são estudar a saúde no contexto ambiental (Susser, 1994), entender como o contexto afeta a saúde de pessoas e grupos, estudar a relação entre incidência de doenças e potencializar fatores etiológicos, que expliquem as diferenças na incidência de determinado evento de saúde (Ministério da Saúde, 2007).

Segundo Susser (1994), os padrões de morbimortalidade, propagação de epidemias, transmissão sexual de doenças e a transferência de comportamentos ou valores não podem ser compreendidos somente a partir do indivíduo. As pessoas vivem em grupos e somente a análise dos grupos permite captar comportamentos, valores, ou mesmo a transmissão de infecções que ocorre nessa escala.

Para a utilização do estudo ecológico como desenho de pesquisa é necessário definir as delimitações geográficas de cada área estudada para que assim seja possível a organização de um banco de dados.

\subsection{PERÍODO DO ESTUDO}

Os dados utilizados nesta dissertação são referentes aos anos de 2006, 2007, 2008 e 2009. Os dados referentes ao número populacional e dados referentes às classificações sóciodemográficas que compõem as covariáveis deste estudo foram obtidos por meio do CD de informações do Censo Demográfico de 2000 realizado pelo IBGE no município de Ribeirão Preto.

\subsection{LOCAL DO ESTUDO}


O município de Ribeirão Preto está localizado a $21^{\circ} 12^{\prime} 42^{\prime \prime}$ de latitude sul e $47^{\circ}$ $48^{\prime} 24^{\prime \prime}$ de longitude oeste, distante 313 quilômetros a noroeste da capital estadual e a 706 quilômetros de Brasília, conforme a Figura 3.1.

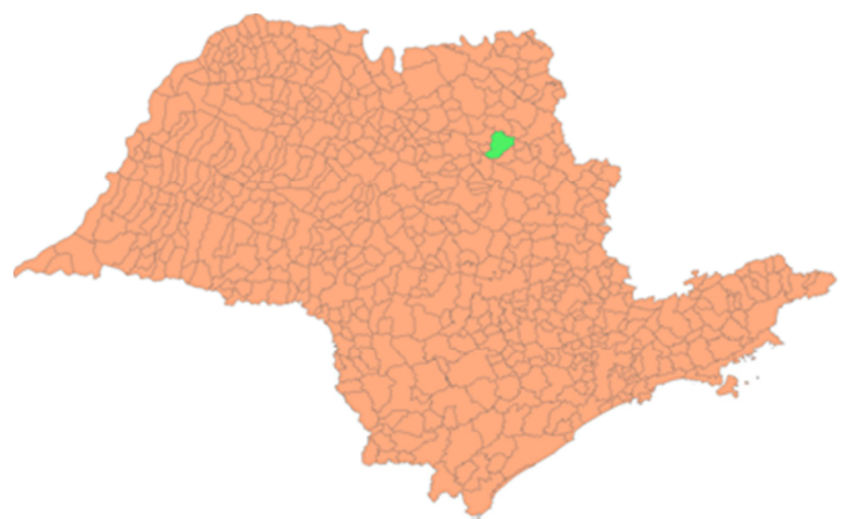

Figura 3.1. Localização do Município de Ribeirão Preto no Estado de São Paulo.

Ribeirão Preto conta com uma área total de $650 \mathrm{~km}^{2}$ e população estimada em 563.107 habitantes para o ano de 2009, implicando em uma densidade demográfica de 866 habitantes por $\mathrm{km}^{2}$ (IBGE, 2010). O município conta atualmente com 651 setores censitários e 44 áreas pertencentes ao nosso estudo. Ribeirão Preto é subdividido em 5 distritos (Norte, Oeste, Central, Leste e Sul) e estas delimitações geográficas são as áreas de abrangência de cada distrital de saúde. Como as delimitações geográficas eram disponíveis apenas por meio de nomes de ruas e avenidas, sem que houvesse um mapa com estas delimitações, se tornou um dos objetivos deste trabalho a construção de um mapa baseado nas áreas de abrangência das UBS (Unidades Básicas de Saúde), UBDS (Unidades Básicas Distritais de Saúde) e USF (Unidade Saúde da Família).

Os distritos de saúde são regiões delimitadas a partir de aspectos de extensão territorial e populacional, geográficos, econômicos, sociais que agrupam Unidades Básicas de Saúde (UBS), Unidades Básicas Distritais de Saúde (UBDS) e Centros de Referência em Saúde.

Desse modo o distrito de saúde considera o atendimento em saúde básica para uma área de abrangência limitada, configurada nas Unidades Básicas de Saúde, Programas 
de Agentes Comunitários de Saúde, Estratégia de Saúde da Família, assim como o atendimento de média complexidade oferecido em Unidades Básicas Distritais de Saúde (Ribeirão Preto, 2005).

\subsection{CONSTRUÇÃO DO MAPA}

Embora muitos estudos ecológicos desenvolvidos no país utilizem os setores censitários definidos pelo IBGE (Instituto Brasileiro de Geografia e Estatística) como divisões para o mapeamento da doença ou características de interesse, o uso de áreas administrativas de saúde como unidade de análise pode ser mais apropriada quando o objetivo é descrever as regiões que requerem ações prioritárias por parte do sistema municipal de saúde. Em Ribeirão Preto, o sistema municipal de saúde é organizado em regiões que são chamados de distritos de saúde. Os distritos de saúde de Ribeirão Preto estão localizados nas cinco regiões da cidade, ao norte, sul, leste, oeste e central. Em cada distrito de saúde está localizado uma Unidade Básica Distrital de Saúde (UBDS) que é a referência em algumas especialidades médicas para aquela região específica. Os distritos de saúde são também compostos por Unidades Básicas de Saúde (UBS) ou Unidades Saúde da Família (USF), que fornecem cuidados primários à população em sua área de cobertura.

Assim, a construção do mapa foi baseada na área de cobertura de cada UBS e UBDS. Os limites das áreas foram delimitados manualmente com o auxílio de um grande mapa impresso contendo ruas e regiões de Ribeirão Preto, cedido pela Secretaria de Planejamento e Gestão Pública da Prefeitura Municipal de Ribeirão Preto, atualizado no ano de 2010. Esses limites foram definidos de acordo com as áreas de abrangência de cada unidade de saúde delimitado pela Secretaria de Saúde do município e obtidos por meio da home page da prefeitura. Entretanto, no município existiam diversas novas unidades de saúde, as quais ainda não constavam na home page. Desta forma, foi necessário agendar visitas com os coordenadores destas unidades de saúde para obtenção detalhada de informações sobre a mesma. Os limites geográficos das áreas de cobertura destas unidades foram identificados percorrendo de carro as ruas que as limitam, visando uma transposição mais precisa dos limites dos mapas. Essas áreas, já numeradas de acordo com o mapa a ser gerado, foram:

- 2. Geraldo Correia de Carvalho; 
- 6. Estação do Alto;

- 16. Eugênio Mendes Lopes;

- 17. Portal do Alto e

- 18. Jardim Paiva.

Além disso, duas áreas foram divididas com o propósito de isolar o Campus da Universidade de São Paulo (USP, área número 19 no mapa) e o Campus do Centro Universitário Moura Lacerda (área número 30), dada a grande extensão das áreas onde originalmente se inseriam estes campi universitários com baixa densidade demográfica. E as áreas 32 (Jardim Recreio) e 33 (Jardim Itaú) originalmente são uma única área, porém, devido à grande heterogeneidade social ali observada, julgamos pertinente dividi-la.

O mapa final com as 44 áreas construídas para os propósitos do presente estudo é mostrado nas Figuras 3.2 e 3.3. A Figura 3.2 situa as 44 áreas nos limites do município de Ribeirão Preto, onde a área rural não é incluída na região em estudo. A Figura 3.3 mostra o mapa da área urbana do município de Ribeirão Preto sobreposta ao mapa com os 651 setores censitários definidos pelo IBGE no ano de 2000. 


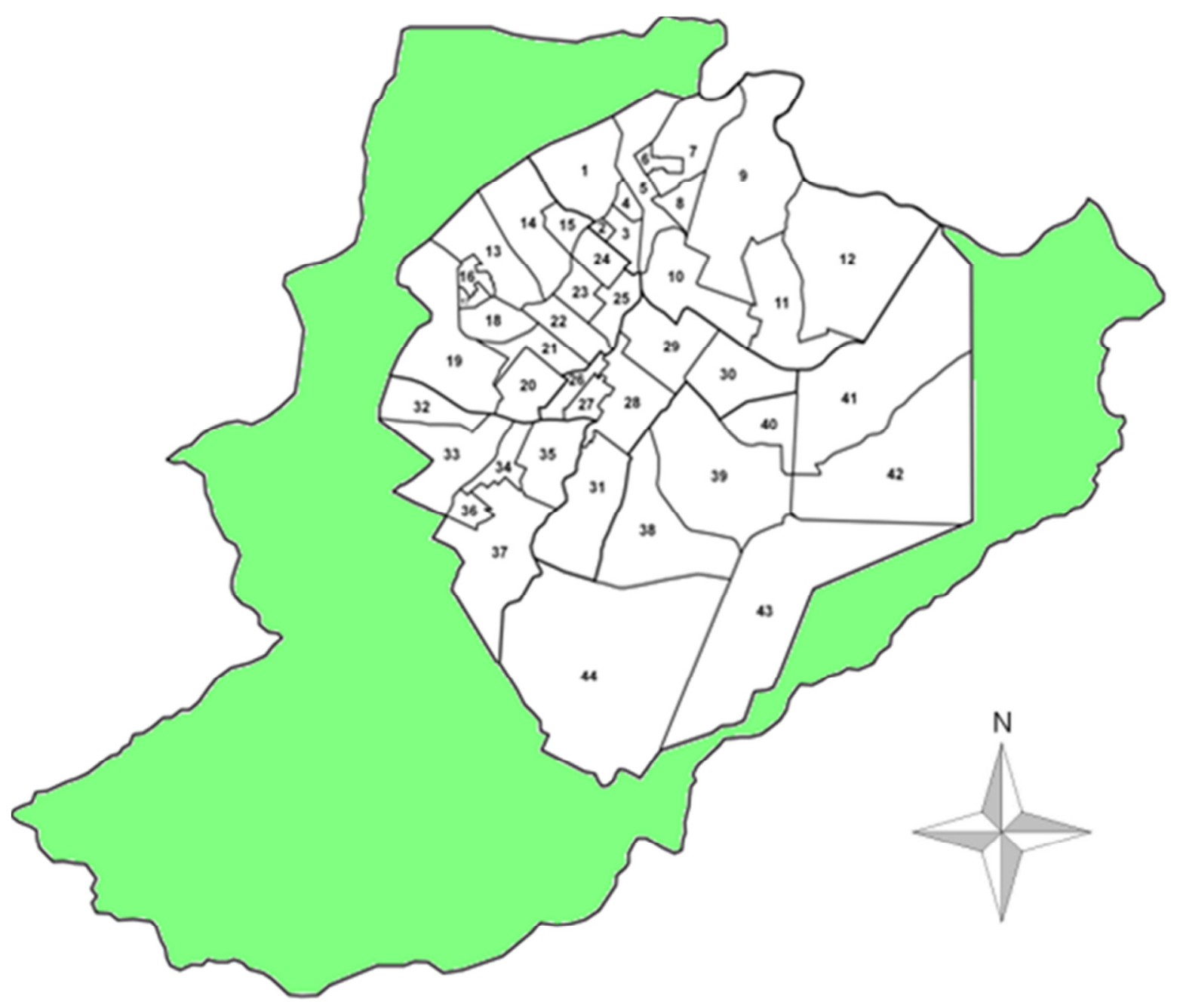

Figura 3.2. Divisão da área urbana do Município de Ribeirão Preto em 44 delimitações geográficas e em verde a área rural. 


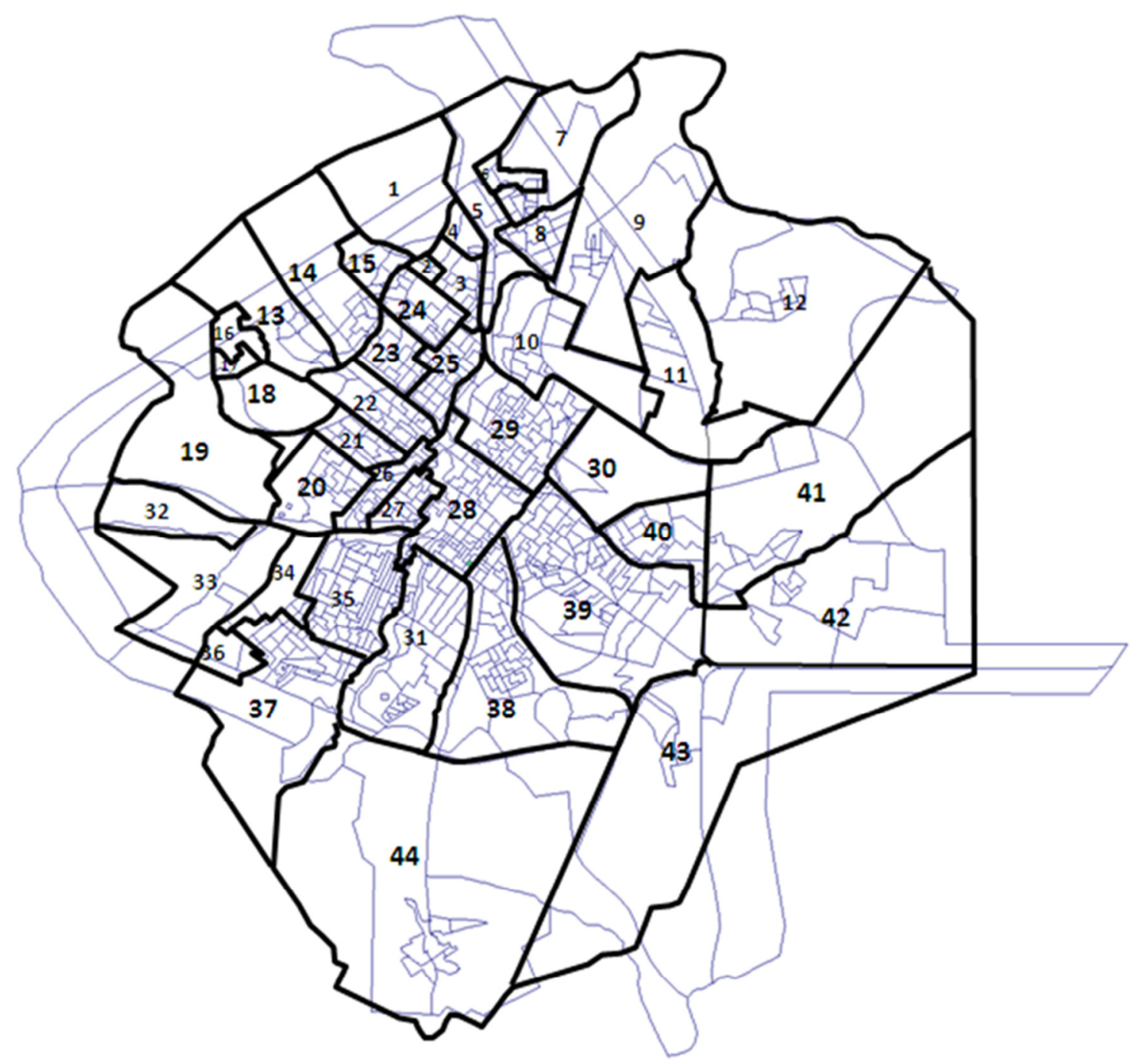

Figura 3.3. Divisão da área urbana do Município de Ribeirão Preto em 44 delimitações geográficas, sobrepostas aos 651 setores censitários definidos pelo IBGE para o Censo

Demográfico de 2000.

O município de Ribeirão Preto está habilitado à gestão plena do sistema de saúde desde 1998. Nesta modalidade de gestão, o município é responsável pelo gerenciamento das unidades de saúde conveniadas e contratadas que executam ações de atenção básica, média e alta complexidade, desenvolvendo ações e estratégias de promoção de saúde, prevenção de doenças, tratamento e reabilitação em todos os níveis de atenção a saúde (Silva, 2009).

Para atender a esses objetivos, o município de Ribeirão Preto foi subdividido e organizado em cinco Distritos de Saúde, conforme Figura 3.4. 


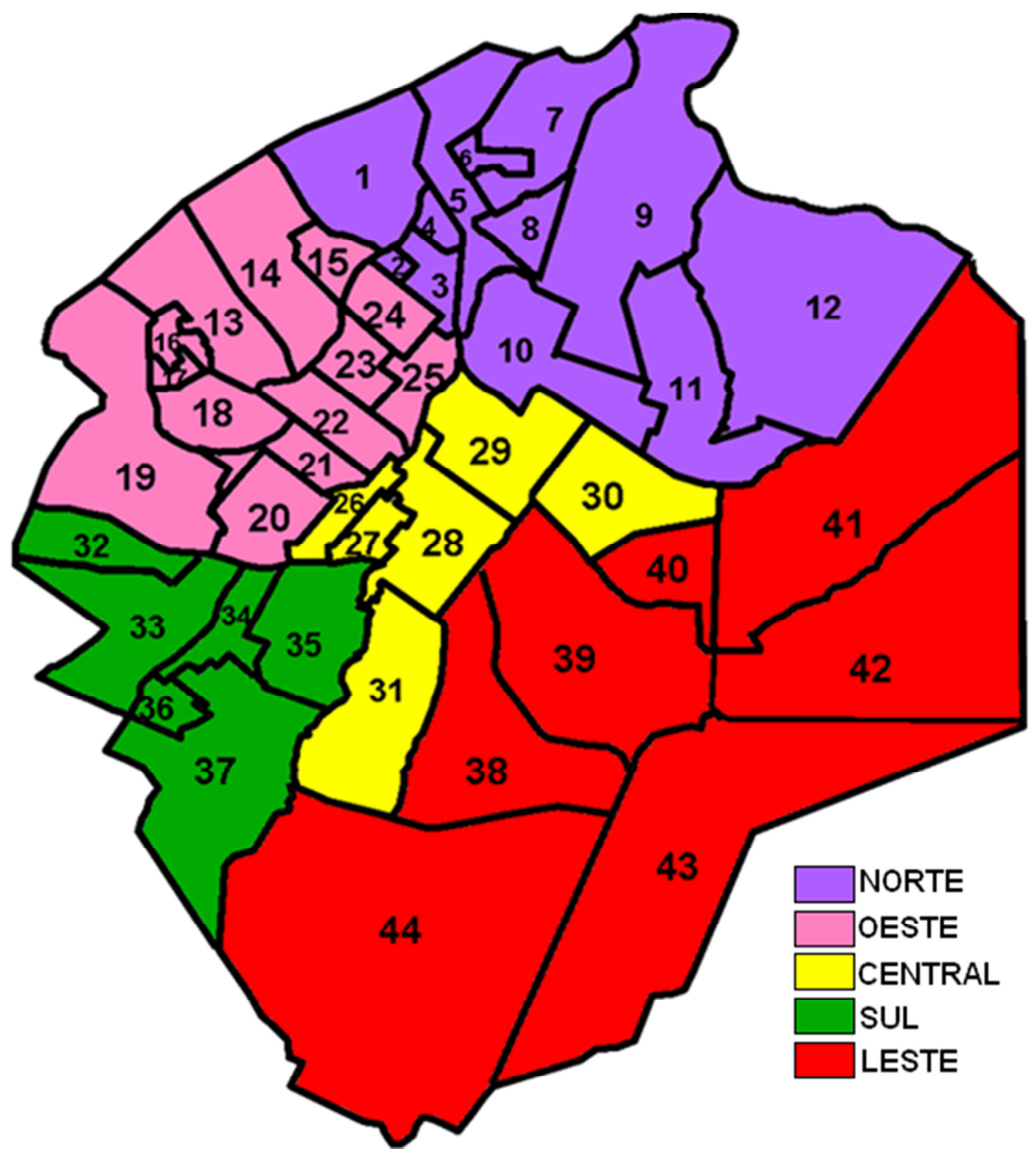

Figura 3.4. Mapa dos distritos de saúde de Ribeirão Preto, SP.

A Tabela 3.1 lista as 44 áreas de estudo segundo a responsabilidade sanitária de cada área e seu distrito de saúde. 
Tabela 3.1 - Áreas em estudo. Em negrito, destaca-se a UBDS de cada distrito.

\begin{tabular}{|c|c|c|c|}
\hline Número & Área & Responsabilidade Sanitária & Distrito \\
\hline 1 & Heitor Rigon & UBS Heitor Rigon & Norte \\
\hline 2 & Geraldo Correia de Carvalho & USF Geraldo Correia de Carvalho & Norte \\
\hline 3 & Marincek & UBS Marincek & Norte \\
\hline 4 & Valentina Figueiredo & UBS Valentina Figueiredo & Norte \\
\hline 5 & Adelino Simioni & UBS Adelino Simioni & Norte \\
\hline 6 & Estação do Alto & USF Estação do Alto & Norte \\
\hline 7 & Quintino II & UBDS Quintino II & Norte \\
\hline 8 & Avelino Palma & UBS Avelino Palma & Norte \\
\hline 9 & Quintino I & UBS Quintino I & Norte \\
\hline 10 & Vila Mariana & UBS Vila Mariana & Norte \\
\hline 11 & Jardim Aeroporto & UBS Jardim Aeroporto & Norte \\
\hline 12 & Ribeirão Verde & UBS Ribeirão Verde & Norte \\
\hline 13 & Dom Mielle & UBS Dom Mielle & Oeste \\
\hline 14 & José Sampaio & UBS José Sampaio & Oeste \\
\hline 15 & Maria Casagrande & UBS Maria Casagrande & Oeste \\
\hline 16 & Eugênio Mendes Lopes & USF Eugênio Mendes Lopes & Oeste \\
\hline 17 & Portal do Alto & USF Portal do Alto & Oeste \\
\hline 18 & Jardim Paiva & UBS Jardim Paiva & Oeste \\
\hline 19 & Campus da USP & UBDS Sumarezinho & Oeste \\
\hline 20 & Vila Lobato & UBS Vila Lobato & Oeste \\
\hline 21 & Sumarezinho & UBDS Sumarezinho & Oeste \\
\hline 22 & Ipiranga & UBS Ipiranga & Oeste \\
\hline 23 & Vila Recreio & UBS Vila Recreio & Oeste \\
\hline 24 & Dutra & UBS Dutra & Oeste \\
\hline 25 & Vila Albertina & UBS Vila Albertina & Oeste \\
\hline
\end{tabular}


Tabela 3.1 - Continuação.

\begin{tabular}{|c|c|c|c|}
\hline Número & Área & Responsabilidade Sanitária & Distrito \\
\hline 26 & Vila Tibério I & UBS Vila Tibério I & Central \\
\hline 27 & Vila Tibério II & UBS Vila Tibério II & Central \\
\hline 28 & Central & UBDS Central & Central \\
\hline 29 & Campos Elíseos & UBS Campos Elíseos & Central \\
\hline 30 & Campus Moura Lacerda & UBS Campos Elíseos & Central \\
\hline 31 & João Rossi & UBS João Rossi & Central \\
\hline 32 & Jardim Recreio & UBDS Vila Virgínia & Sul \\
\hline 33 & Jardim Itaú & UBDS Vila Virgínia & Sul \\
\hline 34 & Adão do Carmo & UBS Adão do Carmo & Sul \\
\hline 35 & Vila Virgínia & UBDS Vila Virgínia & Sul \\
\hline 36 & Maria das Graças & UBS Maria das Graças & Sul \\
\hline 37 & Parque Ribeirão & UBS Parque Ribeirão & Sul \\
\hline 38 & Santa Cruz & UBS Santa Cruz & Leste \\
\hline 39 & Castelo Branco & UBDS Castelo Branco & Leste \\
\hline 40 & Jardim Zara & USF Jardim Zara & Leste \\
\hline 41 & Vila Abranches & UBS Vila Abranches & Leste \\
\hline 42 & Jardim Juliana & UBS Jardim Juliana & Leste \\
\hline 43 & São José & UBS São José & Leste \\
\hline 44 & Bonfim Paulista & UBS Bonfim Paulista & Leste \\
\hline
\end{tabular}

\subsection{CRITÉRIOS DE INCLUSÃO E EXCLUSÃO DA POPULAÇÃO EM ESTUDO}

Foram utilizados todos os casos novos de TB notificados e registrados no município de Ribeirão Preto, nos anos de 2006 a 2009, e disponível no site TBWeb.

Foram retirados do banco de dados os registros em que o indivíduo não tem residência fixa ou casos em que a residência do indivíduo era uma penitenciária. Essas perdas, dentro do total de registros do banco de dados, foram em torno de $3,48 \%$. 


\subsection{POPULAÇÃO DO ESTUDO}

A população do estudo é o número de pessoas residentes em cada região da área urbana do município. Utilizaram-se as estimativas populacionais disponibilizadas pelo IBGE, conforme a Tabela 3.2. O critério para estimação do tamanho populacional de cada uma das 44 áreas descritas no mapa da Figura 3.2 foi o resultado da soma da população de cada setor censitário nelas incluídos.

Tabela 3.2 - Estimativas do número populacional para o município de Ribeirão Preto, SP.

\begin{tabular}{cc}
\hline Ano & Estimativas \\
\hline 2006 & 559.650 \\
2007 & 547.417 \\
2008 & 558.136 \\
2009 & 563.107 \\
\hline
\end{tabular}

Fonte: IBGE

A contagem da população por área de estudo se deu da seguinte maneira. Utilizando o programa TerraView, foi gerado um mapa para cada intervalo de valores referentes ao número populacional. Por exemplo, setores censitários com 0 até 361 habitantes foi colorido no mapa com uma determinada cor, e assim sucessivamente até completar 11 categorias. Utilizando a média do número populacional em cada categoria, somamos a média da população em cada setor censitário correspondente à área do estudo, e com isso conseguimos uma estimativa da população para cada área, de forma que a soma total de todas as áreas é igual a população de Ribeirão Preto em cada um dos anos. O mapa gerado pode ser visualizado na Figura 3.5. 


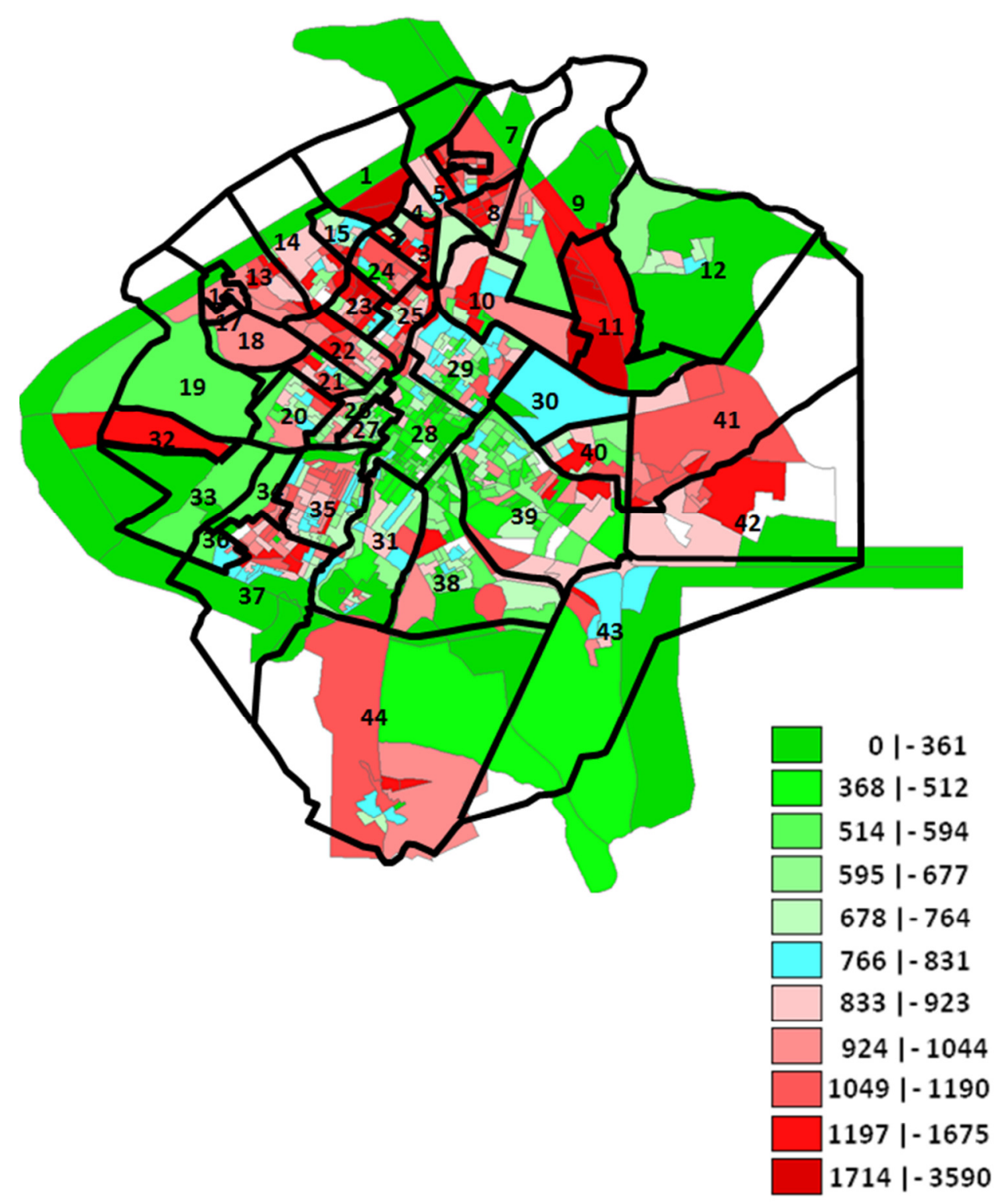

Figura 3.5. Mapa da distribuição da população (número de habitantes) por setor censitário e por áreas de saúde.

A Fonte dos dados populacionais é o Instituto Brasileiro de Geografia e Estatística - IBGE. O IBGE divide os municípios brasileiros em pequenas áreas, os setores censitários, com o objetivo de organizar o trabalho de coleta de dados dos Censos Demográficos decenais. Estas áreas utilizam referenciais geográficos claramente definidos e cobre todo o território nacional, área urbana e rural. Nas áreas urbanas, tipicamente, os setores possuem em média 300 domicílios, variando entre 200 e 500 domicílios, com uma população variando entre 700 e 2000 habitantes. Estas são as menores unidades geográficas brasileiras para as 
quais existem informações populacionais confiáveis e cobrindo todo o território nacional. A informação mais recente é a do Censo Demográfico de 2000, com centenas de informações sobre características dos domicílios, dos responsáveis pelos domicílios e as pessoas residentes nos domicílios (no total de mais de 500 variáveis) por setor censitário dos municípios.

Atualmente, não existe outra base de dados, além das informações censitárias de 2000 por setor censitário, tão detalhada geograficamente, tão confiável e cobrindo todo o município de interesse. Por este motivo, utilizaremos esta base no estudo da tuberculose.

O número médio de domicílios por setor censitário é de 212. Devido ao seu pequeno número de domicílios e de sua pequena extensão geográfica e dos critérios para demarcação dos seus limites, cada setor é composto de domicílios e populações com um perfil social e econômico muito similar. Desta forma, assume-se que não existem diferenças internas a um setor censitário e trabalha-se com os valores médios de características sociais calculadas em cada setor.

\subsection{VARIÁVEIS DO ESTUDO E SUAS FONTES}

Número de casos novos de TB: Denotada no modelo estatístico por $Y_{i t}$, esta variável refere-se ao número de casos novos de tuberculose na região $i(i=1, \ldots, 44)$ no ano $t$ ( $t$ assume valores 1,2,3 e 4, respectivos aos anos de 2006, 2007, 2008 e 2009). Estas informações foram obtidas no site TBWeb <http://www.cvetb.saude.sp.gov.br/tbweb/index. jsp>. Embora exista alguma imprecisão nesse conceito, quando aqui definimos um "caso novo", poderá ser considerando tanto um indivíduo nunca antes infectado quanto uma recidiva.

IPVS: Valor predominante dos IPVS (Índice Paulista de Vulnerabilidade Social) em cada região, sendo classificado em seis diferentes níveis. Os valores do IPVS foram obtidos na página eletrônica do SEADE - Sistema Estadual de Análise de Dados, cujo endereço é <http://www.seade.gov.br/produtos/ipvs/pdf/oipvs.pdf>. 
O Índice Paulista de Vulnerabilidade Social (IPVS) (Ferreira et al, 2006) foi elaborado pela Fundação SEADE (Sistema Estadual de Análise de Dados), a partir dos dados do Censo Demográfico de 2000. O IPVS consiste em uma tipologia derivada da combinação entre duas dimensões (socioeconômica e demográfica), que classifica as áreas geográficas intramunicipais em seis grupos distintos de vulnerabilidade social. A dimensão socioeconômica é composta pela renda apropriada pelas famílias e o poder de geração da mesma por seus membros, enquanto a demográfica relaciona-se ao ciclo de vida familiar. Como áreas geográficas adotaram-se os setores censitários utilizados no Censo Demográfico de 2000.

Os seis grupos ou tipos de áreas que constituem o IPVS são descritos a seguir:

IPVS 1 - Nenhuma Vulnerabilidade: setores censitários em melhor situação socioeconômica, com os responsáveis pelo domicílio possuindo os melhores níveis de renda e escolaridade. Embora o estágio das famílias no ciclo de vida não seja um definidor do grupo, encontram-se aí chefes de domicílio mais velhos, menor presença de crianças pequenas e domicílios com menos moradores, quando comparados com o conjunto do Estado de São Paulo.

IPVS 2 - Vulnerabilidade Muito Baixa: setores censitários que se classificam em segundo lugar, no Estado, em termos da dimensão socioeconômica (média ou alta). Nessas áreas, concentram-se, em média, as famílias mais velhas.

IPVS 3 - Vulnerabilidade Baixa: setores censitários que se classificam nos níveis altos ou médios da dimensão socioeconômica; seu perfil demográfico caracteriza-se pela predominância de famílias jovens e adultas.

IPVS 4 - Vulnerabilidade Média: setores que apresentam níveis médios na dimensão socioeconômica, estando em quarto lugar na escala em termos de renda e escolaridade do responsável pelo domicílio. Nesses setores concentram-se famílias jovens, isto é, grande presença de chefes jovens com menos de 30 anos e de crianças pequenas.

IPVS 5 - Vulnerabilidade Alta: setores censitários que apresentam as piores condições na dimensão socioeconômica (muito baixa), estando entre os dois grupos em que os chefes de domicílios têm, em média, os piores níveis de renda e escolaridade. Concentra famílias mais velhas com menor presença de crianças pequenas. 
IPVS 6 - Vulnerabilidade Muito Alta: um dos dois piores grupos em termos da dimensão socioeconômica (muito baixa), com grande concentração de famílias jovens. A combinação entre chefes jovens com baixos níveis de renda e escolaridade e presença de crianças pequenas torna este o grupo de maior vulnerabilidade à pobreza.

Educação: Valor predominante do nível de instrução do responsável pelo domicilio em cada área. Agregados da seguinte forma:

1 - Sem instrução (Variáveis do Censo Demográfico do IBGE: V25 = Pessoas responsáveis pelos domicílios particulares permanentes - não alfabetizadas + V73 $=$ Pessoas responsáveis pelos domicílios particulares permanentes - sem instrução e menos de 1 ano de estudo);

2 - Ensino Fundamental (Variáveis do Censo: V37 = Pessoas responsáveis pelos domicílios particulares permanentes - curso mais elevado que frequentou - antigo primário + V42 = Pessoas responsáveis pelos domicílios particulares permanentes - curso mais elevado que frequentou - antigo ginásio + V51 = Pessoas responsáveis pelos domicílios particulares permanentes - curso mais elevado que frequentou - ensino fundamental ou primeiro grau);

3 - Ensino Médio (Variáveis do Censo: V47 = Pessoas responsáveis pelos domicílios particulares permanentes - curso mais elevado que frequentou - antigo clássico, científico etc. + V60 $=$ Pessoas responsáveis pelos domicílios particulares permanentes curso mais elevado que frequentou - ensino médio ou segundo grau);

4 - Ensino Superior (Variáveis do Censo: V64 = Pessoas responsáveis pelos domicílios particulares permanentes - curso mais elevado que frequentou - superior);

5 - Mestrado/Doutorado (Variáveis do Censo: V71 = Pessoas responsáveis pelos domicílios particulares permanentes - curso mais elevado que frequentou - mestrado ou doutorado).

Renda: Valor predominante da renda do chefe do domicílio, ou seja, o responsável pelo domicílio. Agregados da seguinte forma:

1 - 0 a 1 salário mínimo (Variáveis do Censo: V145 = Pessoas responsáveis pelos domicílios particulares permanentes - rendimento nominal mensal - sem rendimento + V136 = Pessoas responsáveis pelos domicílios particulares permanentes - rendimento nominal 
mensal - até $1 / 2$ salário mínimo + V137 = Pessoas responsáveis pelos domicílios particulares permanentes - rendimento nominal mensal - mais de $1 / 2$ a 1 salário mínimo);

2 - 1 a 3 salários mínimos (Variáveis do Censo: V138 = Pessoas responsáveis pelos domićlios particulares permanentes - rendimento nominal mensal - mais de 1 a 2 salários mínimos + V139 = Pessoas responsáveis pelos domicílios particulares permanentes rendimento nominal mensal - mais de 2 a 3 salários mínimos);

3 - 3 a 10 salários mínimos (Variáveis do Censo: V140 = Pessoas responsáveis pelos domicílios particulares permanentes - rendimento nominal mensal - mais de 3 a 5 salários mínimos + V141 = Pessoas responsáveis pelos domicílios particulares permanentes rendimento nominal mensal - mais de 5 a 10 salários mínimos);

4 - 10 ou + salários mínimos (Variáveis do Censo: V142 = Pessoas responsáveis pelos domicílios particulares permanentes - rendimento nominal mensal - mais de 10 a 15 salários mínimos + V143 = Pessoas responsáveis pelos domicílios particulares permanentes rendimento nominal mensal - mais de 15 a 20 salários mínimos + V144 = Pessoas responsáveis pelos domicílios particulares permanentes - rendimento nominal mensal - mais de 20 salários mínimos).

Os dados referentes às variáveis: Renda e Educação foram obtidos do $C D$ de Informações do Censo Demográfico de 2000 - IBGE.

As informações referentes às covariáveis IPVS, Renda e Educação foram originalmente coletadas por setor censitário (651 setores) e o objetivo do presente estudo é trabalhar com as áreas (44 áreas) que compõe o estudo. Desta forma, a conversão se deu da seguinte forma:

Utilizando o programa TerraView do INPE (disponível para download em: http://www.dpi.inpe.br/terraview/index.php), foi gerado um mapa para cada covariável com os 651 setores censitários e em seguida foi sobreposto a ele o mapa gerado para os propósitos desta pesquisa (44 áreas), é definido pelo IBGE que cada setor censitário tenha em média 300 domicílios, variando de 700 a 2000 habitantes, desta forma, sabemos que um setor censitário com tamanho geográfico pequeno tem aproximadamente o mesmo número de domicílios e habitantes que um setor censitário de tamanho grande. Baseado nisso, ao observar os mapas que foram coloridos segundo as classificações de cada covariável, o objetivo então é contar dentro de cada área do estudo, quantos setores 
censitários contêm as respectivas classificações, e define-se como resultado o valor predominante (moda) daquela área. Por exemplo:

No mapa do IPVS, a área 12 é composta de:

- 1 setor censitário com IPVS 5,

- 1 setor censitário com IPVS 3 e

- 6 setores censitários com IPVS 4.

Desta forma, a área 12 do nosso estudo, por exemplo, recebeu o valor de IPVS igual a 4, pois é o valor predominante daquela área, e assim sucessivamente para as demais áreas e demais covariáveis. Os mapas resultantes poderão ser visualizados nas Figuras 3.6, 3.7 e 3.8 .

Na Figura 3.6, observa-se apenas uma área (área 11, Jardim Aeroporto) onde é predominante o IPVS com nível 6, ou seja, vulnerabilidade muito alta. Nos modelos de regressão, foram, portanto, agrupadas as áreas com predomínio do IPVS com níveis 5 e 6 em uma única classe.

Na Figura 3.7, observa-se apenas 3 áreas com predomínio de renda abaixo de 1 salário mínimo (área 7, Quintino II, área 4, Valentina Figueiredo e área 19,Campus da USP), desta forma, nos modelos de regressão as categorias 0 a 1 salário mínimo e 1 a 3 salários mínimos foram agrupados em uma única classe, sendo composta assim, por regiões com 0 a 3 salários mínimos.

Na Figura 3.8, observa-se apenas uma área (área 32, Jardim Recreio) onde é predominante o nível de Educação Mestrado e Doutorado, desta forma, nos modelos de regressão, essa área foi agrupada juntamente com a categoria nível superior. 


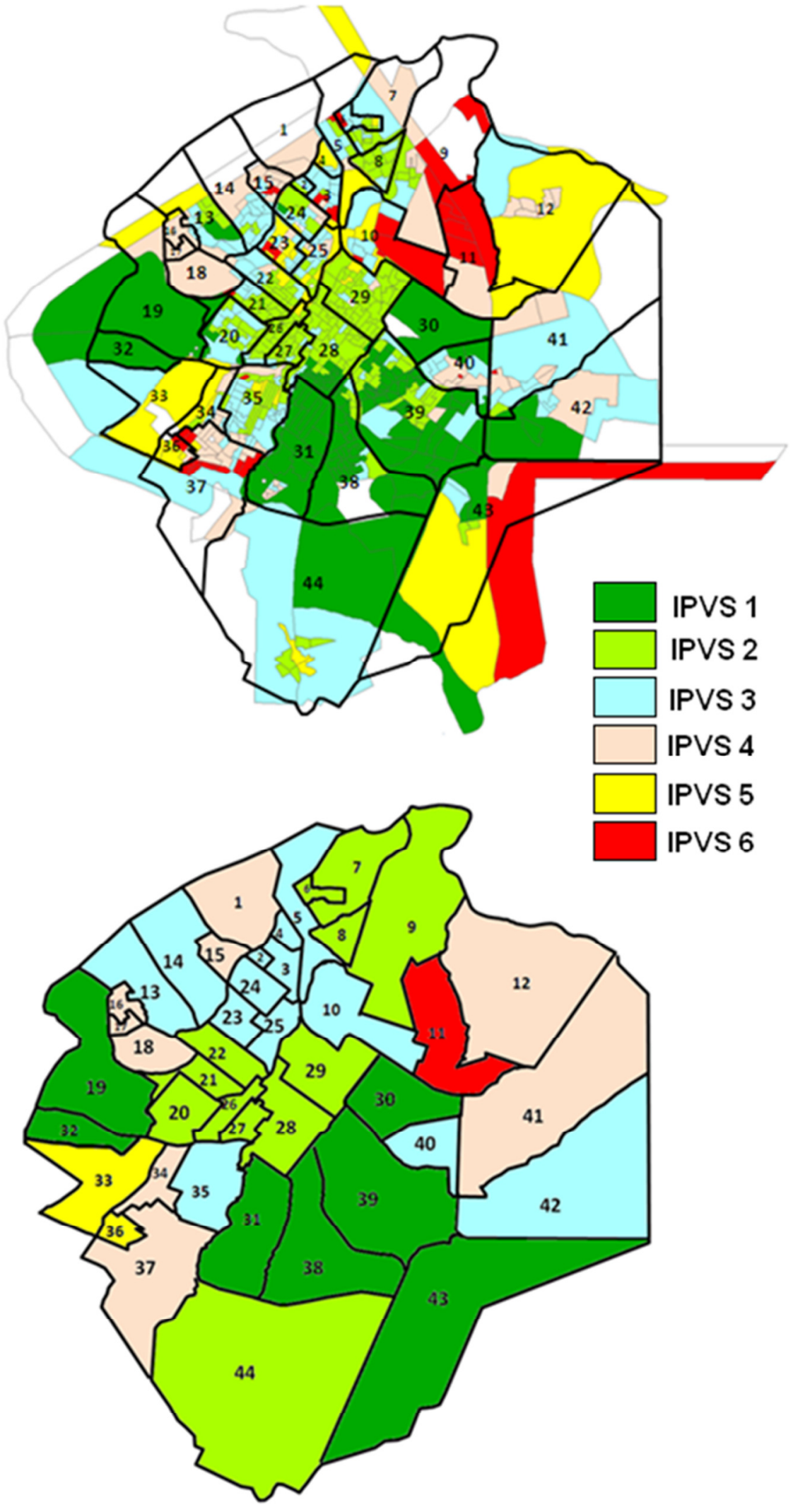

Figura 3.6. Mapa da distribuição do IPVS por setor censitário e por áreas de saúde, respectivamente. 


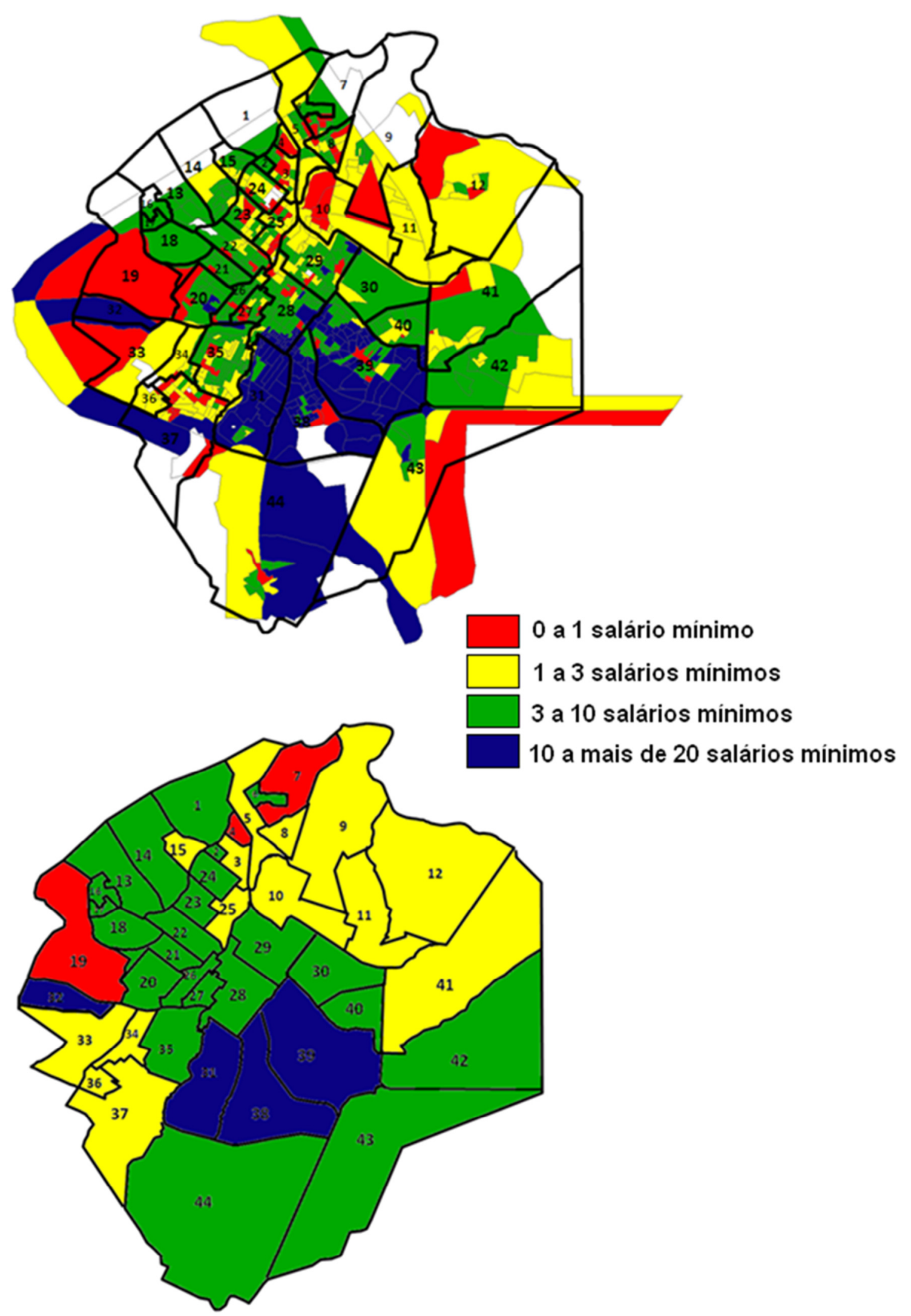

Figura 3.7. Mapa da distribuição da Renda por setor censitário e por áreas de saúde, respectivamente. 


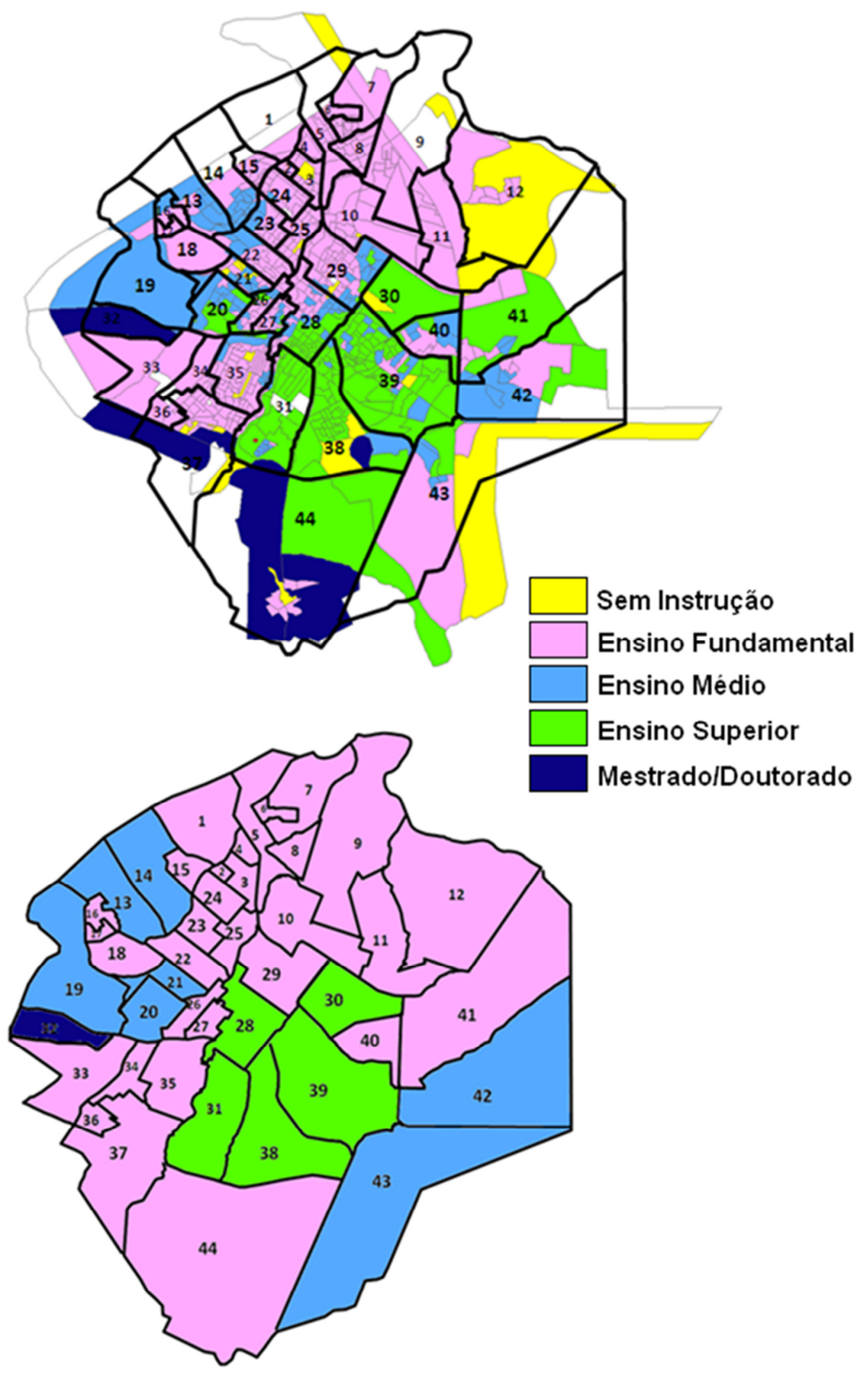

Figura 3.8. Mapa da distribuição da Educação por setor censitário e por áreas de saúde, respectivamente. 


\subsection{ASPECTOS ÉTICOS}

O presente projeto de pesquisa foi aprovado pelo Comitê de Ética em pesquisa da Faculdade de Medicina de Ribeirão Preto da Universidade de São Paulo, sob número de protocolo 11304/2009, em 07 de Dezembro de 2009, a fim de garantir o cumprimento da Resolução 196/96 do Conselho Nacional de Saúde (Brasil, 1996) (Anexo A).

\subsection{ANÁLISE DOS DADOS}

Na modelagem de dados observados no espaço e no tempo, é comum o uso de modelos que estabelecem que cada caso observado em cada região segue uma distribuição Binomial. Quando esses dados epidemiológicos são raros, ou com uma variação grande entre as regiões, o modelo Binomial pode ser aproximado pela distribuição de Poisson, com número de novos casos observados $Y_{i t}$ e valor esperado $\mu_{i t}$, ou seja,

$$
Y_{i t} \mid \mu_{i t} \sim \text { Poisson }\left(\mu_{i t}\right), i=1, \ldots, 44, t=1, \ldots, T \text {, }
$$

onde $\mu_{i t}=N_{i t} \theta_{i t}$, sendo $\theta_{i t}$ a taxa de incidência de TB na $i$-ésima região e no ano $t$, e $N_{i t}$ é o número de habitantes na i-ésima área no ano $t$. Neste modelo, é definido

$$
\ln \left(\mu_{i t}\right)=\ln \left(N_{i t}\right)+\ln \left(\theta_{i t}\right)
$$

sendo considerados cinco diferentes modelos:

Modelo 1: é incluído um efeito espacial para as áreas e um efeito linear para os anos, mas não são incluídas covariáveis.

Temos que

$$
\ln \left(\theta_{i t}\right)=\alpha+\omega_{i}+\left(\beta_{0}+\beta_{i}\right) X_{t}
$$


onde $\alpha$ é uma constante (um "intercepto" do modelo), $\beta_{0}$ é também uma constante (efeito fixo), $\boldsymbol{\omega}=\left(\omega_{1}, \omega_{2}, \ldots, \omega_{44}\right)^{\prime}$ é um vetor de efeitos aleatórios que capturam uma possível estrutura espacial de correlações entre as incidências de TB dadas as vizinhanças entre as $i$ áreas e $\boldsymbol{\beta}=\left(\beta_{1}, \beta_{2}, \ldots, \beta_{44}\right)^{\prime}$ é um vetor de efeitos aleatórios associado ao ano $X_{t}$, sendo assumido $X_{t}=0$ para o ano de 2006, $X_{t}=1$ para o ano de 2007, $X_{t}=2$ para o ano de 2008 e $X_{t}$ $=3$ para o ano de 2009 .

Para a análise bayesiana, foi atribuída aos parâmetros $\alpha$ e $\beta_{0}$ uma distribuição a priori tipo "flat" imprópria, definida sobre todo o conjunto dos números reais (ou seja, uniforme no espaço de $-\infty$ a $\infty$ ). Os efeitos aleatórios $\boldsymbol{\omega}$ e $\boldsymbol{\beta}$ incorporam uma estrutura espacial, captando a influência das áreas vizinhas através de uma distribuição a priori espacialmente estruturada pela definição de matriz de vizinhança entre as regiões. 0 critério utilizado para a definição de vizinhança foi a de adjacência, onde regiões que fazem fronteira umas com as outras foram consideradas vizinhas. Ao efeito $\boldsymbol{\omega}$ se atribui uma distribuição a priori que segue uma estrutura condicional auto-regressiva (CAR) Normal, dependente de um único parâmetro $\boldsymbol{\tau}_{\omega}$, ao qual é atribuída uma distribuição Gama Inversa com hiperparâmetros 0,5 e 0,0005, conforme recomendação de Thomas et al (2004). A distribuição adotada para $\omega$ é tal que

$$
\omega_{i} \mid\left\{\omega_{j}, i \neq j, j \in A^{*}(i)\right\}, \tau_{\omega}^{2} \sim N\left(\bar{\eta}_{\omega i}, \frac{\tau_{\omega}^{2}}{n_{i}}\right)
$$

onde $A^{*}(i)$ denota o conjunto das áreas vizinhas em cada área $i, \bar{\eta}_{i}$ é a média dos efeitos aleatórios $\omega_{\mathrm{j}}$ associadas as áreas vizinhas à área $i, \bar{\eta}_{\omega i}$ corresponde ao número de áreas que são vizinhas à área $i, \tau_{\omega}^{2}$ é a variância da distribuição e $N(a, b)$ genericamente denota uma distribuição normal com média $a$ e variância $b$. Analogamente, a distribuição adotada para $\boldsymbol{\beta}$ é tal que

$$
\beta_{i} \mid\left\{\beta_{j}, i \neq j, j \in A^{*}(i)\right\}, \tau_{\beta}^{2} \sim N\left(\bar{\eta}_{\beta i}, \frac{\tau_{\beta}^{2}}{n_{i}}\right)
$$

considerando que o parâmetro $\tau_{\beta}$, segue, a priori, uma distribuição Gama Inversa também com hiperparâmetros 0,5 e 0,0005. 
No contexto de inferência bayesiana, o modelo CAR (Conditional Autoregressive) é bastante empregado para a modelagem de dados espacialmente estruturados (Castro et al, 2004; Carvalho e Souza-Santos, 2005; Besag e Kooperberg, 1995).

Modelo 2: é incluído um efeito espacial para as áreas e os anos são tratados como variáveis indicadoras (dummies variables), mas não são incluídas covariáveis.

Temos que

$$
\ln \left(\theta_{i t}\right)=\alpha+\omega_{i}+\beta_{i t}
$$

onde $\alpha$ e $\omega_{i}(i=1, \ldots, 44)$ são definidos como no modelo anterior e $\beta_{i t}$ é um efeito (fixo) associado à área $i$ e tempo $t$ (tal que $t=1$ se o ano é $2006, t=2$ se o ano é $2007, t=3$ se o ano é 2008 e $t=4$ se o ano é 2009). Para a análise bayesiana, considerou-se a priori uma distribuição normal para cada parâmetro $\beta_{i t}(i=1, \ldots, 44, t=1,2,3,4)$, ou seja, $\beta_{i t} \sim N(0$; 100.000), com a motivação de atribuir a priori a cada parâmetro $\beta_{i t}$ uma distribuição não informativa (centrada em 0 e com uma grande dispersão). É considerado, a priori, que os parâmetros $\beta_{i t}$ são, entre si, independentes.

Modelo 3.1: é análogo ao Modelo 2, mas agora não é considerado que os parâmetros $\beta_{i t}$ são, entre si, independentes. Foi considerada, a priori, para cada área $i$, uma distribuição normal multivariada (NM) para os parâmetros $\beta_{i t}$, ou seja,

$$
\beta_{i t} \sim N M\left(\left[\begin{array}{l}
\lambda_{1} \\
\lambda_{2} \\
\lambda_{3} \\
\lambda_{4}
\end{array}\right], \Sigma_{\beta}\right), i=1, \ldots, 44
$$

onde a matriz de variâncias-covariâncias $\Sigma_{\beta}$ segue, a priori, uma distribuição multivariada de Wishart com hiperparâmetros não informativos, e, em um segundo nível hierárquico, $\lambda_{t}(t=$ 1,2,3,4) seguem distribuição normal com média 0 e variância 100. 
Modelo 3.2: é análogo ao Modelo 3.1, mas é considerado $\lambda_{t}=0(t=1,2,3,4)$, ou seja, a distribuição a priori para os parâmetros $\beta_{i t}$ é dada por

$$
\beta_{i t} \sim N M\left(\left[\begin{array}{l}
0 \\
0 \\
0 \\
0
\end{array}\right], \Sigma_{\beta}\right), i=1, \ldots, 44
$$

Modelo 4.1: é análogo ao Modelo 2, mas, como nos Modelos 3.1 e 3.2, não é considerado que os parâmetros $\beta_{i t}$ são, entre si, independentes. É considerada uma distribuição a priori normal multivariada para os parâmetros $\beta_{i t}$, dada por

$$
\beta_{i t} \sim N M\left(\left[\begin{array}{l}
0 \\
0 \\
0 \\
0
\end{array}\right], \theta_{1}\left[\begin{array}{cccc}
1 & \exp \left(-\theta_{2}\right) & \exp \left(-2 \theta_{2}\right) & \exp \left(-3 \theta_{2}\right) \\
\exp \left(-\theta_{2}\right) & 1 & \exp \left(-\theta_{2}\right) & \exp \left(-2 \theta_{2}\right) \\
\exp \left(-2 \theta_{2}\right) & \exp \left(-\theta_{2}\right) & 1 & \exp \left(-\theta_{2}\right) \\
\exp \left(-3 \theta_{2}\right) & \exp \left(-2 \theta_{2}\right) & \exp \left(-\theta_{2}\right) & 1
\end{array}\right]\right) \text {, }
$$

para $i=1, \ldots, 44, \theta_{1}>0$ e $\theta_{2}>0$. Assim, as covariâncias dos parâmetros $\beta_{i t}$ são genericamente escritas na forma

$$
\operatorname{cov}\left(\beta_{i t}, \beta_{i t^{*}}\right)=\theta_{1} \exp \left(-\theta_{2}\left|t-t^{*}\right|\right)
$$

para $t=1, \ldots, 4$ e $t^{*}=1, \ldots, 4$. Para maiores informações sobre o uso desta estrutura de variâncias, ver Brascum et al (2008). Na análise bayesiana, atribuiu-se a priori aos parâmetros $\theta_{1}$ e $\theta_{2}$ distribuições Gama Inversa $(G I)$, ou seja, $\theta_{1} \sim G I(0,1 ; 0,1)$ e $\theta_{2} \sim G I(0,1 ; 0,1)$.

Modelo 4.2: os Modelos 4.2 a 4.4 referem-se a uma análise de sensibilidade para a especificação da distribuição a priori para os parâmetros $\theta_{1}$ e $\theta_{2}$ (Modelo 4.1). Assim, o Modelo 4.2 é análogo ao Modelo 4.1, mas, na análise bayesiana, é especificado que $\theta_{1} \sim$ $G I(0,1 ; 0,1)$ e $\theta_{2} \sim G l(0,01 ; 0,01)$. 
Modelo 4.3: análogo ao Modelo 4.1, mas, na análise bayesiana, é especificado que, a priori, $\theta_{1} \sim G I(0,5 ; 0,0005)$ e $\theta_{2} \sim G I(0,5 ; 0,0005)$.

Modelo 4.4: análogo ao Modelo 4.1, mas, na análise bayesiana, é especificado que, a priori, $\theta_{1} \sim$ Uniforme $(0 ; 100)$ e $\theta_{2} \sim$ Uniforme(0;100), ou seja, são atribuídas a estes parâmetros distribuições contínuas uniformes no intervalo $(0 ; 100)$.

Modelo 5: É considerado o modelo

$$
\ln \left(\theta_{i t}\right)=\alpha+\omega_{i}+\beta_{i t}
$$

onde é assumido que $\beta_{i t}$ segue uma estrutura longitudinal baseada em cossenos (cos) (Brascum et al, 2008), dada por uma combinação linear da forma

$$
\beta_{i t}=\alpha_{0 i}+\sum_{j=1}^{4} \alpha_{j i} \cos \left[\frac{j \pi(t-0,5)}{4}\right]
$$

para $i=1, \ldots, 44$ e $t=1,2,3,4$. Para a análise bayesiana, foi assumido, a priori,

$$
\begin{gathered}
\alpha_{j i} \sim N\left(0 ; \sigma_{\alpha}^{2}\right), \\
\sigma_{\alpha}^{2} \sim G I(0,1 ; 0,1)
\end{gathered}
$$

a $\alpha$ foi atribuída a priori uma distribuição do tipo "flat" e, como nos modelos anteriores, atribuiu=se a $\boldsymbol{\omega}$ uma distribuição a priori que segue uma estrutura condicional autoregressiva (CAR) Normal.

Para comparar o ajuste dos diferentes modelos aos dados, utilizou-se o Deviance Information Criterion (DIC). Este critério de discriminação de modelos é semelhante ao Akaike's Information Criterion (AIC) utilizado em modelos de regressão em um contexto frequentista. O modelo que apresenta o menor valor de DIC é considerado aquele que melhor se ajusta aos dados. 
Para o ajuste dos modelos propostos, foi utilizado o módulo GeoBUGS do programa computacional WinBUGS - Bayesian inference Using Gibbs Sampling (Lunn et al, 2000). Os programas WinBUGS para cada um dos modelos descritos são apresentados no Apêndice. Considerando que, nestes modelos, as distribuições condicionais a posteriori possuem alguma complexidade em suas formas, métodos computacionalmente intensivos são utilizados para a simulação de amostras destas distribuições. Mais especificamente, utilizamos o algoritmo Monte Carlo em cadeias de Markov (MCMC) (Gamerman, 1997) para a obtenção de amostras destas distribuições. Foram geradas 150.000 amostras de cada parâmetro de interesse, sendo descartadas as 5.000 primeiras amostras para evitar algum efeito dos valores iniciais (burn-in samples). Para evitar correlações entre amostras sucessivamente geradas, utilizou-se para as inferências saltos de tamanho 50.

Em uma primeira etapa, foram ajustados modelos sem a incorporação das covariáveis, buscando aquele com melhor ajuste aos dados (menor valor de DIC). Em uma segunda etapa, àquele considerado "o melhor modelo", foi adicionado na expressão In $\left(\theta_{i t}\right)$ $=\alpha+\omega_{i}+\beta_{i t}$ (ou na expressão $\ln \left(\theta_{i t}\right)=\alpha+\omega_{i}+\left(\beta_{0}+\beta_{i}\right) X_{\mathrm{t}}$, caso considerado o Modelo 1 ) um termo $\boldsymbol{\gamma} \boldsymbol{Z}_{i}$ onde o vetor $\boldsymbol{\gamma}$ mensura o efeito de cada classe da covariável (ou melhor, um vetor $\boldsymbol{Z}_{i}$ de variáveis indicadoras associado a esta covariável) de interesse (IPVS, renda ou educação). Na análise bayesiana, foi atribuída a priori para cada um dos elementos do vetor $\gamma$ (cuja dimensão é dependente do número de variáveis indicadoras associadas à variável em questão) distribuições normal com média igual a 0 e variância igual a 10.000. Objetiva-se que o parâmetro de dispersão seja assim o maior possível, de modo que estas distribuições a priori sejam pouco informativas. 

Capítulo 4

RESULTADOS 

Nos anos de 2006 a 2009 foram notificados em Ribeirão Preto 705 casos novos de TB, com uma média de 176,25 casos por ano e incidência de 35 casos para cada 100 mil habitantes. Dentre esses 705 casos notificados $68,8 \%$ dos doentes são do sexo masculino, com idade média de 41 anos variando de 0 a 96 anos, a respeito da escolaridade destes doentes mais da metade, ou seja, 60,7\% possui de 1 a 7 anos de estudo, o que equivale a ensino fundamental. $A$ classificação do tipo de TB foi de 77,3\% para pulmonar e 15,3\% para extra-pulmonar. Observa-se que $22,5 \%$ dos doentes são também portadores de HIV e 14,9\% são alcoólatras. A Tabela 4.1 apresenta os casos confirmados de TB segundo ano de diagnóstico e seu respectivo coeficiente de incidência.

Tabela 4.1. Casos confirmados de TB segundo ano de diagnóstico, indivíduos residentes em Ribeirão Preto, SP.

\begin{tabular}{cccc}
\hline Ano & TB $^{(a)}$ & População $^{(b)}$ & Coef. Incidência por $\mathbf{1 0 0 . 0 0 0 ~ h a b ~}$ \\
\hline 2006 & 172 & 559.650 & 30,73 \\
2007 & 184 & 547.417 & 33,61 \\
2008 & 195 & 558.136 & 34,93 \\
2009 & 224 & 563.107 & $39,78^{*}$ \\
\hline
\end{tabular}

(a) Fonte: Ministério da Saúde / SVS - Sistema de Informação de Agravos de Notificação - SINAN Net.

(b) Fonte: IBGE, estimativas para 1ㅇ de julho de cada ano.

* Sujeitos a revisão, dados parciais.

Com o intuito de construir um modelo que melhor se ajustasse aos dados deste estudo, foram formulados cinco modelos espaço-temporais para os casos de tuberculose em Ribeirão Preto nos anos de 2006, 2007, 2008 e 2009, com todos os anos contidos em um mesmo modelo. O primeiro modelo apresenta uma característica linear diferentemente dos demais que são categóricos, ou seja, suas estimativas seguem um padrão pontual, o que melhora os ajustes dos modelos para estes dados. Utilizamos o critério DIC para a seleção do melhor modelo espaço-temporal, conforme já especificado na metodologia deste trabalho. 
Desta forma, o melhor modelo ajustado foi o Modelo 3 conforme pode-se observar na Tabela 4.2.

Tabela 4.2. Modelos espaço-temporais propostos.

\begin{tabular}{ccc}
\hline MODELOS & DIC \\
\hline Modelo 1 & & 751,008 \\
\hline Modelo 2 & & 780,252 \\
\hline \multirow{2}{*}{ Modelo 3 } & 3.1 & 736,985 \\
& 3.2 & 733,823 \\
\hline & 4.1 & 747,851 \\
Modelo 4 & 4.2 & 747,575 \\
& 4.3 & 744,634 \\
& 4.4 & 744,599 \\
\hline Modelo 5 & & 742,292 \\
\hline
\end{tabular}

Observa-se na Tabela 4.2 que os modelos 3 e 4 foram particionados em outros modelos, que são variações de um mesmo modelo, com diferentes especificações das distribuições a priori para alguns parâmetros de interesse (seção 3.9). Este procedimento foi adotado a fim de buscar o melhor modelo estatístico para os dados em estudo. O melhor modelo foi aquele que apresentou o menor valor de DIC. Assim, o modelo 3.2 foi considerado o "melhor" modelo bayesiano espaço-temporal ajustado aos dados.

Usando a formulação do modelo 3.2, inserimos as covariáveis e o efeito espacial, gerando assim cinco novos modelos, com intuito de identificar qual melhor se ajustaria aos dados de TB. Desta forma, os novos modelos com seus respectivos valores de DICs são descritos na Tabela 4.3.

Tabela 4.3. Modelos espaço-temporais propostos com o modelo 3.2.

\begin{tabular}{lc}
\hline MODELO $\mathbf{3 . 2}$ & DIC \\
\hline Com efeito espacial e IPVS predominante na área & 730,618 \\
Com efeito espacial e nível de Educação predominante & 732,470 \\
Sem efeito espacial e sem covariáveis & 733,147 \\
Com efeito espacial e nível de Renda predominante & 733,713 \\
Com efeito espacial e sem covariáveis & 733,823 \\
\hline
\end{tabular}


O modelo com melhor ajuste aos dados foi aquele que considera o efeito espacial (o que evidencia a não homogeneidade da distribuição da ocorrência dos casos de TB em Ribeirão Preto) e a covariável IPVS.

As estatísticas descritivas para as amostras geradas via método MCMC para os parâmetros deste modelo, obtidas pelo programa WinBUGS, podem ser visualizadas no Apêndice. Comparamos o ajuste do modelo em relação aos dados brutos, o ajuste se mostrou satisfatório, conforme pode-se observar na Figura 4.1. 

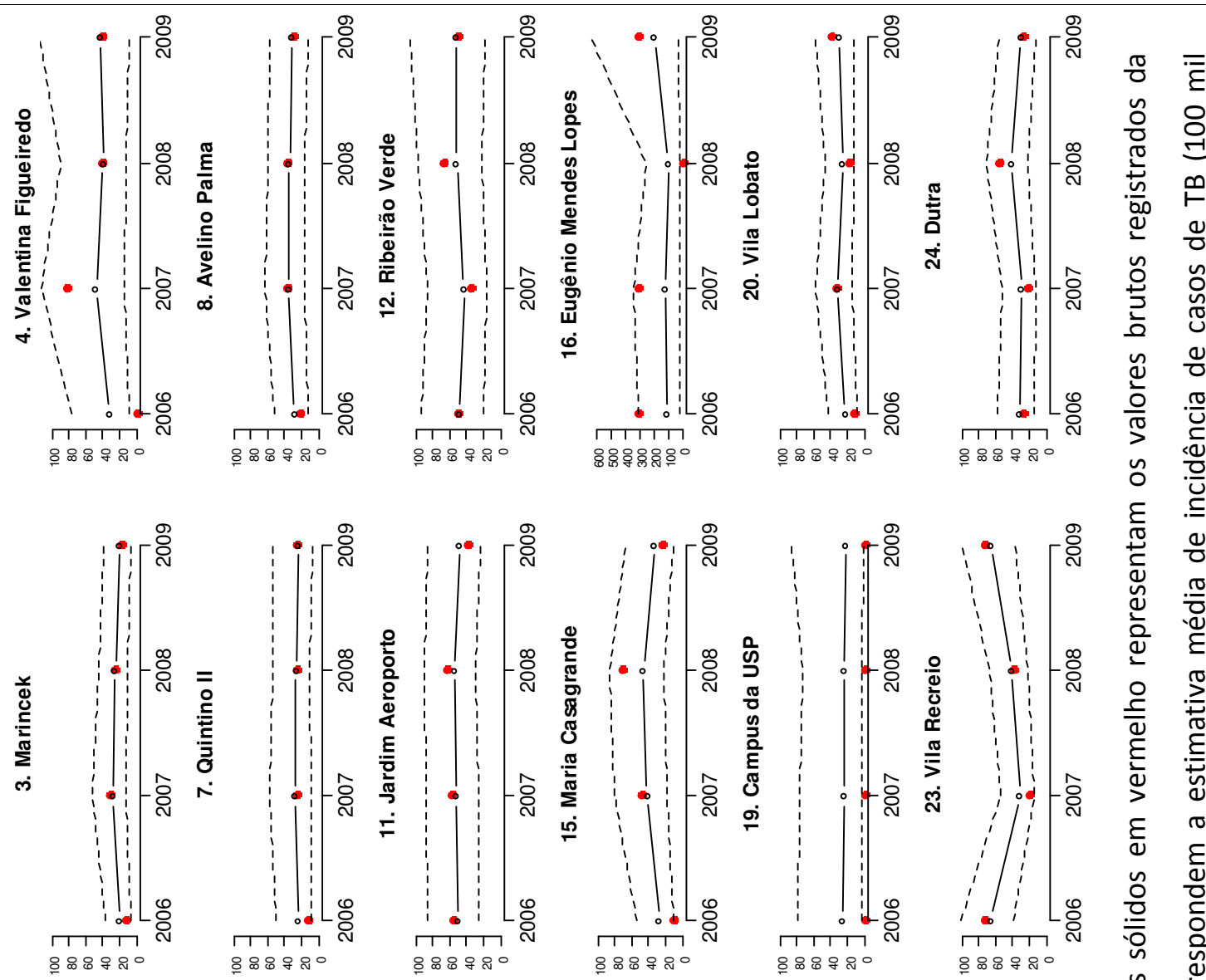

苍

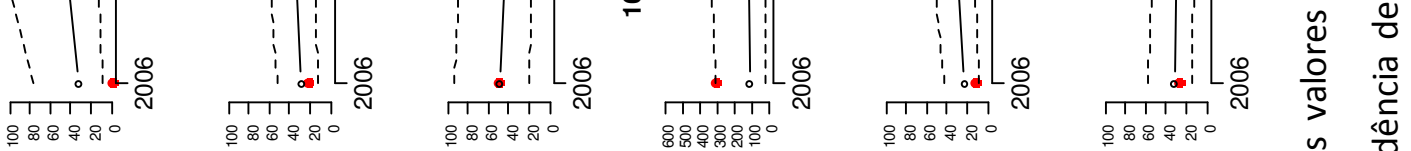
ํ. 흔 $\stackrel{\frac{E}{0}}{\stackrel{0}{*}}$ 这 ฮ 윰
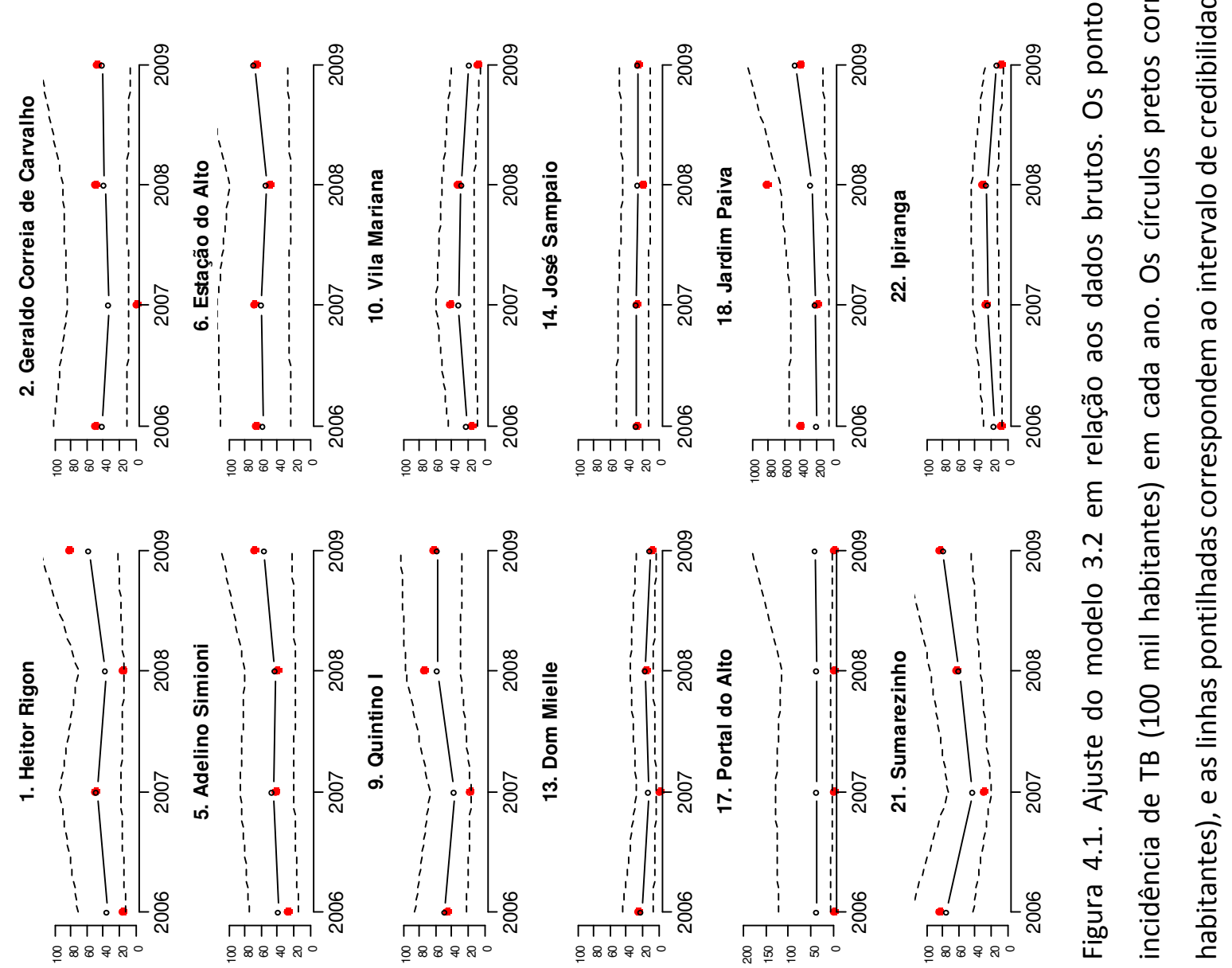

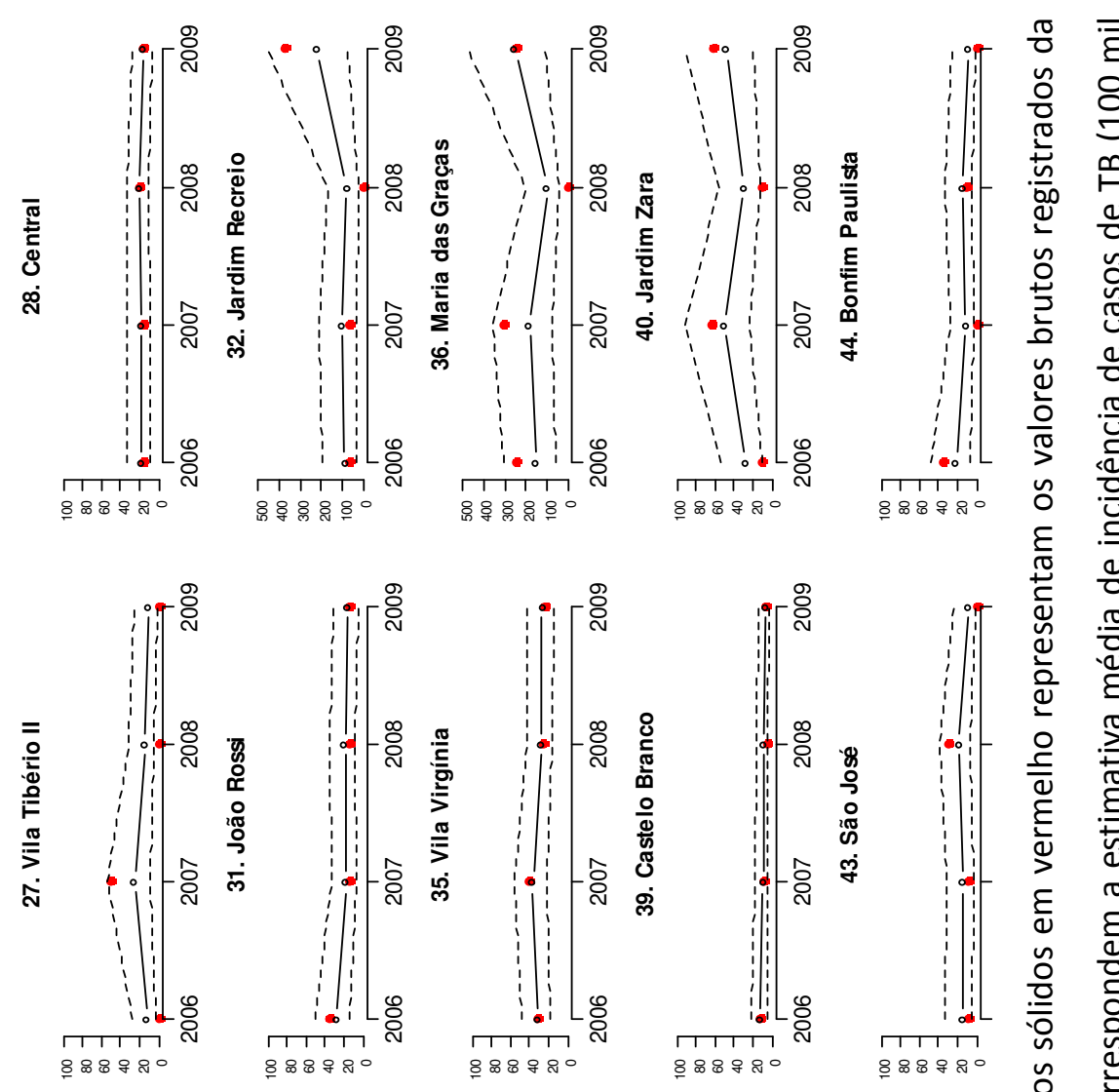

$\frac{\mathrm{O}}{\mathrm{T}}$

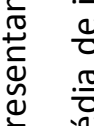
월 है

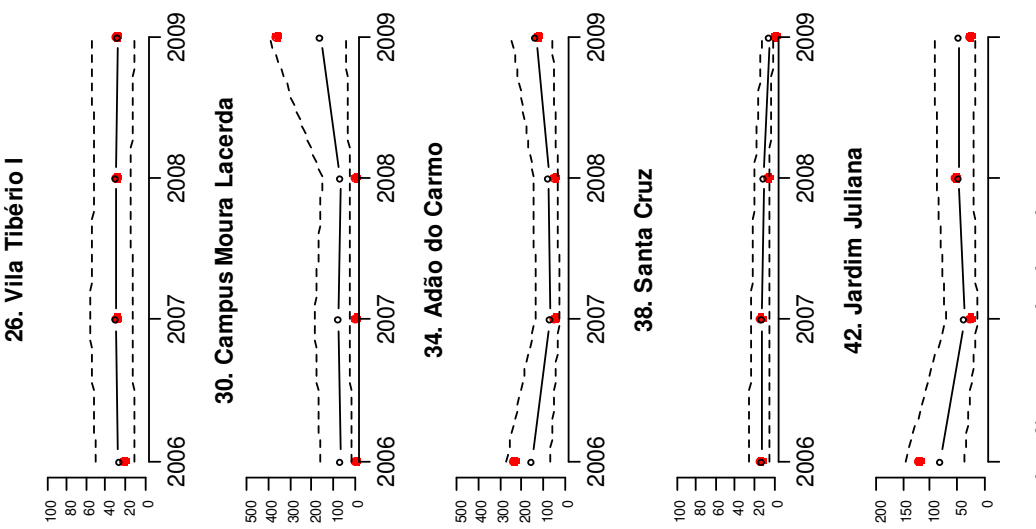

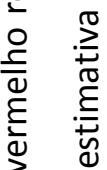

ह

ㅇํㅇ 웡

음

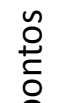

○े ֻ

苍 气 을

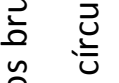

$\frac{0}{0}$

กิ

○ 용

200

$\frac{\varepsilon}{\frac{8}{0}}$

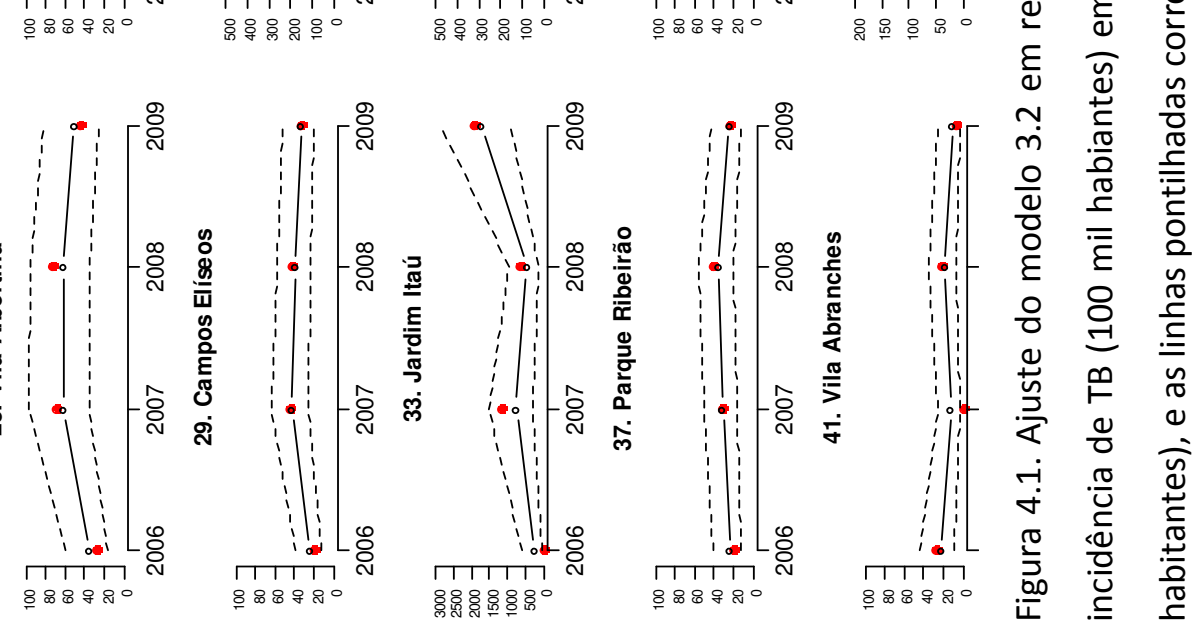


A partir dos resultados obtidos no modelo 3.2 , que inclui o efeito espacial e a covariável IPVS, construímos 6 tabelas resumo, nas quais 3 delas apresentam o coeficiente de incidência da TB em cada ano para cada uma das covariáveis: IPVS, Renda e Educação (Tabelas 4.4, 4.6 e 4.8). E as outras 3 (Tabelas 4.5, 4.7 e 4.9) apresentam as razões entre os coeficientes de incidência para cada variável em cada tempo.

Tabela 4.4 - Coeficientes de incidência de tuberculose, segundo características das regiões de saúde do município de Ribeirão Preto, SP.

\begin{tabular}{|c|c|c|c|c|}
\hline \multirow{2}{*}{ IPVS predominante na área } & \multirow{2}{*}{$\begin{array}{l}\text { Número } \\
\text { de áreas }\end{array}$} & \multirow{2}{*}{ Ano } & \multicolumn{2}{|c|}{ Média do Coeficiente de Incidência } \\
\hline & & & 100 mil habitantes & IC 95\% ${ }^{\text {(a) }}$ \\
\hline \multirow{4}{*}{1 = Nenhuma Vulnerabilidade } & \multirow{4}{*}{7} & 2006 & 26,46 & $(15,73 ; 46,76)$ \\
\hline & & 2007 & 23,03 & $(13,04 ; 42,07)$ \\
\hline & & 2008 & 21,61 & $(12,43 ; 38,30)$ \\
\hline & & 2009 & 57,19 & $(28,56 ; 110,50)$ \\
\hline \multirow{4}{*}{2 = Vulnerabilidade Muito Baixa } & \multirow{4}{*}{12} & 2006 & 29,32 & $(22,93 ; 37,07)$ \\
\hline & & 2007 & 30,93 & $(24,73 ; 38,63)$ \\
\hline & & 2008 & 32,13 & $(25,98 ; 39,68)$ \\
\hline & & 2009 & 33,93 & $(26,67 ; 43,04)$ \\
\hline \multirow{4}{*}{$3=$ Vulnerabilidade Baixa } & \multirow{4}{*}{13} & 2006 & 36,02 & $(28,63 ; 45,64)$ \\
\hline & & 2007 & 35,64 & $(28,63 ; 44,71)$ \\
\hline & & 2008 & 35,34 & $(28,54 ; 44,03)$ \\
\hline & & 2009 & 36,75 & $(28,76 ; 47,57)$ \\
\hline \multirow{4}{*}{4 = Vulnerabilidade Média } & \multirow{4}{*}{9} & 2006 & 77,16 & $(49,30 ; 130,60)$ \\
\hline & & 2007 & 63,16 & $(40,32 ; 105,10)$ \\
\hline & & 2008 & 72,27 & $(47,01 ; 120,70)$ \\
\hline & & 2009 & 102,80 & $(58,95 ; 189,60)$ \\
\hline \multirow{4}{*}{5 ou $6=$ Vulnerabilidade Alta ou Muito Alta } & \multirow{4}{*}{3} & 2006 & 192,20 & $(101,70 ; 348,30)$ \\
\hline & & 2007 & 348,30 & $(196,40 ; 606,40)$ \\
\hline & & 2008 & 235,30 & $(124,40 ; 431,10)$ \\
\hline & & 2009 & 634,00 & $(374,50 ; 1021,00)$ \\
\hline
\end{tabular}

(a) Intervalo de Credibilidade 95\%

Observamos na tabela 4.4 que a incidência de TB aumenta conforme aumenta a vulnerabilidade social predominante em cada área. A incidência de TB nas regiões onde a 64 
vulnerabilidade é predominantemente alta ou muito alta chega a 634 para cada 100 mil habitantes. Um resultado preocupante é que aparentemente a incidência de TB vem aumentando ao longo do tempo em estudo, sendo os maiores valores de incidência registrados no ano de 2009.

Tabela 4.5 - Razão entre os coeficientes de incidência de tuberculose, segundo características das regiões de saúde do município de Ribeirão Preto, SP.

\begin{tabular}{|c|c|c|c|c|}
\hline \multirow{2}{*}{ IPVS predominante na área } & \multirow[b]{2}{*}{ Ano } & \multirow{2}{*}{$\begin{array}{l}\text { Número } \\
\text { de áreas }\end{array}$} & \multicolumn{2}{|c|}{ Razão entre as incidências } \\
\hline & & & Razão & IC $95 \%^{(a)}$ \\
\hline 1 = Nenhuma Vulnerabilidade & 2006 & 7 & Referência & \\
\hline $2=$ Vulnerabilidade Muito Baixa & 2006 & 12 & 1,10 & $(0,59 ; 1,95)$ \\
\hline $3=$ Vulnerabilidade Baixa & 2006 & 13 & 1,36 & $(0,74 ; 2,41)$ \\
\hline $4=$ Vulnerabilidade Média & 2006 & 9 & 2,92 & $(1,48 ; 5,83)^{*}$ \\
\hline 5 ou $6=$ Vulnerabilidade Alta ou Muito Alta & 2006 & 3 & 7,22 & $(3,27 ; 15,13)^{*}$ \\
\hline 1 = Nenhuma Vulnerabilidade & 2007 & 7 & Referência & \\
\hline $2=$ Vulnerabilidade Muito Baixa & 2007 & 12 & 1,34 & $(0,71 ; 2,47)$ \\
\hline $3=$ Vulnerabilidade Baixa & 2007 & 13 & 1,54 & $(0,82 ; 2,83)$ \\
\hline $4=$ Vulnerabilidade Média & 2007 & 9 & 2,75 & $(1,37 ; 5,44)^{*}$ \\
\hline 5 ou $6=$ Vulnerabilidade Alta ou Muito Alta & 2007 & 3 & 14,97 & $(7,23 ; 31,60)^{*}$ \\
\hline 1 = Nenhuma Vulnerabilidade & 2008 & 7 & Referência & \\
\hline $2=$ Vulnerabilidade Muito Baixa & 2008 & 12 & 1,48 & $(0,81 ; 2,70)$ \\
\hline $3=$ Vulnerabilidade Baixa & 2008 & 13 & 1,63 & $(0,88 ; 2,96)$ \\
\hline $4=$ Vulnerabilidade Média & 2008 & 9 & 3,36 & $(1,75 ; 6,67)^{*}$ \\
\hline 5 ou $6=$ Vulnerabilidade Alta ou Muito Alta & 2008 & 3 & 10,81 & $(5,17 ; 22,79)^{*}$ \\
\hline 1 = Nenhuma Vulnerabilidade & 2009 & 7 & Referência & \\
\hline $2=$ Vulnerabilidade Muito Baixa & 2009 & 12 & 0,59 & $(0,29 ; 1,22)$ \\
\hline $3=$ Vulnerabilidade Baixa & 2009 & 13 & 0,64 & $(0,31 ; 1,34)$ \\
\hline $4=$ Vulnerabilidade Média & 2009 & 9 & 1,81 & $(0,78 ; 4,30)$ \\
\hline 5 ou 6 = Vulnerabilidade Alta ou Muito Alta & 2009 & 3 & 11,04 & $(4,94 ; 24,73)^{*}$ \\
\hline
\end{tabular}

Observa-se, por exemplo, no ano de 2007, nas regiões com vulnerabilidade predominantemente alta ou muita alta (5 ou 6) a incidência de TB é 14,97 vezes a incidência das 


\section{Resultados}

regiões sem vulnerabilidade (1), uma diferença significativa. Com os achados da tabela 4.5 se verifica a grande associação da tuberculose com vulnerabilidade social, medido pelo Índice Paulista de Vulnerabilidade Social (IPVS). Desta forma, regiões com mais vulnerabilidade social há também mais casos de tuberculose.

Além da grande associação da tuberculose com IPVS, há também grande associação com as variáveis Renda e Educação predominante dos responsáveis pelos domicílios, porém de forma inversa, ou seja, aumentando o níveis de renda e educação diminui-se a incidência de TB.

Tabela 4.6 - Coeficientes de incidência de tuberculose, segundo características das regiões de saúde do município de Ribeirão Preto, SP.

\begin{tabular}{|c|c|c|c|c|}
\hline \multirow{2}{*}{ Renda predominante } & \multirow{2}{*}{$\begin{array}{l}\text { Número } \\
\text { de áreas }\end{array}$} & \multirow{2}{*}{ Ano } & \multicolumn{2}{|c|}{ Média do Coeficiente de Incidência } \\
\hline & & & 100 mil habitantes & IC (95\%) ${ }^{(a)}$ \\
\hline \multirow{4}{*}{0 a 3 salários mínimos } & \multirow{4}{*}{17} & 2006 & 62,12 & $(44,93 ; 90,24)$ \\
\hline & & 2007 & 88,64 & $(61,01 ; 136,80)$ \\
\hline & & 2008 & 66,15 & $(48,87 ; 97,09)$ \\
\hline & & 2009 & 150,70 & $(101,70 ; 222,20)$ \\
\hline \multirow{4}{*}{3 a 10 salários mínimos } & \multirow{4}{*}{23} & 2006 & 45,39 & $(34,16 ; 66,50)$ \\
\hline & & 2007 & 42,41 & $(32,29 ; 60,92)$ \\
\hline & & 2008 & 41,60 & $(31,96 ; 59,60)$ \\
\hline & & 2009 & 63,55 & $(43,51 ; 100,90)$ \\
\hline \multirow{4}{*}{10 ou + salários mínimos } & \multirow{4}{*}{4} & 2006 & 28,42 & $(15,63 ; 56,65)$ \\
\hline & & 2007 & 26,29 & $(13,72 ; 54,46)$ \\
\hline & & 2008 & 21,12 & $(11,50 ; 41,31)$ \\
\hline & & 2009 & 60,19 & $(26,49 ; 127,30)$ \\
\hline
\end{tabular}

Observamos na Tabela 4.6 que as maiores taxas ficam nas menores rendas, com o aumento da renda diminui-se a incidência, como exemplo, no ano de 2009 a incidência de TB nas regiões cuja renda predominante é de 0 a 3 salários mínimos é de 150,70 em contrapartida para o mesmo ano nas regiões cuja renda predominante foi de 10 ou mais salários mínimos a incidência é de 60,19. Outro fator importante a se observar é o aumento da incidência no ano de 2009. Outro exemplo do declínio das taxas em relação ao aumento da renda pode ser observado 
no ano de 2007, que temos taxas de 88,64 para regiões predominantes de 0 a 3 salários mínimos, de 42,41 para 3 a 10 salários mínimos e de 26,29 para 10 ou mais salários mínimos.

Tabela 4.7 - Razão entre os coeficientes de incidência de tuberculose, segundo características das regiões de saúde do município de Ribeirão Preto, SP.

\begin{tabular}{lcccc}
\hline \multirow{2}{*}{ Renda predominante } & & Número & \multicolumn{2}{c}{ Razão entre as incidências } \\
\cline { 5 - 6 } & Ano & de áreas & Razão & IC (95\%) \\
\hline 0 a 3 salários mínimos & 2006 & 17 & 2,19 & $(1,07 ; 4,22)^{*}$ \\
3 a 10 salários mínimos & 2006 & 23 & 1,61 & $(0,79 ; 3,13)$ \\
10 ou + salários mínimos & 2006 & 4 & Referência & \\
\hline 0 a 3 salários mínimos & 2007 & 17 & 3,36 & $(1,59 ; 7,08)^{*}$ \\
3 a 10 salários mínimos & 2007 & 23 & 1,62 & $(0,77 ; 3,23)$ \\
10 ou + salários mínimos & 2007 & 4 & Referência & \\
\hline 0 a 3 salários mínimos & 2008 & 17 & 3,15 & $(1,61 ; 6,03)^{*}$ \\
3 a 10 salários mínimos & 2008 & 23 & 1,98 & $(1,02 ; 3,77)^{*}$ \\
10 ou + salários mínimos & 2008 & 4 & Referência & \\
\hline 0 a 3 salários mínimos & 2009 & 17 & 2,50 & $(1,09 ; 6,06)^{*}$ \\
3 a 10 salários mínimos & 2009 & 23 & 1,07 & $(0,46 ; 2,61)$ \\
10 ou + salários mínimos & 2009 & 4 & Referência & \\
\hline (a) Intervalo de Credibilidade 95\% & & & & \\
* Diferenças significantes em relação à classe de referência & &
\end{tabular}

A Tabela 4.7 apresenta as razões entre as incidências de TB, onde observamos que as maiores razões estão nas regiões onde predominam as menores rendas. Como exemplo, no ano de 2008, observamos que quando colocamos a maior renda como referência, a incidência de TB nas regiões com rendas predominantes de 0 a 3 salários mínimos é de 3,15 em relação a regiões com rendas predominantes de 10 ou mais salários mínimos, e nas regiões predominantes de 3 a 10 salários mínimos a razão de incidência é de 1,98 em relação a regiões com 10 ou mais salários mínimos.

Observamos a existência de associação da incidência de TB também com a Educação predominante, porém de uma forma não tão acentuada como nas demais variáveis em estudo. Podemos observar os resultados na Tabela 4.8. 
Como exemplo, podemos citar o ano de 2008 onde a incidência de TB nas regiões com predomínio de chefes de domicílio com ensino fundamental é 60,34 novos casos por 100.000 habitantes, em regiões com ensino médio a incidência diminui para 28,32 e em regiões com ensino superior a incidência diminui para 25,37.

Tabela 4.8 - Coeficientes de incidência de tuberculose, segundo características das regiões de saúde do município de Ribeirão Preto, SP.

\begin{tabular}{|c|c|c|c|c|}
\hline \multirow{2}{*}{$\begin{array}{l}\text { Nível de educação predominante } \\
\text { dos responsáveis dos domicílios }\end{array}$} & \multirow{2}{*}{$\begin{array}{l}\text { Número } \\
\text { de áreas }\end{array}$} & \multirow{2}{*}{ Ano } & \multicolumn{2}{|c|}{ Média do Coeficiente de Incidência } \\
\hline & & & 100 mil habitantes & IC (95\%) ${ }^{(\mathrm{a})}$ \\
\hline \multirow{4}{*}{ Ensino Fundamental } & \multirow{4}{*}{31} & 2006 & 59,33 & $(43,96 ; 83,53)$ \\
\hline & & 2007 & 71,38 & $(52,86 ; 101,70)$ \\
\hline & & 2008 & 60,34 & $(46,14 ; 84,32)$ \\
\hline & & 2009 & 119,0 & $(85,75 ; 165,70)$ \\
\hline \multirow{4}{*}{ Ensino Médio } & \multirow{4}{*}{7} & 2006 & 37,21 & $(26,48 ; 52,33)$ \\
\hline & & 2007 & 24,55 & $(16,76 ; 35,40)$ \\
\hline & & 2008 & 28,32 & $(19,95 ; 39,88)$ \\
\hline & & 2009 & 31,91 & $(22,51 ; 45,55)$ \\
\hline \multirow{4}{*}{ Ensino Superior } & \multirow{4}{*}{6} & 2006 & 31,53 & $(18,26 ; 57,19)$ \\
\hline & & 2007 & 29,60 & $(16,90 ; 54,28)$ \\
\hline & & 2008 & 25,37 & $(14,91 ; 44,96)$ \\
\hline & & 2009 & 67,99 & $(34,26 ; 130,00)$ \\
\hline
\end{tabular}

A respeito das razões entre as taxas de incidência observamos que as taxas de incidência de tuberculose das regiões onde predomina o ensino fundamental é 2 vezes a incidência em regiões com ensino superior (Tabela 4.9). 
Tabela 4.9 - Razão entre os coeficientes de incidência de tuberculose, segundo características das regiões de saúde do município de Ribeirão Preto, SP.

\begin{tabular}{lcccc}
\hline \multirow{2}{*}{ Educação predominante } & & Número & \multicolumn{2}{c}{ Razão entre as incidências } \\
\cline { 5 - 5 } & Ano & de áreas & Razão & IC $(95 \%)^{\text {(a) }}$ \\
\hline Ensino Fundamental & 2006 & 31 & 1,88 & $(1,04 ; 3,38)^{*}$ \\
Ensino Médio & 2006 & 7 & 1,17 & $(0,59 ; 2,28)$ \\
Ensino Superior & 2006 & 6 & Referência & \\
\hline Ensino Fundamental & 2007 & 31 & 2,41 & $(1,31 ; 4,43)^{*}$ \\
Ensino Médio & 2007 & 7 & 0,83 & $(0,41 ; 1,60)$ \\
Ensino Superior & 2007 & 6 & Referência & \\
\hline Ensino Fundamental & 2008 & 31 & 2,39 & $(1,37 ; 4,15)^{*}$ \\
Ensino Médio & 2008 & 7 & 1,11 & $(0,57 ; 2,11)$ \\
Ensino Superior & 2008 & 6 & Referência & \\
\hline Ensino Fundamental & 2009 & 31 & 1,75 & $(0,88 ; 3,59)$ \\
Ensino Médio & 2009 & 7 & 0,47 & $(0,22 ; 1,01)$ \\
Ensino Superior & 2009 & 6 & Referência & \\
\hline
\end{tabular}

(a) Intervalo de Credibilidade 95\%

* Diferenças significantes em relação à classe de referência

Para facilitar a visualização das taxas de incidência em todo o município de Ribeirão Preto ao longo do tempo, dispomos os resultados em mapas que poderão ser observados na Figura 4.2. Os quatro mapas contidos na Figura 4.2 (A) representam as taxas brutas, valores reais registrados no município, já na Figura 4.2 (B) encontramos as taxas ajustadas pelo modelo, levando em consideração na modelagem à vulnerabilidade social contida em cada região do município. As taxas ajustadas se mostraram mais suavizadas nos mapas e mais condizente com a realidade do município. 

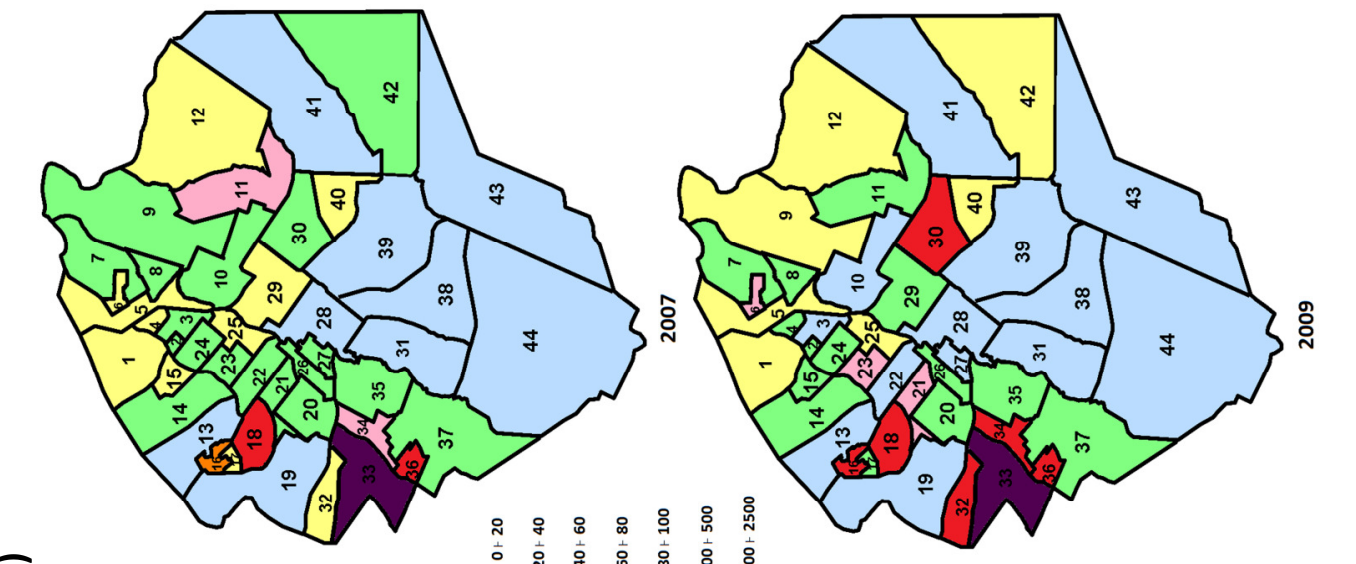

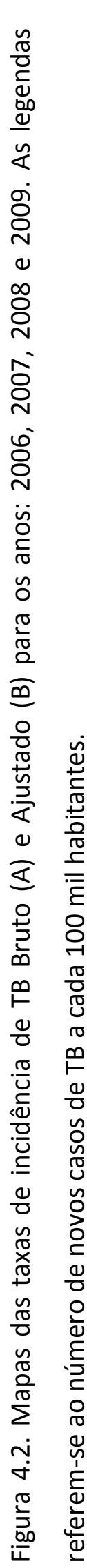

$\underline{\underline{\theta}}$
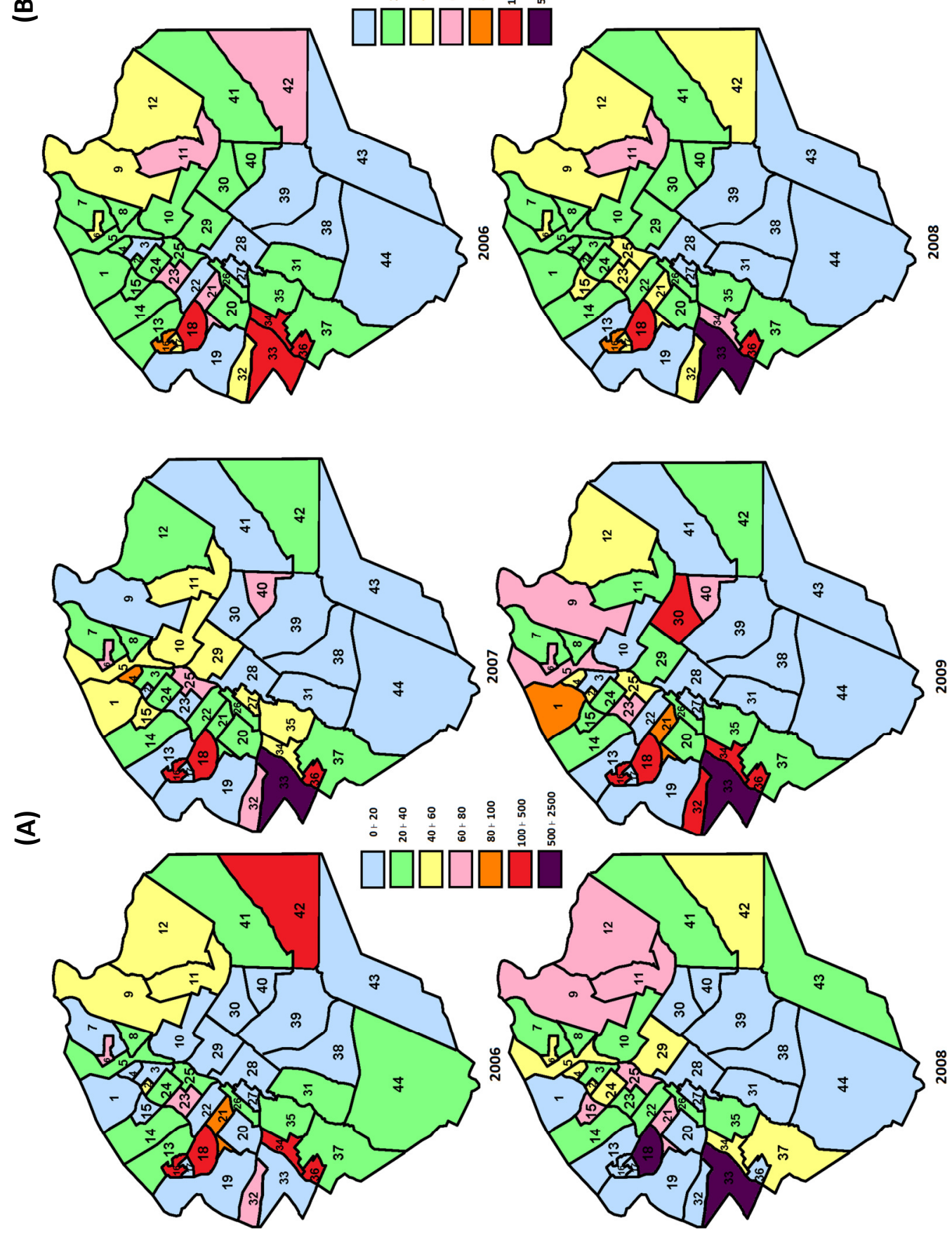
Observamos que as áreas com as mais altas taxas de incidência também possuem índice de vulnerabilidade social predominantemente médio e alto, respectivamente, 4 e 5 . Em relação à renda, a média salarial predominante dos responsáveis pelo domicílio nestas regiões são entre 0 e 3 salários mínimos e o nível de escolaridade predominante dos chefes do domicílio nestas regiões é o ensino fundamental.

Ao compararmos as taxas brutas com as taxas estimadas nas áreas em estudo, podemos observar que algumas áreas não tiveram grandes alterações na incidência de TB, algumas tiveram um aumento na taxa estimada e outras tiveram uma diminuição na taxa estimada. As áreas que nos chamaram mais a atenção foram as áreas 33 (Jardim Itaú), 18 (Portal do Alto), 36 (Maria das Graças) e 34 (Adão do Carmo) que tiveram altas taxas de incidência de TB, tanto bruta como estimada.

Outras áreas que nos chamaram a atenção são as áreas vizinhas 32 (Jardim Recreio) e 33 (Jardim Itaú), a área 32 é uma região com alto nível de escolaridade, baixo índice de IPVS e alta renda, contrastando com a área 33 onde o IPVS é alto, o nível de escolaridade é baixo e a renda é baixa, além de ser uma área com favela e muito próxima da Fundação CASA (Fundação Centro de Atendimento Socioeducativo ao Adolescente), quando olhamos apenas para a taxa bruta observamos que no ano de 2006 a área 32 teve 1 caso notificado e a área 33 não teve nenhum caso notificado, desta forma, ao ajustar as taxas verificamos que a área 32 teve uma diminuição acentuada da taxa bruta para a taxa estimada, e na área 33 houve o inverso um aumento acentuado na taxa estimada, o que parece mais condizente com a realidade daquela região. Observamos também que no mapa com as taxas ajustadas houve uma suavização, um alisamento nas taxas.

Nota-se que a incidência é relativamente baixa para as áreas: 27 (Vila Tibério II), 28 (Central), 38 (Santa Cruz), 39 (Castelo Branco), 43 (São José), 44 (Bonfim Paulista), 31 (João Rossi) e 19 (Campus da USP). Em todas essas áreas a incidência é menor que 20 casos para cada 100 mil habitantes. 

Capítulo 5

DISCUSSÃO 



\section{DISCUSSÕES E CONCLUSÕES FINAIS}

Neste trabalho foram utilizados modelos de regressão espaço-temporais bayesianos para estimar a incidência de TB em Ribeirão Preto (anos de 2006 a 2009) por área de abrangência de unidades de saúde, associando-a a covariáveis de interesse (IPVS, Renda e Educação predominantes naquelas áreas). O método baseia-se em simulações MCMC para estimar as distribuições a posteriori das incidências de TB em Ribeirão Preto. Como resultado, temos mapas que mostram mais claramente um padrão espacial, com estimativas mais suavizadas e com menos flutuações aleatórias.

Observou-se que os modelos que incorporam a estrutura espacial além das covariáveis apresentaram melhor desempenho (menores valores de DIC), o que evidencia a distribuição não homogênea dos novos casos de TB no município. Com a inserção das covariáveis, observou-se que a incidência de TB é diretamente correlacionada com a vulnerabilidade social. E, com a inclusão do efeito do tempo na modelagem, foi possível descrever a evolução das taxas ao longo deste período.

$\mathrm{Na}$ modelagem espacial existem diferentes maneiras de explorar a correlação espacial, sendo uma das maneiras por meio de diferentes estruturas de vizinhança. Diferentes matrizes de vizinhança podem gerar diferentes estimativas. Neste trabalho não foi viável a construção de várias matrizes de vizinhança, devido a grande demanda de tempo. Dessa forma utilizou-se apenas o critério de mesma fronteira, ou seja, duas áreas são vizinhas se elas compartilham a mesma fronteira geográfica.

Observamos que as áreas com as mais altas taxas de incidência também possuem índice de vulnerabilidade social predominantemente médio e alto. Em relação à renda, a média salarial predominante dos responsáveis pelo domicílio nestas regiões está entre 0 e 3 salários mínimos e o nível de escolaridade predominante dos chefes do domicílio nestas regiões é o ensino fundamental.

Os resultados dos modelos bayesianos analisados nos evidenciam que com o aumento da vulnerabilidade social aumentamos significativamente a incidência de TB em Ribeirão Preto. Nas regiões onde a vulnerabilidade é alta a incidência de TB chega a quase 15 vezes a incidência das regiões sem vulnerabilidade. Observamos também para Renda e 


\section{Discussão}

Educação, que regiões com predomínio de altas rendas e altos níveis educacionais diminui a incidência de TB em Ribeirão Preto.

Estes resultados são compatíveis com estudos ecológicos relatados pela literatura (Myers, 2006 ; Hawker, 1999 ; Leung, 2004), confirmando que a tuberculose continua sendo uma doença fortemente relatada com características sociais da população. Marais et al (2009) cita três causas primárias que determina o papel da pobreza na transmissão do Mycobacterium tuberculosis: 1) é influenciado por condições de vida, tais como pessoas vivendo aglomeradas e em casas pouco ventiladas, 2) demora no diagnóstico e 3) aumento da vulnerabilidade devido a desnutrição e a infecção pelo HIV. Estudos ecológicos permitem examinar a TB em seu contexto social (Myers, 2006), a relação entre a doença e as condições de pobreza e baixo nível socioeconômico não podem ser estudados em nível individual.

Neste estudo existem limitações que são intrínsecas aos estudos ecológicos, como a possibilidade de haver migrações entre as áreas, a ambiguidade temporal (a doença pode influenciar a vulnerabilidade social) e vieses ecológicos (Morgenstern, 1998). O número de habitantes em cada área foi estimado baseado em informações do IBGE, e por se tratar de estimativas, esses valores podem não ser muito precisos, especialmente em áreas onde surgiram novos bairros no período estudado.

O sistema de informações TBWeb foi implantado em 2006, abrangendo todos os municípios do estado de São Paulo. A qualidade das informações do TBWeb é muito superior quando comparado com o sistema EPI-TB (usado até 2006). Entretanto, o atual sistema também está sujeito a deficiências, como a possibilidade de subnotificação de casos devido a falta de conscientização dos cuidadores e atraso na procura dos serviços de saúde. Indivíduos sem residência fixa e moradores de área rural não foram georreferenciados, pois não havia informações disponíveis sobre a localização exata destes indivíduos. Porém, essas perdas foram pequenas, o que representa somente $3,5 \%$ de todos os registros.

O uso de mapas facilita a visualização de áreas que merecem uma atenção especial no controle da TB, além disso, a associação da doença com renda, escolaridade e vulnerabilidade social trazem subsídios para que os gestores responsáveis pelo planejamento do município planejem intervenções com uma atenção especial a estas áreas, reunindo esforços para a redução da pobreza e da desigualdade social, alternativas para uma melhor distribuição de renda e melhorar o acesso ao saneamento básico dentre outras prioridades. 
Diferente de outros estudos já realizados para Ribeirão Preto (Hino et al, 2005 e Santos et al, 2004) nosso estudo consegue identificar quais as áreas que devem receber atenção prioritária por parte dos gestores de saúde e qual a Unidade Básica e Distrital responsável por ela. Destacamos algumas áreas com coeficientes de incidência altíssimos: (1) Área número 33: Jardim Itaú. Responsável: UBDS Vila Virgínia; (2) Área número 36: Maria da Graças. Responsáveis: UBS Maria das Graças e UBDS Sumarezinho; (3) Área número 18: Jardim Paiva. Responsáveis: UBS Jardim Paiva e UBDS Sumarezinho; (4) Área número 34: Adão do Carmo. Responsáveis: UBS Adão do Carmo e UBDS Vila Virginia e (5) Área número 16: Eugênio Mendes Lopes. Responsáveis: USF Eugênio Mendes Lopes e UBDS Sumarezinho. Estas são cinco áreas que identificamos com altíssima incidência de tuberculose, mas diversas outras áreas são identificadas como situação parecida.

Neste estudo é possível identificar as áreas com maiores coeficientes, bem como identificar as áreas mais propensas a altas taxas de incidência de TB, resultado do modelo desenvolvido. O modelo é composto por um efeito aleatório, com distribuição CAR (Conditional autoregressivo), que não sofre influência direta das covariáveis, mas quando calculamos para cada área seu respectivo valor e colocamos em uma ordem decrescente, conseguimos identificar quais as áreas com maior propensão a ter altos índices, geralmente essas áreas são vizinhas a áreas com altíssimas taxas. São as áreas: 33 (Jardim Itaú), 36 (Maria das Graças), 18 (Jardim Paiva), 34 (Adão do Carmo), 16 (Eugênio Mendes Lopes), 32 (Jardim Recreio) e 17 (Portal do Alto). Também conseguimos identificar as áreas menos propensas: 38 (Santa Cruz), 39 (Castelo Branco), 43 (São José), 44 (Bonfim Paulista), 27 (Vila Tibério II) e 28 (Central).

As áreas aqui identificadas como mais propensas no município de Ribeirão Preto, na maioria delas há presença de favelas e assentamentos, com exceção da área 32 (Jardim Recreio).

A Organização Mundial de Saúde espera eliminar a TB como problema de saúde pública até 2050, isso significa, uma incidência de menos de 1 caso para cada 1 milhão de habitantes (WHO, 2006). Atualmente, em Ribeirão Preto temos áreas com incidência registrada de quase 20.000 casos para cada 1 milhão de habitantes, sendo a média do município de 350 casos em cada 1 milhão de habitantes.

Por se tratar de um estudo ecológico, as características aqui identificadas se referem a uma comunidade, ou seja, a um grande contingente populacional e não a características individuais. Com base nos resultados, acreditamos que a Secretaria de Saúde do município 


\section{Discussão}

poderá ter uma melhor visão da incidência de tuberculose no município, podendo assim ter melhores subsídios para geração de políticas públicas. 
REFERÊNCIAS BIBLIOGRÁFICAS 

ALVAREZ-HERNÁNDEZ G, LARA-VALENCIA F, REYES-CASTRO PA, RASCÓN-PACHECO RA. Na analysis of spatial and ócio-economic determinants of tuberculosis in Hermosillo, Mexico, 20002006. Int J Tubercul Lung Dis. 2010; 14(6): 708-713.

BAILEY TC. Spatial statistical methods in health. Cad. Saúde Pública, Rio de Janeiro, 2001; 17(5): 1083-1098.

BESAG J , KOOPERBERG CL. On conditional and intrinsic autoregressions. Biometrika, 1995; 82: 733-746.

BIERRENBACH AL, GOMES AB, NORONHA EF, SOUZA M de F. Tuberculosis incidence and cure rates, Brazil, 2000-2004. Rev Saúde Pública 2007; 41(1):24-33.

BORGDORFF MW. New measurable indicator for tuberculosis case detection. Emerg. Infect. Dis. [página na internet]. Disponível em: <http://www.cdc.gov/neidod/EID/Vol10no9/04-0349.htm>. Acesso em: 11 jul 2010.

BRANSCUM AJ, PEREZ AM, JOHNSON WO, THURMOND MC. Bayesian spatiotemporal analysis of foot-and-mouth disease data from the Republic of Turkey. Epidemiol Infect. 2008; 136(6): 833842.

BRASIL. Ministério da Saúde. Conselho Nacional de Saúde. Resolução 196/96: diretrizes e normas regulamentadoras de pesquisa envolvendo seres humanos. Brasília, DF, 1996.

BRUNELLO MEF, CHIARAVALLOTI NETO F, ARCÊNCIO RA, ANDRADE RLP, MAGNABOSCO GT, VILLA TCS. Áreas de vulnerabilidade para co-infecção HIV-aids/TB em Ribeirão Preto, SP. Rev Saúde Pública. 2011; 45(3):556-563.

BURGOS MV, PYM AS. Molecular epidemiology of tuberculosis. Eur Respir J. Suppl. 2002; 36: 5465.

CARDOZO GONZÁLES RIC, MONROE AA, ARCÊNCIO RA, OLIVEIRA MF, RUFFINO NETTO A, VILLA TCS. Indicadores de desempenho do DOT no domicílio para o controle da tuberculose em município de grande porte, SP, Brasil. Rev. Latino-Am Enfermagem. 2008; 16(1): 95-100.

CARVALHO, M. S.; SOUZA-SANTOS, R. Análise de dados espaciais em saúde pública: métodos, problemas, perspectivas. Cad. Saúde Pública, Rio de Janeiro; 2005, 21 (2): 361-378.

CASTRO, M. S. M ; VIEIRA, V. A. ; ASSUNÇÃO, R. M. Padrões espaço-temporais da mortalidade por câncer de pulmão no Sul do Brasil. Rev Bras Epidemiol; 2004, 7(2): 131-143.

DALCOLMO M. Tuberculosis and HIV infection in Brazil - update and overview. TB HIV 1996; (11):26. 
ELLIOTT P, WARTENBERG D. Spatial Epidemiology: current approaches and future challenges. Environmental Health Perspectives. 2004 ; 112(9): 998-1006.

FERREIRA MP, DINI NP, FERREIRA SP. Espaços e dimensões da pobreza nos municípios de São Paulo: Índice Paulista de Vulnerabilidade Social - IPVS. São Paulo Perspect, 2006; 20:5-17.

FUNDAÇÃO SEADE [página na internet]. São Paulo-SP. Índice Paulista de Vulnerabilidade Social IPVS. Espaços e dimensões da pobreza nos municípios do Estado de São Paulo. Disponível em: <http://www.seade.gov.br.br/produtos/ipvs/pdf/oipvs.pdf>. Acesso em: 17 mai 2010.

GAMERMAN D. Markov Chain Monte Carlo: Stochastic simulation for Bayesian inference. Chapman and Hall, 245 p. London, 1997.

GANDY M, ZUMLA A. The resurgence of disease: Social and historical perspectives on the 'new' tuberculosis. Soc Sci Med. 2002; 55(3): 385-396; discussion 397-401.

GESLER W. The uses of spatial analysis in medical geography: a review. Soc Sci Med 1986; 23(10): 963-973.

GEWEKE J. Evaluating the accuracy of sampling-basead approaches to the calculation of posterior moments (with discussion). In: Bernardo JM, Berger J, Dawid AP, Smith AFM. (eds). Bayesian statistics 4. Oxford: Oxford University Press, 1992; p.169-193

HAWKER JL, BAKHSHI SS, ALI S, FARRINGTON CP. Ecological analysis of ethnic differences in relation between tuberculosis and poverty. BMJ. 1999; 319(7216): 1031-1034.

HINO P, COSTA-JUNIOR ML, SASSAKI CM, OLIVEIRA MF, VILLA TCS, SANTOS CB. Time series of tuberculosis mortality in Brazil (1980-2001). Rev Latino-Am Enfermagem. 2007; 15(5):936-941.

HINO P, SANTOS CB, VILLA TCS, BERTOLOZZI MR, TAKAHASHI RF. O controle da tuberculose na perspectiva da vigilância da saúde. Esc Anna Nery. 2005a; 15(2): 417-421.

HINO P, SANTOS CB, VILLA TCS, MUNIZ JN, MONROE AA. Tuberculosis patients submetted to supervised treatment Ribeirão Preto - São Paulo-Brazil. 1998 and 1999. Rev Latino-Am Enfermagem. 2005b; 13(1):27-31.

HINO P, VILLA TCS, CUNHA TN, SANTOS CB. Distribuição espacial de doenças endêmicas no município de Ribeirão Preto (SP). Ciência \& Saúde Coletiva. 2011; 16(1):1289-1294.

HUONG NT, VREE M, DUONG BD, KHANH VT, LOAN VT, CO NV, BORGDORFF MW, COBELENS FG. Delays in the diagnosis and treatment of tuberculosis patients in Vietnam: a cross-sectional study. BMC Public Health. 2007; 7(110):1-8.

INSTITUTO BRASILEIRO DE GEOGRAFIA E ESTATÍ́STICA - IBGE. Censo Demográfico de 2000. Disponível em: <http://www.ibge.gov.br>. Acesso em: 24 mai 2010. 
INSTITUTO NACIONAL DE PESQUISAS ESPACIAIS - INPE. Projeto TerraView. Disponível em: <http://www.dpi.inpe.br/terraview/index.php>. Acesso em: 11 jun 2010.

KOYANAGI A, KUFFÓ D, GRESELY L, SHENKIN A, CUEVAS LE. Relationships between serum concentrations of C-reactive protein and micronutriens, in patients with tuberculosis. Ann Trop Med Parasitol. 2004; 98(4):391-399.

LEUNG CC, YEW WW, TAM CM, CHAN CK, CHANG KC, LAW WS, WONG MY, AU KF. Socioeconomic factors and tuberculosis: a district-basead ecological analysis in Hong Kong. Int J Tuberc Lung Dis. 2004; 8(8):958-964.

LUNN DJ, THOMAS A, BEST N, SPIEGELHALTER D. WinBUGS - A Bayesian modeling framewok: Concepts, structure, and extensibility. Stat Computing. 2000; 10:325-337.

MACIEL EL, PAN W, DIETZE R, PERES RL, VINHAS SA, RIBEIRO FK, PALACI M, RODRIGUES RR, ZANDONADE E, GOLUB JE. Spatial patterns of pulmonary tuberculosis incidence and their relationship to socio-economic status in Vitoria, Brazil. Int J Tubec Lung Dis. 2010; 14(11): 13951402.

MARAIS BJ, HESSELING AC, COTTON MF. Poverty and tuberculosis: is it truly a simple inverse linear correlation? Eur Respir J. 2009 ; 33(4): 943-944.

MEDRONHO, R. A. Epidemiologia. Rio de Janeiro: Editora Atheneu, 493p., 2002.

MINISTÉRIO DA SAÚDE. Introdução à estatística espacial para a saúde pública. Série: Capacitação e atualização em geoprocessamento em saúde. Brasília-DF, 2007.

MORGENSTERN, H. Ecologic studies. In: Modern Epidemiology (K. J. Rothman \& S. Greenland, eds.), Philadelphia: Lippincott-Raven Publishers, 1998; 459-480.

MUNIZ JN, VILLA TCS. O impacto epidemiológico do tratamento supervisionado no controle da tuberculose em Ribeirão Preto 1998-2000. Bol Pneumol Sanit. 2002; 10(1): 49-54.

MUNCH Z, VAN LILL SW, BOOYSEN CN, ZIETSMAN HL, ENARSON DA, BEYERS N. Tuberculosis transmission patterns in a high-incidence area: a spatial analysis. Int J Tuberc Lung Dis. 2003; $7(3): 271-277$.

MYERS WP, WESTENHOUSE JL, FLOOD J, RILEY LW. An ecological study of tuberculosis transmission in California. Am J Public Health. 2006 Apr; 96(4):685-690.

ORGANIZAÇÃO PANAMERICANA DE SAÚDE. Organização Mundial de Saúde. Reunion regional de directores nacionales de programas de controle de la tuberculose. Informe final. Ecuador, 1997.

PETHE K, ALONSO S, BIET F, DELOGU G, BRENNAN MJ, LOCHT C,MENOZZI FD. The heparinbinding haemagglutinin of $\mathrm{M}$. tuberculosis is required for extrapulmonary dissemination. Nature 2001; 412 (6843): 190-194; 
RAVIGLIONE, M. C.; UPLEKAR, M. W. WHO’s new Stop TB Strategy. Lancet, 18(9514):952-955.

RIBEIRÃO PRETO. Prefeitura Municipal. Secretaria Municipal da Saúde. Plano de Saúde Ribeirão Preto: 2005-2008. Ribeirão Preto, 2005. 75p. Disponível em: <http://www.ribeiraopreto.sp.gov.br/ssaude/vigilancia/planea/plano05-08.pdf>. Acesso em: 18 mai 2010.

RODRIGUES GO, SÁ LD, NOGUEIRA JA, DAMASCENA LCL, GOMES ALC, VILLA TCS. A expansão do tratamento supervisionado (TS) para o controle da tuberculose na Paraíba (1999/2005). Rev. Eletr. Enf. [Internet]. 2008; 10(3):632-642.

RUSSELL DG, BARRY CE $3^{\text {rd }}$, FLYNN JL. Tuberculosis: what we don't know can, and does, hurt us. Science 2010; 328 (5980):852-856.

SANTOS CB, HINO P, CUNHA TN, VILLA TCS, MUNIZ JN. Utilização de um Sistema de Informação Geográfica para descrição dos casos de Tuberculose. Boletim de Pneumologia Sanitária; 2004, 12(1): 5-10.

SANTOS CB, HINO P, VILLA TCS, MUNIZ JN. Indicadores epidemiológicos e de impacto da tuberculose para Ribeirão Preto no período de 1990 a 2000. Boletim de Pneumologia Sanitária; 2002; 10(1): 31-40.

SILVA ASB. Avaliação da atenção em diabetes mellitus em uma Unidade Básica Distrital de Saúde em Ribeirão Preto-SP. 2009. 130 f. Tese (Doutorado) - Escola de Enfermagem de Ribeirão Preto, Universidade de São Paulo. Ribeirão Preto, 2009.

SPENCE DP, HOTCHKISS J, WILLIAMS CS, DAVIES PD. Tuberculosis and poverty. BMJ. 1993; 307(6907):759-61.

SPINDOLA DE MIRANDA S, KRITSKI A, FILLIOL I, MABILAT C, PANTEIX G, DROUET E. Mutations in the poB gene of rifampicin-resistant Mycobacterium tuberculosis strains isolated in Brazil and France. Mem Inst Oswaldo Cruz 2001; 96(2): 247-250.

SUSSER, M. The logic in ecological. American Journal Public Health, 1994; 84:825-835.

TBWeb. [página na internet]. Disponível em: <http://www.cvetb.saude.sp.gov.br/tbweb/ index.jsp>. Acesso em: 20 set 2009.

TEIXEIRA, GM. Os novos alcances da parceria STOP TB. Boletim de Pneumologia Sanitaria. 2006; 14(1): 5-6.

THOMAS A, BEST N, LUNN D, ARNOLD R, SPIEGELHALTER D. GeoBUGS User Manual. Cambridge: Medical Research Council Biostatistics Unit; 2004. 
TOURAY K, ADETIFA IM, JALLOW A, RIGBY J, JEFFRIES D, CHEUNG YB, DONKOR S, ADEGBOLA RA, HILL PC. Spatial analysis of tuberculosis in an urban West African setting: is there evidence of clustering? Trop Med Int Health. 2010; 15(6): 664-672.

VENDRAMINI SHF, GAZETTA CE, CHIARAVALOTTI NETTO F, CURY MR, MEIRELLES EB, KUYUMJIAN FG, VILLA TCS. Tuberculosis in a medium-sized city in the Southeast of Brazil: morbidity and mortality rates (1985-2003). J. Bras. Pneumol. 2005; 31(3):237-43.

WHO. What is DOTS? A Guide to understanding the WHO-recommended TB Control Strategy Know as DOT. WHO/CDS/CPC/TB/99.270. 39p. 1999.

WHO. A estratégia Stop TB. STOP TB Partnership. 2006. 
APÊNDICES

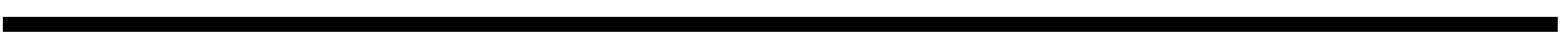





\section{APÊNDICE A}

\section{SUMÁRIO A POSTERIORI ASSUMINDO O MODELO COM EFEITO ESPACIAL E COVARIÁVEL IPVS E CONVERGÊNCIA DO MODELO}

\begin{tabular}{|c|c|c|c|c|c|}
\hline Parâmetros & Média & Desvio-Padrão & Mediana & IC 95\% & $\mathrm{Z}_{\mathrm{G}} *$ \\
\hline$\alpha 1$ & $-0,0115$ & 0,0847 & $-0,00189$ & $(-0,2131 ; 0,1103)$ & 1,6290 \\
\hline$\alpha 2$ & $-0,008$ & 0,0931 & $-0,00153$ & $(-0,2121 ; 0,1422)$ & 0,9068 \\
\hline$\alpha 3$ & $-0,00845$ & 0,07992 & $-0,0015$ & $(-0,1902 ; 0,1137)$ & 1,1100 \\
\hline$\alpha 4$ & $-0,0058$ & 0,09969 & $-0,00105$ & $(-0,2185 ; 0,1668)$ & $-1,5080$ \\
\hline$\alpha 5$ & $-0,00129$ & 0,06636 & $-5,09 E-01$ & $(-0,134 ; 0,1241)$ & $-0,06317$ \\
\hline$\alpha 6$ & 0,01865 & 0,1289 & 0,002586 & $(-0,1588 ; 0,3396)$ & $-0,2788$ \\
\hline$\alpha 7$ & $-7,83 \mathrm{E}-04$ & 0,09004 & $-6,56 \mathrm{E}-01$ & $(-0,1808 ; 0,1763)$ & $-0,1152$ \\
\hline$\alpha 8$ & $-3,35 E-01$ & 0,08532 & $-5,24 \mathrm{E}-01$ & $(-0,1684 ; 0,1682)$ & $-1,0450$ \\
\hline$\alpha 9$ & $-0,00292$ & 0,08259 & $-0,00128$ & $(-0,1714 ; 0,1482)$ & $-0,3908$ \\
\hline$\alpha 10$ & $-0,00658$ & 0,06684 & $-0,0015$ & $(-0,1588 ; 0,1021)$ & 1,8600 \\
\hline$\alpha 11$ & $-0,02636$ & 0,1112 & $-0,00465$ & $(-0,3194 ; 0,08157)$ & 1,5170 \\
\hline$\alpha 12$ & $-0,01668$ & 0,1012 & $-0,00338$ & $(-0,2754 ; 0,1273)$ & 1,6660 \\
\hline$\alpha 13$ & 0,002807 & 0,08137 & 0,001154 & $(-0,1401 ; 0,1649)$ & 0,9623 \\
\hline$\alpha 14$ & $-0,00704$ & 0,07582 & $-9,12 E-04$ & $(-0,178 ; 0,1108)$ & 2,5040 \\
\hline$\alpha 15$ & $-0,00781$ & 0,08314 & $-0,00132$ & $(-0,1983 ; 0,1225)$ & 1,2920 \\
\hline$\alpha 16$ & 0,02693 & 0,1228 & 0,004672 & $(-0,1007 ; 0,3425)$ & $-1,0230$ \\
\hline$\alpha 17$ & 0,01971 & 0,1203 & 0,003866 & $(-0,1299 ; 0,3085)$ & 0,08356 \\
\hline$\alpha 18$ & 0,03267 & 0,129 & 0,00504 & $(-0,0698 ; 0,3718)$ & $-0,84270$ \\
\hline$\alpha 19$ & 0,01984 & 0,08707 & 0,003787 & $(-0,07635 ; 0,2535)$ & 0,07771 \\
\hline$\alpha 20$ & 0,01334 & 0,07441 & 0,002918 & $(-0,0864 ; 0,202)$ & $-1,8910$ \\
\hline$\alpha 21$ & 0,02225 & 0,09887 & 0,00389 & $(-0,08013 ; 0,2825)$ & $-1,0030$ \\
\hline$\alpha 22$ & 0,00407 & 0,06001 & 0,001018 & $(-0,09547 ; 0,1322)$ & 0,6017 \\
\hline$\alpha 23$ & $-0,00164$ & 0,07561 & $-3,58 \mathrm{E}-01$ & $(-0,1556 ; 0,14)$ & 0,05101 \\
\hline$\alpha 24$ & $-0,0045$ & 0,07495 & $-9,55 E-01$ & $(-0,1663 ; 0,1255)$ & 1,546 \\
\hline$\alpha 25$ & 0,002793 & 0,06165 & $8,94 \mathrm{E}-02$ & $(-0,1 ; 0,1297)$ & $-0,2837$ \\
\hline$\alpha 26$ & 0,003357 & 0,06977 & $8,49 \mathrm{E}-01$ & $(-0,1203 ; 0,1487)$ & $-0,7929$ \\
\hline$\alpha 27$ & $-0,01056$ & 0,1041 & $-0,00136$ & $(-0,242 ; 0,1409)$ & $-0,8698$ \\
\hline$\alpha 28$ & $-0,00743$ & 0,06285 & $-0,00114$ & $(-0,1493 ; 0,08038)$ & 0,4377 \\
\hline$\alpha 29$ & $-0,00191$ & 0,07125 & $-7,66 \mathrm{E}-01$ & $(-0,1452 ; 0,1276)$ & 0,0789 \\
\hline$\alpha 30$ & $-0,01101$ & 0,07995 & $-0,0023$ & $(-0,2028 ; 0,1009)$ & $-0,3406$ \\
\hline$\alpha 31$ & $-0,00318$ & 0,0796 & $-2,65 E-01$ & $(-0,1671 ; 0,1369)$ & 0,5630 \\
\hline$\alpha 32$ & 0,0339 & 0,1402 & 0,005847 & $(-0,09695 ; 0,4069)$ & $-0,3104$ \\
\hline$\alpha 33$ & 0,02809 & 0,117 & 0,004695 & $(-0,07581 ; 0,3312)$ & $-1,091$ \\
\hline$\alpha 34$ & 0,01862 & 0,09553 & 0,003534 & $(-0,09712 ; 0,2639)$ & $-1,325$ \\
\hline$\alpha 35$ & 0,00277 & 0,06422 & $8,84 \mathrm{E}-01$ & $(-0,117 ; 0,1374)$ & $-2,003$ \\
\hline$\alpha 36$ & 0,01411 & 0,1049 & 0,003025 & $(-0,1392 ; 0,2651)$ & $-2,272$ \\
\hline$\alpha 37$ & $-5,02 \mathrm{E}-01$ & 0,07501 & $6,76 \mathrm{E}-01$ & $(-0,1464 ; 0,1391)$ & $-0,2967$ \\
\hline$\alpha 38$ & $-0,01491$ & 0,09545 & $-0,00222$ & $(-0,2408 ; 0,1033)$ & 0,5422 \\
\hline$\alpha 39$ & $-0,01929$ & 0,08703 & $-0,00335$ & $(-0,2449 ; 0,07053)$ & $-0,07684$ \\
\hline
\end{tabular}




\begin{tabular}{|c|c|c|c|c|c|}
\hline$\alpha 40$ & $-0,01816$ & 0,09521 & $-0,00373$ & $(-0,272 ; 0,107)$ & 1,286 \\
\hline$\alpha 41$ & $-0,02762$ & 0,1106 & $-0,00486$ & $(-0,3262 ; 0,0747)$ & 1,635 \\
\hline$\alpha 42$ & $-0,00759$ & 0,08713 & $-0,00201$ & $(-0,2033 ; 0,1409)$ & $-0,1639$ \\
\hline$\alpha 43$ & $-0,01983$ & 0,1065 & $-0,00338$ & $(-0,2874 ; 0,107)$ & 0,7331 \\
\hline$\alpha 44$ & $-0,01199$ & 0,1008 & $-0,0015$ & $(-0,2419 ; 0,1277)$ & 0,771 \\
\hline$\alpha 0$ & $-8,725$ & 0,3071 & $-8,724$ & $(-9,333 ;-8,127)$ & $-0,6657$ \\
\hline$\beta 1,1$ & $-0,3343$ & 0,4649 & $-0,3172$ & $(-1,302 ; 0,5269)$ & $-1,266$ \\
\hline$\beta 1,2$ & $-0,00788$ & 0,4139 & 0,001449 & $(-0,8456 ; 0,7814)$ & $-0,4557$ \\
\hline$\beta 1,3$ & $-0,2639$ & 0,4172 & $-0,2509$ & $(-1,121 ; 0,5267)$ & $-0,9797$ \\
\hline$\beta 1,4$ & 0,06977 & 0,5142 & 0,0837 & $(-0,9786 ; 1,034)$ & $-0,1081$ \\
\hline$\beta 2,1$ & 0,08534 & 0,5554 & 0,09679 & $(-1,042 ; 1,144)$ & $-0,000841$ \\
\hline$\beta 2,2$ & $-0,1085$ & 0,5221 & $-0,0884$ & $(-1,188 ; 0,8693)$ & 1,39 \\
\hline$\beta 2,3$ & 0,04076 & 0,4938 & 0,05087 & $(-0,9597 ; 0,9863)$ & 0,2472 \\
\hline$\beta 2,4$ & 0,0268 & 0,7214 & 0,05564 & $(-1,486 ; 1,351)$ & $-0,5114$ \\
\hline$\beta 3,1$ & $-0,5699$ & 0,4237 & $-0,5553$ & $(-1,452 ; 0,2161)$ & $-0,8444$ \\
\hline$\beta 3,2$ & $-0,165$ & 0,3652 & $-0,1587$ & $(-0,9075 ; 0,5321)$ & $-0,9411$ \\
\hline$\beta 3,3$ & $-0,2986$ & 0,3635 & $-0,2913$ & $(-1,035 ; 0,3975)$ & $-2,106$ \\
\hline$\beta 3,4$ & $-0,5825$ & 0,4898 & $-0,5652$ & $(-1,596 ; 0,3294)$ & $-0,1466$ \\
\hline$\beta 4,1$ & $-0,2009$ & 0,5588 & $-0,1799$ & $(-1,362 ; 0,8369)$ & 0,05786 \\
\hline$\beta 4,2$ & 0,2129 & 0,4904 & 0,2144 & $(-0,7646 ; 1,166)$ & 0,1237 \\
\hline$\beta 4,3$ & 0,03044 & 0,4805 & 0,0365 & $(-0,9486 ; 0,9546)$ & $-0,5167$ \\
\hline$\beta 4,4$ & 0,03897 & 0,6862 & 0,06806 & $(-1,38 ; 1,294)$ & $-0,02086$ \\
\hline$\beta 5,1$ & 0,07069 & 0,4269 & 0,08355 & $(-0,8054 ; 0,8775)$ & $-0,4285$ \\
\hline$\beta 5,2$ & 0,2323 & 0,3868 & 0,2367 & $(-0,5438 ; 0,9788)$ & 3,092 \\
\hline$\beta 5,3$ & 0,1879 & 0,3762 & 0,1928 & $(-0,5684 ; 0,9132)$ & 1,728 \\
\hline$\beta 5,4$ & 0,4808 & 0,4552 & 0,495 & $(-0,4557 ; 1,332)$ & $-0,6424$ \\
\hline$\beta 6,1$ & 0,5768 & 0,4209 & 0,5838 & $(-0,2761 ; 1,381)$ & 0,1299 \\
\hline$\beta 6,2$ & 0,5526 & 0,4003 & 0,5527 & $(-0,2348 ; 1,341)$ & $-1,048$ \\
\hline$\beta 6,3$ & 0,4717 & 0,3961 & 0,4713 & $(-0,3095 ; 1,252)$ & $-0,8757$ \\
\hline$\beta 6,4$ & 0,8316 & 0,4696 & 0,8483 & $(-0,1295 ; 1,706)$ & $-0,9653$ \\
\hline$\beta 7,1$ & $-0,3121$ & 0,4823 & $-0,2935$ & $(-1,308 ; 0,5775)$ & $-0,612$ \\
\hline$\beta 7,2$ & $-0,1091$ & 0,4319 & $-0,1012$ & $(-0,9839 ; 0,7138)$ & $-0,4226$ \\
\hline$\beta 7,3$ & $-0,1446$ & 0,417 & $-0,1376$ & $(-0,9885 ; 0,6562)$ & $-0,3585$ \\
\hline$\beta 7,4$ & $-0,2674$ & 0,5776 & $-0,2439$ & $(-1,468 ; 0,7989)$ & $-0,8066$ \\
\hline$\beta 8,1$ & $-0,1065$ & 0,4059 & $-0,09407$ & $(-0,9356 ; 0,6533)$ & 0,7584 \\
\hline$\beta 8,2$ & 0,1521 & 0,3656 & 0,1548 & $(-0,5777 ; 0,8566)$ & $-0,229$ \\
\hline$\beta 8,3$ & 0,1225 & 0,3594 & 0,1234 & $(-0,5925 ; 0,823)$ & 0,4308 \\
\hline$\beta 8,4$ & 0,04648 & 0,4563 & 0,06068 & $(-0,8873 ; 0,9073)$ & 0,3757 \\
\hline$\beta 9,1$ & 0,4654 & 0,3789 & 0,4719 & $(-0,2966 ; 1,188)$ & $-0,6541$ \\
\hline$\beta 9,2$ & 0,1458 & 0,381 & 0,1532 & $(-0,6297 ; 0,8729)$ & $-0,7973$ \\
\hline$\beta 9,3$ & 0,6313 & 0,3476 & 0,6287 & $(-0,04289 ; 1,32)$ & $-0,2479$ \\
\hline$\beta 9,4$ & 0,7237 & 0,4055 & 0,733 & $(-0,101 ; 1,491)$ & $-0,7222$ \\
\hline$\beta 10,1$ & $-0,4948$ & 0,4448 & $-0,4805$ & $(-1,414 ; 0,3395)$ & $-1,205$ \\
\hline$\beta 10,2$ & $-0,07594$ & 0,3858 & $-0,07033$ & $(-0,8479 ; 0,6655)$ & 0,08465 \\
\hline$\beta 10,3$ & $-0,2007$ & 0,3807 & $-0,1937$ & $(-0,9775 ; 0,5313)$ & $-1,269$ \\
\hline$\beta 10,4$ & $-0,6962$ & 0,5449 & $-0,6705$ & $(-1,835 ; 0,3001)$ & $-0,7944$ \\
\hline
\end{tabular}




\begin{tabular}{|c|c|c|c|c|c|}
\hline$\beta 11,1$ & $-0,8909$ & 0,4571 & $-0,8807$ & $(-1,817 ;-0,01816)$ & $-0,4684$ \\
\hline$\beta 11,2$ & $-0,8337$ & 0,4217 & $-0,8297$ & $(-1,678 ;-0,01956)$ & $-1,876$ \\
\hline$\beta 11,3$ & $-0,7997$ & 0,436 & $-0,7896$ & $(-1,686 ; 0,03314)$ & $-0,5965$ \\
\hline$\beta 11,4$ & $-1,371$ & 0,5732 & $-1,365$ & $(-2,508 ;-0,2583)$ & $-0,7363$ \\
\hline$\beta 12,1$ & $-0,01553$ & 0,4398 & $-0,00686$ & $(-0,9074 ; 0,827)$ & $-0,7105$ \\
\hline$\beta 12,2$ & $-0,1356$ & 0,4187 & $-0,1244$ & $(-0,9929 ; 0,6576)$ & 0,3505 \\
\hline$\beta 12,3$ & 0,06179 & 0,3969 & 0,06278 & $(-0,7245 ; 0,8407)$ & $-0,03159$ \\
\hline$\beta 12,4$ & $-0,07092$ & 0,5328 & $-0,05809$ & $(-1,156 ; 0,9338)$ & $-1,057$ \\
\hline$\beta 13,1$ & $-0,4561$ & 0,4628 & $-0,4407$ & $(-1,407 ; 0,4129)$ & $-1,919$ \\
\hline$\beta 13,2$ & $-0,8838$ & 0,4776 & $-0,8557$ & $(-1,898 ;-0,02314)$ & $-1,481$ \\
\hline$\beta 13,3$ & $-0,6202$ & 0,4328 & $-0,6055$ & $(-1,522 ; 0,1867)$ & $-0,1980$ \\
\hline$\beta 13,4$ & $-1,191$ & 0,6324 & $-1,159$ & $(-2,526 ;-0,04421)$ & $-1,344$ \\
\hline$\beta 14,1$ & $-0,2191$ & 0,3925 & $-0,2086$ & $(-1,021 ; 0,5189)$ & $-1,93$ \\
\hline$\beta 14,2$ & $-0,1929$ & 0,3682 & $-0,1836$ & $(-0,9384 ; 0,5061)$ & $-1,037$ \\
\hline$\beta 14,3$ & $-0,2885$ & 0,3637 & $-0,28$ & $(-1,033 ; 0,4048)$ & $-1,992$ \\
\hline$\beta 14,4$ & $-0,3218$ & 0,4623 & $-0,3061$ & $(-1,275 ; 0,5433)$ & $-2,055$ \\
\hline$\beta 15,1$ & $-0,6048$ & 0,4705 & $-0,5849$ & $(-1,587 ; 0,2655)$ & 2,993 \\
\hline$\beta 15,2$ & $-0,1621$ & 0,4102 & $-0,1538$ & $(-0,9998 ; 0,6167)$ & $-0,8477$ \\
\hline$\beta 15,3$ & $-0,04754$ & 0,3899 & $-0,04392$ & $(-0,824 ; 0,711)$ & $-1,158$ \\
\hline$\beta 15,4$ & $-0,5948$ & 0,5519 & $-0,577$ & $(-1,722 ; 0,439)$ & $-1,762$ \\
\hline$\beta 16,1$ & 0,628 & 0,6289 & 0,6231 & $(-0,5992 ; 1,868)$ & 1,372 \\
\hline$\beta 16,2$ & 0,5751 & 0,5761 & 0,5748 & $(-0,5602 ; 1,713)$ & 2,146 \\
\hline$\beta 16,3$ & 0,4553 & 0,556 & 0,4537 & $(-0,6394 ; 1,549)$ & 2,246 \\
\hline$\beta 16,4$ & 1,009 & 0,8169 & 1,034 & $(-0,6698 ; 2,533)$ & 2,571 \\
\hline$\beta 17,1$ & $-0,256$ & 0,7057 & $-0,2342$ & $(-1,715 ; 1,073)$ & $-0,9257$ \\
\hline$\beta 17,2$ & $-0,237$ & 0,6503 & $-0,2164$ & $(-1,585 ; 0,9858)$ & $-1,419$ \\
\hline$\beta 17,3$ & $-0,2373$ & 0,6267 & $-0,2163$ & $(-1,544 ; 0,9397)$ & $-0,9974$ \\
\hline$\beta 17,4$ & $-0,4352$ & 1,005 & $-0,3983$ & $(-2,519 ; 1,441)$ & $-0,6476$ \\
\hline$\beta 18,1$ & 1,301 & 0,5777 & 1,299 & $(0,1649 ; 2,437)$ & 0,4646 \\
\hline$\beta 18,2$ & 1,027 & 0,5399 & 1,025 & $(-0,038 ; 2,089)$ & $-1,995$ \\
\hline$\beta 18,3$ & 1,432 & 0,5313 & 1,422 & $(0,4288 ; 2,504)$ & $-1,533$ \\
\hline$\beta 18,4$ & 1,955 & 0,6312 & 1,982 & $(0,6391 ; 3,11)$ & 0,7082 \\
\hline$\beta 19,1$ & $-0,2801$ & 0,7048 & $-0,2602$ & $(-1,726 ; 1,051)$ & $-0,2917$ \\
\hline$\beta 19,2$ & $-0,2613$ & 0,6449 & $-0,2403$ & $(-1,598 ; 0,9445)$ & 0,8378 \\
\hline$\beta 19,3$ & $-0,265$ & 0,6219 & $-0,242$ & $(-1,551 ; 0,9029)$ & $-0,2445$ \\
\hline$\beta 19,4$ & $-0,4819$ & 1,001 & $-0,4448$ & $(-2,556 ; 1,376)$ & 0,0652 \\
\hline$\beta 20,1$ & $-0,3293$ & 0,4151 & $-0,3134$ & $(-1,199 ; 0,4362)$ & $-0,602$ \\
\hline$\beta 20,2$ & 0,06506 & 0,3593 & 0,06845 & $(-0,6547 ; 0,7568)$ & $-1,829$ \\
\hline$\beta 20,3$ & $-0,1629$ & 0,3654 & $-0,1534$ & $(-0,9059 ; 0,5351)$ & $-0,8331$ \\
\hline$\beta 20,4$ & 0,04974 & 0,437 & 0,0643 & $(-0,8488 ; 0,8637)$ & $-1,288$ \\
\hline$\beta 21,1$ & 0,92 & 0,3219 & 0,9254 & $(0,2742 ; 1,54)$ & $-1,269$ \\
\hline$\beta 21,2$ & 0,2613 & 0,3565 & 0,268 & $(-0,4595 ; 0,9388)$ & $-0,9875$ \\
\hline$\beta 21,3$ & 0,6527 & 0,3296 & 0,6536 & $(0,003958 ; 1,299)$ & $-0,7129$ \\
\hline$\beta 21,4$ & 1,025 & 0,3489 & 1,034 & $(0,314 ; 1,681)$ & $-0,2628$ \\
\hline$\beta 22,1$ & $-0,6852$ & 0,4282 & $-0,6675$ & $(-1,577 ; 0,1083)$ & $-2,130$ \\
\hline$\beta 22,2$ & $-0,1841$ & 0,3617 & $-0,1788$ & $(-0,908 ; 0,5129)$ & $-0,9934$ \\
\hline
\end{tabular}




\begin{tabular}{|c|c|c|c|c|c|}
\hline$\beta 22,3$ & $-0,1595$ & 0,3493 & $-0,1554$ & $(-0,8585 ; 0,5151)$ & $-1,022$ \\
\hline$\beta 22,4$ & $-0,809$ & 0,5041 & $-0,7876$ & $(-1,856 ; 0,1263)$ & $-1,797$ \\
\hline$\beta 23,1$ & 0,6698 & 0,2963 & 0,6721 & $(0,08485 ; 1,246)$ & $-2,051$ \\
\hline$\beta 23,2$ & $-0,09665$ & 0,3365 & $-0,08775$ & $(-0,7833 ; 0,5397)$ & $-1,178$ \\
\hline$\beta 23,3$ & 0,2062 & 0,3122 & 0,2087 & $(-0,4199 ; 0,8077)$ & $-0,5465$ \\
\hline$\beta 23,4$ & 0,6693 & 0,322 & 0,6748 & $(0,02117 ; 1,289)$ & 1,499 \\
\hline$\beta 24,1$ & $-0,09764$ & 0,3843 & $-0,08753$ & $(-0,8774 ; 0,6281)$ & 0,1342 \\
\hline$\beta 24,2$ & $-0,1801$ & 0,3692 & $-0,171$ & $(-0,9316 ; 0,5222)$ & $-0,8865$ \\
\hline$\beta 24,3$ & 0,2016 & 0,3379 & 0,2031 & $(-0,468 ; 0,8594)$ & 0,5028 \\
\hline$\beta 24,4$ & $-0,1618$ & 0,4469 & $-0,1474$ & $(-1,077 ; 0,6752)$ & $-2,115$ \\
\hline$\beta 25,1$ & $-0,00222$ & 0,3601 & 0,006425 & $(-0,7327 ; 0,6796)$ & $-0,1902$ \\
\hline$\beta 25,2$ & 0,5598 & 0,3047 & 0,5614 & $(-0,04529 ; 1,155)$ & 0,4965 \\
\hline$\beta 25,3$ & 0,5662 & 0,3027 & 0,5653 & $(-0,02515 ; 1,159)$ & $-0,1924$ \\
\hline$\beta 25,4$ & 0,3906 & 0,3614 & 0,3998 & $(-0,347 ; 1,074)$ & 0,7536 \\
\hline$\beta 26,1$ & $-0,1545$ & 0,4065 & $-0,1438$ & $(-0,9871 ; 0,6123)$ & $-1,066$ \\
\hline$\beta 26,2$ & $-0,00449$ & 0,3722 & $8,80 \mathrm{E}-01$ & $(-0,7537 ; 0,7093)$ & $-2,112$ \\
\hline$\beta 26,3$ & $-0,02592$ & 0,3619 & $-0,0211$ & $(-0,7509 ; 0,6747)$ & $-2,047$ \\
\hline$\beta 26,4$ & $-0,06852$ & 0,4636 & $-0,05479$ & $(-1,017 ; 0,8033)$ & $-2,425$ \\
\hline$\beta 27,1$ & $-1,022$ & 0,5821 & $-0,9883$ & $(-2,272 ; 0,01614)$ & $-0,5843$ \\
\hline$\beta 27,2$ & $-0,1456$ & 0,4531 & $-0,1395$ & $(-1,049 ; 0,7287)$ & $-1,862$ \\
\hline$\beta 27,3$ & $-0,7721$ & 0,4923 & $-0,745$ & $(-1,816 ; 0,1203)$ & 0,4426 \\
\hline$\beta 27,4$ & $-1,226$ & 0,7176 & $-1,18$ & $(-2,746 ; 0,06251)$ & $-1,266$ \\
\hline$\beta 28,1$ & $-0,4408$ & 0,3723 & $-0,4297$ & $(-1,205 ; 0,2611)$ & $-0,9463$ \\
\hline$\beta 28,2$ & $-0,3963$ & 0,346 & $-0,3885$ & $(-1,097 ; 0,2656)$ & 0,03028 \\
\hline$\beta 28,3$ & $-0,342$ & 0,3317 & $-0,3378$ & $(-1,006 ; 0,2965)$ & $-2,07$ \\
\hline$\beta 28,4$ & $-0,6117$ & 0,4384 & $-0,6002$ & $(-1,506 ; 0,2138)$ & $-0,1479$ \\
\hline$\beta 29,1$ & $-0,2014$ & 0,3329 & $-0,1929$ & $(-0,8767 ; 0,4283)$ & $-2,033$ \\
\hline$\beta 29,2$ & 0,3847 & 0,2892 & 0,3843 & $(-0,1813 ; 0,9562)$ & $-0,53$ \\
\hline$\beta 29,3$ & 0,2945 & 0,2908 & 0,2946 & $(-0,2765 ; 0,8676)$ & $-0,3826$ \\
\hline$\beta 29,4$ & 0,1878 & 0,3387 & 0,1926 & $(-0,4928 ; 0,8385)$ & $-0,06473$ \\
\hline$\beta 30,1$ & 0,8663 & 0,6259 & 0,8671 & $(-0,3808 ; 2,091)$ & 2,23 \\
\hline$\beta 30,2$ & 0,8652 & 0,5632 & 0,8629 & $(-0,2368 ; 1,978)$ & 1,377 \\
\hline$\beta 30,3$ & 0,8042 & 0,5424 & 0,8014 & $(-0,2643 ; 1,865)$ & 1,001 \\
\hline$\beta 30,4$ & 2,013 & 0,7058 & 2,033 & $(0,5696 ; 3,328)$ & 1,863 \\
\hline$\beta 31,1$ & 0,4058 & 0,4278 & 0,405 & $(-0,4299 ; 1,245)$ & 0,9608 \\
\hline$\beta 31,2$ & $-0,08751$ & 0,4251 & $-0,08069$ & $(-0,9399 ; 0,7308)$ & 0,811 \\
\hline$\beta 31,3$ & $-0,01569$ & 0,414 & $-0,00951$ & $(-0,8508 ; 0,7841)$ & 1,084 \\
\hline$\beta 31,4$ & 0,005348 & 0,5425 & 0,01725 & $(-1,09 ; 1,042)$ & 1,046 \\
\hline$\beta 32,1$ & 1,183 & 0,593 & 1,186 & $(0,01063 ; 2,347)$ & 0,3787 \\
\hline$\beta 32,2$ & 1,149 & 0,5368 & 1,147 & $(0,09612 ; 2,205)$ & 1,042 \\
\hline$\beta 32,3$ & 0,984 & 0,5204 & 0,985 & $(-0,05506 ; 1,994)$ & 0,3461 \\
\hline$\beta 32,4$ & 2,452 & 0,5938 & 2,473 & $(1,224 ; 3,554)$ & 0,2984 \\
\hline$\beta 33,1$ & 0,6413 & 0,5579 & 0,6565 & $(-0,5033 ; 1,695)$ & 0,4808 \\
\hline$\beta 33,2$ & 1,57 & 0,4904 & 1,559 & $(0,6338 ; 2,555)$ & 2,087 \\
\hline$\beta 33,3$ & 1,169 & 0,4788 & 1,164 & $(0,2317 ; 2,116)$ & $-0,1108$ \\
\hline$\beta 33,4$ & 2,326 & 0,5115 & 2,332 & $(91,3 ; 3,306)$ & 0,4092 \\
\hline
\end{tabular}




\begin{tabular}{|c|c|c|c|c|c|}
\hline$\beta 34,1$ & 1,069 & 0,4035 & 1,069 & $(0,2769 ; 1,858)$ & 0,2893 \\
\hline$\beta 34,2$ & 0,2006 & 0,4262 & 0,2083 & $(-0,6645 ; 1,018)$ & 0,409 \\
\hline$\beta 34,3$ & 0,3316 & 0,4137 & 0,3326 & $(-0,4836 ; 1,139)$ & $-0,3525$ \\
\hline$\beta 34,4$ & 0,8486 & 0,479 & 0,8628 & $(-0,1327 ; 1,751)$ & $-0,3159$ \\
\hline$\beta 35,1$ & $-0,07975$ & 0,299 & $-0,07514$ & $(-0,678 ; 0,495)$ & $-0,03391$ \\
\hline$\beta 35,2$ & 0,09194 & 0,279 & 0,09448 & $(-0,4628 ; 0,6358)$ & $-0,4264$ \\
\hline$\beta 35,3$ & $-0,2022$ & 0,2944 & $-0,1972$ & $(-0,7952 ; 0,3621)$ & $-0,5216$ \\
\hline$\beta 35,4$ & $-0,2405$ & 0,3462 & $-0,2319$ & $(-0,9474 ; 0,4162)$ & $-1,300$ \\
\hline$\beta 36,1$ & 0,2191 & 0,4731 & 0,2248 & $(-0,7199 ; 1,134)$ & 1,41 \\
\hline$\beta 36,2$ & 0,3243 & 0,4446 & 0,3219 & $(-0,5409 ; 1,21)$ & 0,9802 \\
\hline$\beta 36,3$ & $-0,215$ & 0,4608 & $-0,2003$ & $(-1,17 ; 0,6551)$ & $-0,2853$ \\
\hline$\beta 36,4$ & 0,3276 & 0,5707 & 0,3364 & $(-0,8145 ; 1,427)$ & 0,4683 \\
\hline$\beta 37,1$ & $-0,7211$ & 0,3724 & $-0,7118$ & $(-1,48 ;-0,01657)$ & $-0,7506$ \\
\hline$\beta 37,2$ & $-0,4475$ & 0,3441 & $-0,44$ & $(-1,142 ; 0,2099)$ & $-0,3183$ \\
\hline$\beta 37,3$ & $-0,3246$ & 0,33 & $-0,3214$ & $(-0,9793 ; 0,3172$ & $-1,732$ \\
\hline$\beta 37,4$ & $-0,8166$ & 0,432 & $-0,809$ & $(-1,687 ; 0,006034)$ & $-1,325$ \\
\hline$\beta 38,1$ & $-0,399$ & 0,4683 & $-0,3909$ & $(-1,343 ; 0,5081)$ & $-0,2198$ \\
\hline$\beta 38,2$ & $-0,4113$ & 0,4468 & $-0,4004$ & $(-1,324 ; 0,4328)$ & 0,4512 \\
\hline$\beta 38,3$ & $-0,5716$ & 0,4521 & $-0,5539$ & $(-1,512 ; 0,2684)$ & 0,705 \\
\hline$\beta 38,4$ & $-1,132$ & 0,6519 & $-1,105$ & $(-2,49 ; 0,07352)$ & $-0,1011$ \\
\hline$\beta 39,1$ & $-0,3654$ & 0,4157 & $-0,3606$ & $(-1,196 ; 0,4384)$ & 0,4979 \\
\hline$\beta 39,2$ & $-0,548$ & 0,4122 & $-0,5374$ & $(-1,389 ; 0,2314)$ & 1,472 \\
\hline$\beta 39,3$ & $-0,6155$ & 0,4159 & $-0,6017$ & $(-1,475 ; 0,1645)$ & 1,463 \\
\hline$\beta 39,4$ & $-0,7917$ & 0,5367 & $-0,7829$ & $(-1,875 ; 0,2302)$ & 0,2501 \\
\hline$\beta 40,1$ & $-0,2892$ & 0,4491 & $-0,2682$ & $(-1,23 ; 0,5368)$ & $-0,9266$ \\
\hline$\beta 40,2$ & 0,3766 & 0,369 & 0,3784 & $(-0,3495 ; 1,098)$ & $-1,126$ \\
\hline$\beta 40,3$ & $-0,1579$ & 0,3948 & $-0,1428$ & $(-0,9771 ; 0,5813)$ & $-1,297$ \\
\hline$\beta 40,4$ & 0,3405 & 0,448 & 0,3523 & $(-0,5711 ; 1,185)$ & $-0,3963$ \\
\hline$\beta 41,1$ & $-0,709$ & 0,4624 & $-0,6964$ & $(-1,656 ; 0,1619)$ & $-0,349$ \\
\hline$\beta 41,2$ & $-1,21$ & 0,4977 & $-1,181$ & $(-2,27 ;-0,3155)$ & $-0,7098$ \\
\hline$\beta 41,3$ & $-0,8563$ & 0,4364 & $-0,8421$ & $(-1,759 ;-0,03921)$ & $-0,05249$ \\
\hline$\beta 41,1$ & $-1,678$ & 0,6499 & $-1,653$ & $(-3,043 ;-0,4809)$ & $-0,80$ \\
\hline$\beta 42,1$ & 0,8604 & 0,3793 & 0,8657 & $(0,1115 ; 1,596)$ & $-1,448$ \\
\hline$\beta 42,2$ & $-0,02332$ & 0,4225 & $-0,01141$ & $(-0,8838 ; 0,7735)$ & $-1,094$ \\
\hline$\beta 42,3$ & 0,3036 & 0,3853 & 0,3066 & $(-0,4578 ; 1,061)$ & $-0,9159$ \\
\hline$\beta 42,4$ & 0,239 & 0,4965 & 0,2567 & $(-0,7972 ; 1,152)$ & $-1,221$ \\
\hline$\beta 43,1$ & $-0,7116$ & 0,5258 & $-0,6891$ & $(-1,812 ; 0,256)$ & 0,2142 \\
\hline$\beta 43,2$ & $-0,6584$ & 0,4866 & $-0,634$ & $(-1,684 ; 0,2422)$ & $-0,607$ \\
\hline$\beta 43,3$ & $-0,4385$ & 0,4443 & $-0,4288$ & $(-1,341 ; 0,4114)$ & $-0,2331$ \\
\hline$\beta 43,4$ & $-1,263$ & 0,703 & $-1,223$ & $(-2,748 ; 0,001888)$ & $-0,2219$ \\
\hline$\beta 44,1$ & 0,01548 & 0,5342 & 0,02057 & $(-1,055 ; 1,05)$ & $-0,2919$ \\
\hline$\beta 44,2$ & $-0,5637$ & 0,5465 & $-0,5347$ & $(-1,724 ; 0,4343)$ & 0,407 \\
\hline$\beta 44,3$ & $-0,3351$ & 0,5067 & $-0,318$ & $(-1,385 ; 0,6166)$ & 0,4028 \\
\hline$\beta 44,4$ & $-0,7337$ & 0,7593 & $-0,6979$ & $(-2,323 ; 0,6565)$ & 1,503 \\
\hline$\beta 12$ & 0,5311 & 0,3725 & 0,5298 & $(-0,2016 ; 1,27)$ & 1,192 \\
\hline$\beta 13$ & 0,6987 & 0,3606 & 0,6982 & $(-0,00702 ; 1,409)$ & 0,8951 \\
\hline
\end{tabular}




\begin{tabular}{|c|c|c|c|c|c|}
\hline$\beta 14$ & 1,13 & 0,3955 & 1,127 & $(0,3606 ; 1,916)$ & 0,8063 \\
\hline$\beta 15$ & 2,228 & 0,4872 & 2,228 & $(1,266 ; 3,188)$ & 0,4354 \\
\hline$\sigma \beta 1,1$ & 5,714 & 2,313 & 5,312 & $(2,426 ; 11,28)$ & 0,5051 \\
\hline$\sigma \beta 1,2$ & 1,035 & 1,823 & 0,9962 & $(-2,569 ; 4,789)$ & $-1,020$ \\
\hline$\sigma \beta 1,3$ & $-1,44$ & 1,945 & $-1,334$ & $(-5,63 ; 2,169)$ & 0,9401 \\
\hline$\sigma \beta 1,4$ & $-2,683$ & 1,689 & $-2,465$ & $(-6,59 ; 0,007339)$ & $-1,425$ \\
\hline$\sigma \beta 2,1$ & 1,035 & 1,823 & 0,9962 & $(-2,569 ; 4,789)$ & $-1,020$ \\
\hline$\sigma \beta 2,2$ & 7,586 & 2,869 & 7,136 & $(3,335 ; 14,4)$ & $-2,134$ \\
\hline$\sigma \beta 2,3$ & $-1,682$ & 2,152 & $-1,553$ & $(-6,367 ; 2,272)$ & 0,8447 \\
\hline$\sigma \beta 2,4$ & $-3,331$ & 1,861 & $-3,115$ & $(-7,581 ;-0,2698)$ & 1,13 \\
\hline$\sigma \beta 3,1$ & $-1,44$ & 1,945 & $-1,334$ & $(-5,63 ; 2,169)$ & 0,9401 \\
\hline$\sigma \beta 3,2$ & $-1,682$ & 2,152 & $-1,553$ & $(-6,367 ; 2,272)$ & 0,8447 \\
\hline$\sigma \beta 3,3$ & 8,218 & 3,143 & 7,725 & $(3,541 ; 15,65)$ & $-0,2068$ \\
\hline$\sigma \beta 3,4$ & $-2,268$ & 1,897 & $-2,074$ & $(-6,554 ; 0,9497)$ & $-0,3509$ \\
\hline$\sigma \beta 4,1$ & $-2,683$ & 1,689 & $-2,465$ & $(-6,59 ; 0,007339)$ & $-1,425$ \\
\hline$\sigma \beta 4,2$ & $-3,331$ & 1,861 & $-3,115$ & $(-7,581 ;-0,2698)$ & 1,13 \\
\hline$\sigma \beta 4,3$ & $-2,268$ & 1,897 & $-2,074$ & $(-6,554 ; 0,9497)$ & $-0,3509$ \\
\hline$\sigma \beta 4,4$ & 5,129 & 2,026 & 4,8 & $(2,149 ; 9,971)$ & 0,4994 \\
\hline$\tau \alpha$ & 1028 & 1421 & 481,1 & $(3,726 ; 5030)$ & 0,9366 \\
\hline$\theta 1,1$ & 39,02 & 16,83 & 36,36 & $(14,12 ; 78,86)$ & $-0,1034$ \\
\hline$\theta 1,2$ & 52,89 & 20,05 & 49,84 & $(22,74 ; 100,4)$ & 0,8657 \\
\hline$\theta 1,3$ & 41,08 & 15,78 & 38,85 & $(16,89 ; 78,18)$ & $-0,1783$ \\
\hline$\theta 1,4$ & 58,39 & 25,12 & 54,4 & $(21,62 ; 118,2)$ & 0,8430 \\
\hline$\theta 2,1$ & 41 & 23,5 & 35,86 & $(11,37 ; 100,7)$ & $-0,0953$ \\
\hline$\theta 2,2$ & 33,23 & 17,66 & 29,78 & $(9,622 ; 77,13)$ & 0,856 \\
\hline$\theta 2,3$ & 38,07 & 19,36 & 34,21 & $(12,2 ; 86,06)$ & 0,5009 \\
\hline$\theta 2,4$ & 41,99 & 29,76 & 34,49 & $(7,488 ; 120,1)$ & $-0,7588$ \\
\hline$\theta 3,1$ & 19,79 & 7,773 & 18,69 & $(7,907 ; 38,05)$ & $-0,006711$ \\
\hline$\theta 3,2$ & 29,06 & 9,813 & 27,74 & $(13,7 ; 51,86)$ & $-0,2284$ \\
\hline$\theta 3,3$ & 25,41 & 8,51 & 24,3 & $(11,96 ; 44,99)$ & $-1,710$ \\
\hline$\theta 3,4$ & 19,85 & 8,576 & 18,47 & $(7,202 ; 40,37)$ & 0,447 \\
\hline$\theta 4,1$ & 30,85 & 17,4 & 27,23 & $(8,252 ; 74,22)$ & $-0,02755$ \\
\hline$\theta 4,2$ & 45,15 & 22,72 & 40,58 & $(15,04 ; 102)$ & 0,517 \\
\hline$\theta 4,3$ & 37,46 & 18,33 & 33,95 & $(12,5 ; 82,98)$ & $-0,238$ \\
\hline$\theta 4,4$ & 41,52 & 27,49 & 34,89 & $(8,386 ; 111,8)$ & 0,09507 \\
\hline$\theta 5,1$ & 37,97 & 15,39 & 35,58 & $(14,89 ; 74,71)$ & $-0,261$ \\
\hline$\theta 5,2$ & 43,98 & 16,22 & 41,58 & $(19,39 ; 82,24)$ & 3,667 \\
\hline$\theta 5,3$ & 41,9 & 14,97 & 39,72 & $(19,04 ; 77,06)$ & 2,386 \\
\hline$\theta 5,4$ & 57,19 & 23,03 & 53,69 & $(22,68 ; 111,8)$ & $-0,06627$ \\
\hline$\theta 6,1$ & 54,13 & 21,56 & 50,73 & $(22,21 ; 105,6)$ & 1,004 \\
\hline$\theta 6,2$ & 52,42 & 19,92 & 49,27 & $(23,15 ; 99,96)$ & $-0,3469$ \\
\hline$\theta 6,3$ & 48,17 & 17,75 & 45,45 & $(21,56 ; 90,34)$ & $-0,3852$ \\
\hline$\theta 6,4$ & 70,08 & 28,21 & 65,9 & $(27,84 ; 136,5)$ & 0,07671 \\
\hline$\theta 7,1$ & 22,43 & 10,36 & 20,61 & $(7,644 ; 47,87)$ & 0,2753 \\
\hline$\theta 7,2$ & 26,96 & 11,35 & 25,03 & $(10,51 ; 54,48)$ & 0,1945 \\
\hline$\theta 7,3$ & 25,85 & 10,4 & 24,26 & $(10,43 ; 50,46)$ & 0,5438 \\
\hline
\end{tabular}




\begin{tabular}{|c|c|c|c|c|c|}
\hline$\theta 7,4$ & 24,21 & 12,76 & 21,73 & $(6,818 ; 55,57)$ & $-0,2638$ \\
\hline$\theta 8,1$ & 26,63 & 9,999 & 25,23 & $(11,36 ; 50,06)$ & 1,658 \\
\hline$\theta 8,2$ & 33,98 & 11,38 & 32,47 & $(16,28 ; 60,54)$ & 0,7286 \\
\hline$\theta 8,3$ & 32,89 & 10,72 & 31,46 & $(16,22 ; 57,83)$ & 1,359 \\
\hline$\theta 8,4$ & 31,22 & 12,21 & 29,42 & $(12,63 ; 60,03)$ & 1,148 \\
\hline$\theta 9,1$ & 46,53 & 16,03 & 44,4 & $(21,67 ; 83,47)$ & $-0,1183$ \\
\hline$\theta 9,2$ & 33,9 & 11,9 & 32,41 & $(15,22 ; 61,57)$ & $-0,1445$ \\
\hline$\theta 9,3$ & 54,25 & 16,69 & 52,11 & $(28,04 ; 93,23)$ & 0,6345 \\
\hline$\theta 9,4$ & 60,12 & 20,26 & 57,51 & $(28,05 ; 107)$ & 0,04203 \\
\hline$\theta 10,1$ & 21,6 & 9,117 & 20,16 & $(8,133 ; 43,31)$ & $-0,8831$ \\
\hline$\theta 10,2$ & 32,08 & 11,64 & 30,38 & $(14,4 ; 59,4)$ & 0,5035 \\
\hline$\theta 10,3$ & 28,26 & 10,09 & 26,84 & $(12,76 ; 51,91)$ & $-0,4734$ \\
\hline$\theta 10,4$ & 18,22 & 8,924 & 16,65 & $(5,588 ; 39,78)$ & $-0,1660$ \\
\hline$\theta 11,1$ & 63,07 & 18,95 & 61,06 & $(32,09 ; 106)$ & 0,3088 \\
\hline$\theta 11,2$ & 66,66 & 19,63 & 64,59 & $(34,68 ; 111,2)$ & $-1,592$ \\
\hline$\theta 11,3$ & 68,63 & 19,06 & 66,64 & $(37,24 ; 111,4)$ & 0,0788 \\
\hline$\theta 11,4$ & 39,84 & 14,5 & 37,83 & $(17,32 ; 73,48)$ & $-0,4205$ \\
\hline$\theta 12,1$ & 52,6 & 20,9 & 49,43 & $(21,26 ; 102,3)$ & 0,5592 \\
\hline$\theta 12,2$ & 46,46 & 17,98 & 43,76 & $(19,29 ; 88,77)$ & 1,222 \\
\hline$\theta 12,3$ & 55,97 & 20,02 & 53,03 & $(25,46 ; 103,2)$ & 0,8364 \\
\hline$\theta 12,4$ & 50,77 & 22,54 & 47,01 & $(18,06 ; 104,5)$ & $-0,6072$ \\
\hline$\theta 13,1$ & 22,82 & 10,07 & 21,12 & $(8,335 ; 47,26)$ & $-1,150$ \\
\hline$\theta 13,2$ & 15,04 & 6,892 & 13,94 & $(4,966 ; 31,5)$ & $-0,000867$ \\
\hline$\theta 13,3$ & 19,19 & 7,998 & 17,95 & $(7,32 ; 38,32)$ & 0,5422 \\
\hline$\theta 13,4$ & 11,75 & 6,853 & 10,34 & $(2,795 ; 28,93)$ & $-0,4393$ \\
\hline$\theta 14,1$ & 27,81 & 10,08 & 26,42 & $(12,29 ; 51,34)$ & $-0,8252$ \\
\hline$\theta 14,2$ & 28,35 & 9,717 & 27,08 & $(13,1 ; 50,79)$ & $-0,1002$ \\
\hline$\theta 14,3$ & 25,71 & 8,624 & 24,61 & $(12,04 ; 45,46)$ & $-1,329$ \\
\hline$\theta 14,4$ & 25,51 & 10,33 & 23,99 & $(9,944 ; 49,87)$ & $-1,604$ \\
\hline$\theta 15,1$ & 29,83 & 12,68 & 27,96 & $(10,79 ; 59,85)$ & $-2,694$ \\
\hline$\theta 15,2$ & 45,26 & 16,45 & 42,97 & $(20,07 ; 83,68)$ & 0,4018 \\
\hline$\theta 15,3$ & 50,39 & 17,29 & 48,04 & $(23,7 ; 91,17)$ & $-0,2040$ \\
\hline$\theta 15,4$ & 30,61 & 14,15 & 28,29 & $(10,2 ; 64,36)$ & $-0,8716$ \\
\hline$\theta 16,1$ & 118,8 & 83,51 & 97,1 & $(26,78 ; 335,1)$ & 1,027 \\
\hline$\theta 16,2$ & 109,9 & 72,2 & 92,01 & $(27,83 ; 296,8)$ & 2,152 \\
\hline$\theta 16,3$ & 95,83 & 58,78 & 81,9 & $(25,56 ; 247,3)$ & 1,415 \\
\hline$\theta 16,4$ & 191,4 & 158,2 & 147,2 & $(26,27 ; 612,7)$ & 1,994 \\
\hline$\theta 17,1$ & 51,53 & 40,99 & 40,64 & $(8,57 ; 157,9)$ & $-1,455$ \\
\hline$\theta 17,2$ & 50,82 & 37,89 & 41,18 & $(10 ; 148,1)$ & $-0,9522$ \\
\hline$\theta 17,3$ & 50,06 & 35,35 & 41,39 & $(10,06 ; 141,1)$ & $-0,9969$ \\
\hline$\theta 17,4$ & 53,68 & 60,96 & 34,53 & $(3,935 ; 219,4)$ & $-1,136$ \\
\hline$\theta 18,1$ & 222,5 & 130 & 192,8 & $(61,52 ; 555,2)$ & 0,3853 \\
\hline$\theta 18,2$ & 167,8 & 95,26 & 146,4 & $(48,31 ; 413,5)$ & $-2,366$ \\
\hline$\theta 18,3$ & 247,5 & 134 & 217,9 & $(80,45 ; 586,6)$ & $-1,777$ \\
\hline$\theta 18,4$ & 427,6 & 238,3 & 378,7 & $(109,7 ; 1020)$ & $-0,2263$ \\
\hline$\theta 19,1$ & 16,39 & 13,09 & 12,92 & $(2,577 ; 50,77)$ & $-0,6968$ \\
\hline
\end{tabular}




\begin{tabular}{|c|c|c|c|c|c|}
\hline$\theta 19,2$ & 16,07 & 11,76 & 13,08 & $(3,05 ; 46,46)$ & 0,06698 \\
\hline$\theta 19,3$ & 15,8 & 11,28 & 12,96 & $(3,193 ; 45,11)$ & $-0,6172$ \\
\hline$\theta 19,4$ & 16,52 & 18,59 & 10,73 & $(1,209 ; 65,99)$ & 0,03451 \\
\hline$\theta 20,1$ & 21,67 & 8,285 & 20,54 & $(8,884 ; 40,98)$ & $-0,5062$ \\
\hline$\theta 20,2$ & 31,52 & 10,4 & 30,13 & $(15,22 ; 55,8)$ & $-1,22$ \\
\hline$\theta 20,3$ & 25,17 & 8,446 & 24,11 & $(11,84 ; 44,74)$ & 0,04629 \\
\hline$\theta 20,4$ & 31,53 & 11,72 & 29,94 & $(13,37 ; 58,84)$ & $-1,279$ \\
\hline$\theta 21,1$ & 73,5 & 19,76 & 71,36 & $(40,96 ; 117,7)$ & $-0,7578$ \\
\hline$\theta 21,2$ & 38,62 & 12,33 & 37,15 & $(18,7 ; 66,52)$ & $-0,6813$ \\
\hline$\theta 21,3$ & 56,37 & 15,59 & 54,65 & $(30,87 ; 91,65)$ & 0,05387 \\
\hline$\theta 21,4$ & 81,57 & 21,71 & 79,41 & $(45,22 ; 129,7)$ & 0,3758 \\
\hline$\theta 22,1$ & 15,09 & 5,892 & 14,27 & $(6,052 ; 28,9)$ & $-1,007$ \\
\hline$\theta 22,2$ & 24,32 & 7,916 & 23,33 & $(11,83 ; 42,54)$ & 0,00213 \\
\hline$\theta 22,3$ & 24,82 & 7,752 & 23,88 & $(12,43 ; 42,63)$ & 0,3822 \\
\hline$\theta 22,4$ & 13,59 & 5,946 & 12,66 & $(4,79 ; 27,8)$ & $-1,205$ \\
\hline$\theta 23,1$ & 65,6 & 15,77 & 64,12 & $(39,02 ; 100,5)$ & $-1,599$ \\
\hline$\theta 23,2$ & 31,02 & 9,412 & 30 & $(15,54 ; 52,17)$ & $-0,7882$ \\
\hline$\theta 23,3$ & 41,56 & 11,17 & 40,43 & $(22,95 ; 66,7)$ & 0,0418 \\
\hline$\theta 23,4$ & 65,67 & 16,13 & 64,23 & $(38,23 ; 101,2)$ & 3,096 \\
\hline$\theta 24,1$ & 31,36 & 11,03 & 29,87 & $(14,17 ; 57,05)$ & 0,9559 \\
\hline$\theta 24,2$ & 28,78 & 9,827 & 27,53 & $(13,3 ; 51,55)$ & $-0,656$ \\
\hline$\theta 24,3$ & 41,63 & 12,67 & 39,97 & $(21,7 ; 70,92)$ & 0,9997 \\
\hline$\theta 24,4$ & 29,82 & 11,57 & 28,18 & $(12,23 ; 56,91)$ & $-1,797$ \\
\hline$\theta 25,1$ & 34,44 & 11,08 & 33,13 & $(16,52 ; 59,63)$ & $-0,000993$ \\
\hline$\theta 25,2$ & 59,29 & 15,35 & 57,64 & $(33,86 ; 93,73)$ & 0,9439 \\
\hline$\theta 25,3$ & 59,58 & 15,12 & 57,95 & $(34,9 ; 93,66)$ & 0,1060 \\
\hline$\theta 25,4$ & 50,53 & 14,69 & 49,03 & $(26,28 ; 83,37)$ & 1,329 \\
\hline$\theta 26,1$ & 25,48 & 9,612 & 24,11 & $(10,79 ; 47,96)$ & $-0,3645$ \\
\hline$\theta 26,2$ & 29,28 & 10,14 & 27,91 & $(13,59 ; 52,86)$ & $-1,052$ \\
\hline$\theta 26,3$ & 28,54 & 9,522 & 27,28 & $(13,6 ; 50,73)$ & $-1,127$ \\
\hline$\theta 26,4$ & 28,08 & 11,37 & 26,32 & $(11,06 ; 55,11)$ & $-1,869$ \\
\hline$\theta 27,1$ & 11,43 & 6,276 & 10,21 & $(2,896 ; 26,92)$ & $-0,2059$ \\
\hline$\theta 27,2$ & 25,91 & 11,39 & 23,9 & $(9,801 ; 53,69)$ & $-1,140$ \\
\hline$\theta 27,3$ & 14,11 & 6,604 & 13,04 & $(4,458 ; 30,03)$ & 1,011 \\
\hline$\theta 27,4$ & 9,907 & 6,514 & 8,439 & $(1,859 ; 26,49)$ & $-1,197$ \\
\hline$\theta 28,1$ & 18,62 & 6,095 & 17,88 & $(8,887 ; 32,55)$ & $-0,04555$ \\
\hline$\theta 28,2$ & 19,36 & 6,014 & 18,68 & $(9,695 ; 33,11)$ & 1,424 \\
\hline$\theta 28,3$ & 20,35 & 6,015 & 19,67 & $(10,61 ; 34,05)$ & $-0,8206$ \\
\hline$\theta 28,4$ & 15,92 & 5,873 & 15,1 & $(6,857 ; 29,67)$ & 0,5239 \\
\hline$\theta 29,1$ & 23,5 & 6,721 & 22,84 & $(12,31 ; 38,41)$ & $-1,353$ \\
\hline$\theta 29,2$ & 41,57 & 9,432 & 40,73 & $(25,62 ; 62,44)$ & 1,070 \\
\hline$\theta 29,3$ & 37,99 & 8,615 & 37,24 & $(23,31 ; 57,06)$ & 1,03 \\
\hline$\theta 29,4$ & 34,37 & 8,727 & 33,62 & $(19,62 ; 53,58)$ & 1,19 \\
\hline$\theta 30,1$ & 46,01 & 29,75 & 39,03 & $(10,71 ; 122,4)$ & 1,781 \\
\hline$\theta 30,2$ & 45,03 & 27,7 & 38,33 & $(11,97 ; 116)$ & 0,6815 \\
\hline$\theta 30,3$ & 42,1 & 25,31 & 36,13 & $(11,38 ; 106,4)$ & 0,777 \\
\hline
\end{tabular}




\begin{tabular}{|c|c|c|c|c|c|}
\hline$\theta 30,4$ & 147 & 94,93 & 124,8 & $(30,31 ; 391,4)$ & 1,310 \\
\hline$\theta 31,1$ & 25,79 & 8,978 & 24,53 & $(11,98 ; 46,69)$ & 0,549 \\
\hline$\theta 31,2$ & 15,9 & 5,952 & 15,05 & $(6,827 ; 29,93)$ & 0,7824 \\
\hline$\theta 31,3$ & 16,95 & 5,989 & 16,12 & $(7,719 ; 30,88)$ & 0,5378 \\
\hline$\theta 31,4$ & 17,74 & 7,375 & 16,62 & $(6,729 ; 35,16)$ & 0,8744 \\
\hline$\theta 32,1$ & 63,77 & 36,37 & 55,77 & $(17,41 ; 156,2)$ & $-0,7189$ \\
\hline$\theta 32,2$ & 60,84 & 33,42 & 53,48 & $(18,31 ; 145,2)$ & 0,4003 \\
\hline$\theta 32,3$ & 51,48 & 27,89 & 45,58 & $(15,41 ; 121,8)$ & $-0,4758$ \\
\hline$\theta 32,4$ & 218,3 & 104 & 200 & $(70,54 ; 468,8)$ & $-1,027$ \\
\hline$\theta 33,1$ & 334,4 & 167,9 & 304,5 & $(97,3 ; 742,4)$ & 0,4518 \\
\hline$\theta 33,2$ & 798,3 & 298,2 & 754,7 & $(346,7 ; 1498)$ & 1,381 \\
\hline$\theta 33,3$ & 542,8 & 223,8 & 507,2 & $(211,8 ; 1080)$ & $-0,9689$ \\
\hline$\theta 33,4$ & 1659 & 487,8 & 1608 & $(856,1 ; 2745)$ & 0,5254 \\
\hline$\theta 34,1$ & 158 & 54,03 & 150,3 & $(74,78 ; 284,3)$ & 0,2131 \\
\hline$\theta 34,2$ & 67,86 & 27,43 & 63,71 & $(27,03 ; 133,2)$ & 0,1551 \\
\hline$\theta 34,3$ & 76,46 & 28,65 & 72,38 & $(32,83 ; 143,9)$ & $-0,4641$ \\
\hline$\theta 34,4$ & 128,6 & 48,82 & 121,8 & $(53,27 ; 242,1)$ & $-0,5635$ \\
\hline$\theta 35,1$ & 31,17 & 7,627 & 30,49 & $(18,25 ; 48,01)$ & 0,2394 \\
\hline$\theta 35,2$ & 36,83 & 8,249 & 36,08 & $(22,81 ; 55,13)$ & $-0,4867$ \\
\hline$\theta 35,3$ & 27,57 & 6,674 & 26,99 & $(16,13 ; 42,23)$ & $-0,05736$ \\
\hline$\theta 35,4$ & 26,7 & 7,128 & 26,06 & $(14,72 ; 42,44)$ & $-1,325$ \\
\hline$\theta 36,1$ & 204,2 & 77,15 & 192,8 & $(87,3 ; 385,6)$ & 0,8386 \\
\hline$\theta 36,2$ & 224,7 & 78,68 & 213,8 & $(103,6 ; 409)$ & 0,4202 \\
\hline$\theta 36,3$ & 132,7 & 50,54 & 125,8 & $(54,44 ; 250,1)$ & $-1,256$ \\
\hline$\theta 36,4$ & 228,6 & 88,17 & 216,2 & $(94,17 ; 436,2)$ & $-0,05174$ \\
\hline$\theta 37,1$ & 25,56 & 7,625 & 24,77 & $(12,91 ; 42,62)$ & $-0,6591$ \\
\hline$\theta 37,2$ & 33,26 & 8,742 & 32,43 & $(18,59 ; 52,62)$ & 0,1218 \\
\hline$\theta 37,3$ & 37,44 & 9,23 & 36,56 & $(22 ; 58,06)$ & $-1,512$ \\
\hline$\theta 37,4$ & 23,37 & 7,436 & 22,53 & $(11,37 ; 40,29)$ & $-1,392$ \\
\hline$\theta 38,1$ & 11,69 & 4,856 & 10,92 & $(4,523 ; 23,27)$ & $-0,6443$ \\
\hline$\theta 38,2$ & 11,46 & 4,548 & 10,76 & $(4,683 ; 22,38)$ & 0,2085 \\
\hline$\theta 38,3$ & 9,749 & 3,817 & 9,194 & $(3,965 ; 18,72)$ & 0,5173 \\
\hline$\theta 38,4$ & 5,972 & 3,24 & 5,366 & $(1,557 ; 13,91)$ & $-0,3313$ \\
\hline$\theta 39,1$ & 11,69 & 3,928 & 11,19 & $(5,497 ; 20,71)$ & 0,06432 \\
\hline$\theta 39,2$ & 9,753 & 3,295 & 9,319 & $(4,538 ; 17,26)$ & 1,396 \\
\hline$\theta 39,3$ & 9,094 & 3,007 & 8,721 & $(4,307 ; 15,92)$ & 1,326 \\
\hline$\theta 39,4$ & 7,824 & 3,146 & 7,364 & $(3,099 ; 15,24)$ & 0,01901 \\
\hline$\theta 40,1$ & 26,28 & 11,1 & 24,65 & $(9,513 ; 52,34)$ & $-0,54$ \\
\hline$\theta 40,2$ & 49,5 & 16,95 & 47,08 & $(23,54 ; 89,25)$ & $-0,1465$ \\
\hline$\theta 40,3$ & 29,32 & 10,78 & 27,94 & $(12,41 ; 54,51)$ & $-0,7101$ \\
\hline$\theta 40,4$ & 48,6 & 18,83 & 45,93 & $(19,89 ; 93,01)$ & 0,5967 \\
\hline$\theta 41,1$ & 26,08 & 10,51 & 24,48 & $(10,35 ; 51)$ & 1,119 \\
\hline$\theta 41,2$ & 16,09 & 7,103 & 15,01 & $(5,477 ; 32,91)$ & 0,2005 \\
\hline$\theta 41,3$ & 22,42 & 8,761 & 21,14 & $(8,999 ; 42,91)$ & 0,6552 \\
\hline$\theta 41,4$ & 10,65 & 5,941 & 9,466 & $(2,665 ; 25,37)$ & 0,04437 \\
\hline$\theta 42,1$ & 81,21 & 27,87 & 77,29 & $(38,4 ; 146,6)$ & $-1,376$ \\
\hline
\end{tabular}




\begin{tabular}{llllll}
$\theta 42,2$ & 34,35 & 13,91 & 32,2 & $(13,55 ; 67,26)$ & $-0,2077$ \\
$\theta 42,3$ & 46,84 & 17,07 & 44,24 & $(21,16 ; 87,53)$ & $-0,6298$ \\
$\theta 42,4$ & 45,32 & 19,81 & 42,17 & $(15,84 ; 92,26)$ & $-0,3986$ \\
$\theta 43,1$ & 14,99 & 7,444 & 13,61 & $(4,623 ; 33,23)$ & 0,9371 \\
$\theta 43,2$ & 15,61 & 7,272 & 14,37 & $(5,138 ; 33,21)$ & 0,6175 \\
$\theta 43,3$ & 19,11 & 8,207 & 17,76 & $(97,23 ; 38,84)$ & 0,6699 \\
$\theta 43,4$ & 9,363 & 6,026 & 7,998 & $(1,865 ; 24,65)$ & 0,1197 \\
$\theta 44,1$ & 18,51 & 9,615 & 16,59 & $(5,712 ; 42,65)$ & $-0,5165$ \\
$\theta 44,2$ & 10,47 & 5,528 & 9,453 & $(2,883 ; 24,06)$ & $-0,1272$ \\
$\theta 44,3$ & 12,87 & 6,282 & 11,71 & $(4,19 ; 28,31)$ & 0,3043 \\
$\theta 44,4$ & 9,67 & 6,674 & 8,083 & $(1,709 ; 26,75)$ & 2,483 \\
\hline
\end{tabular}

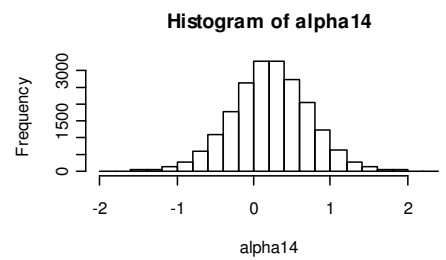

Series alpha14
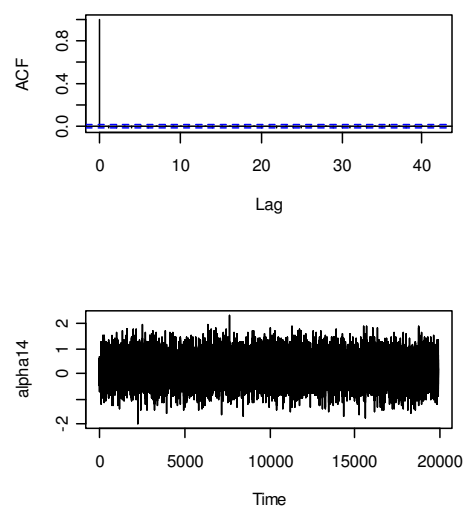

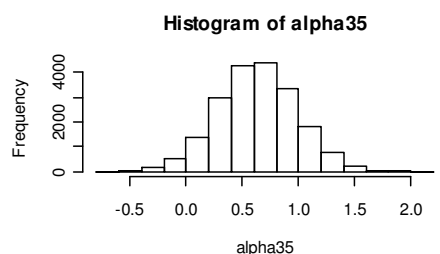

Series alpha35
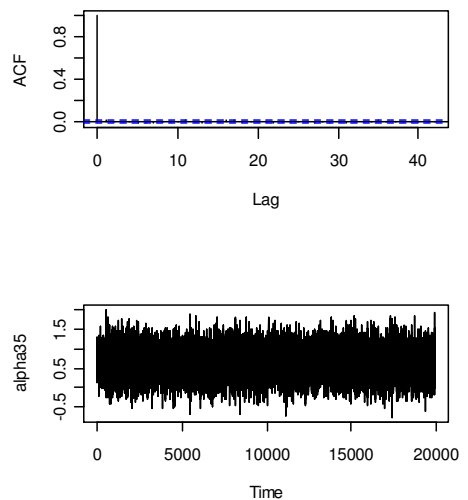

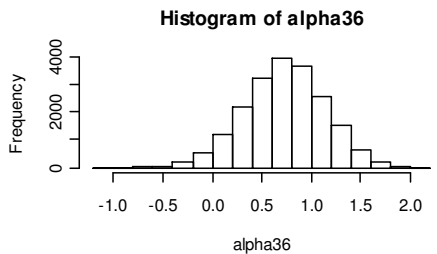

Series alpha36
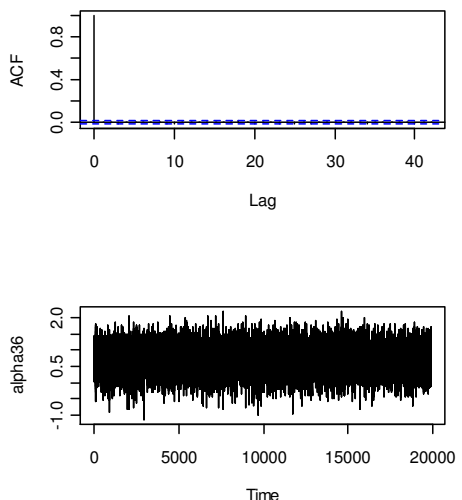


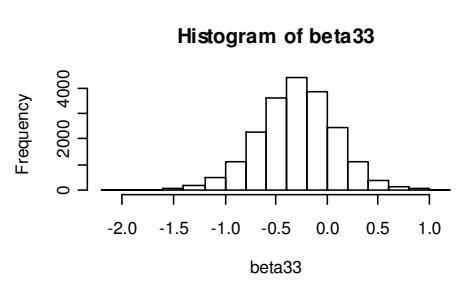

Series beta33
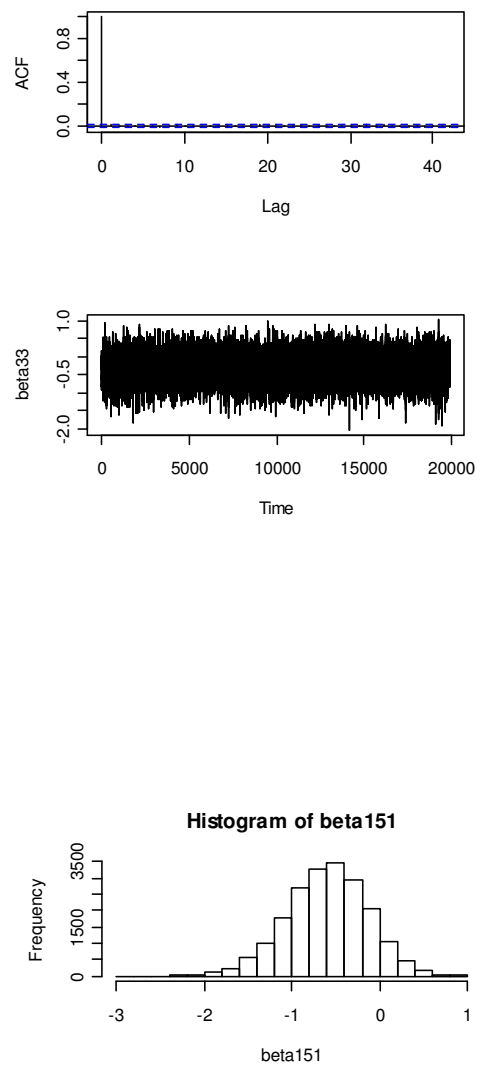

Series beta15
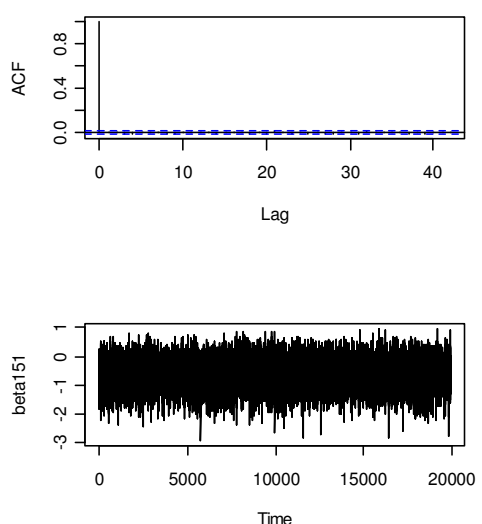
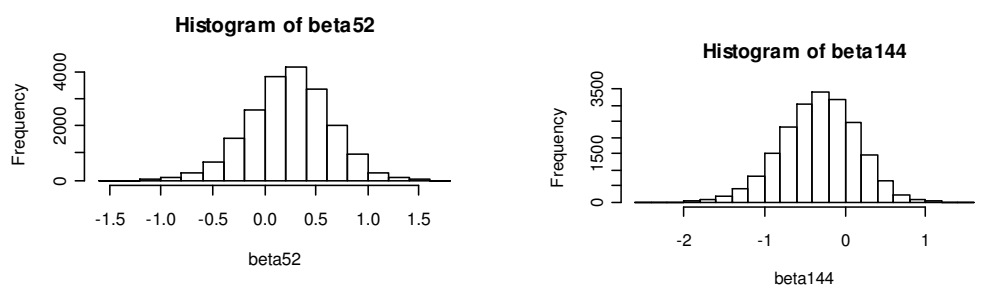

Series beta52
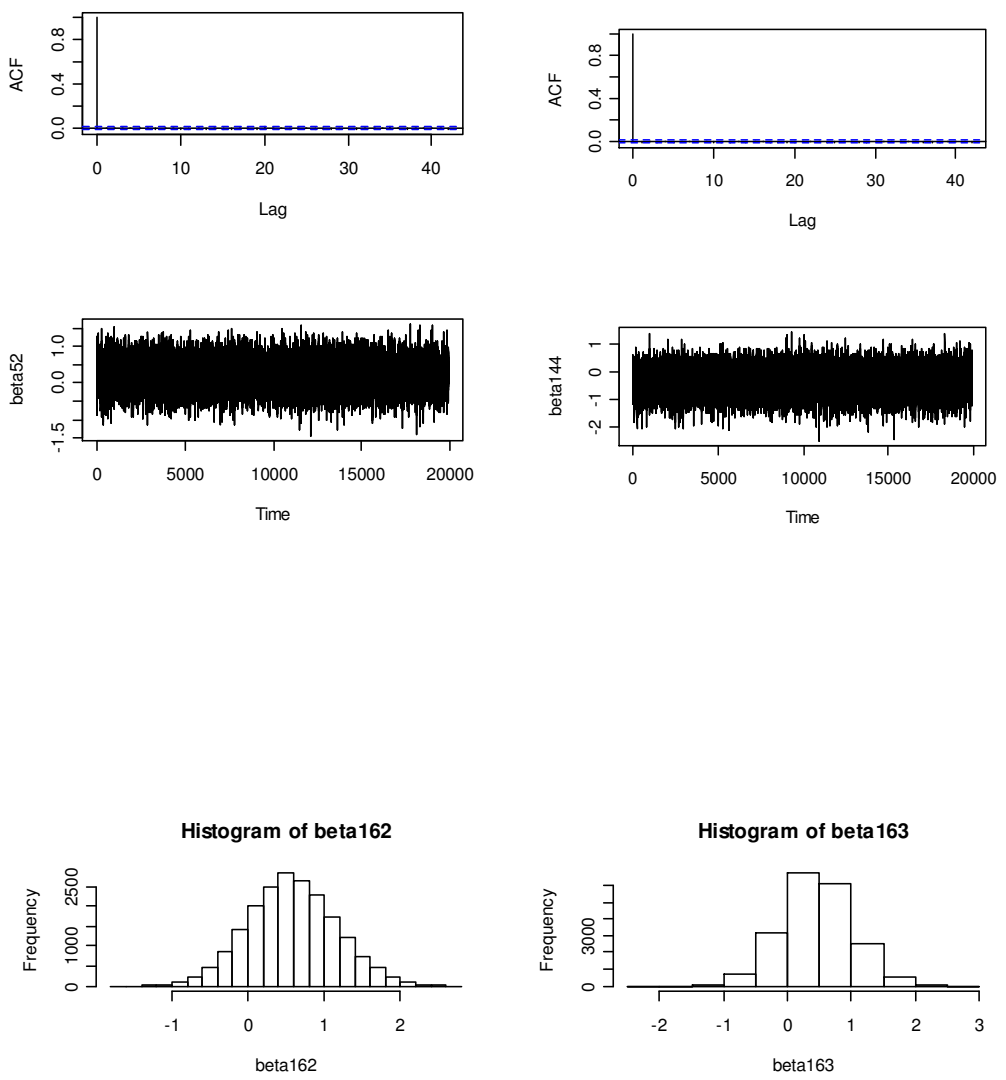

Series beta162
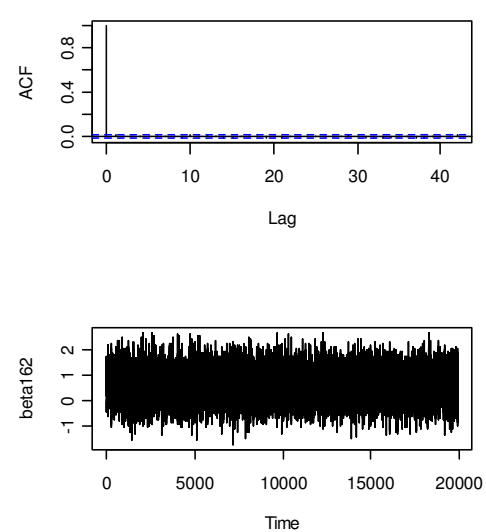
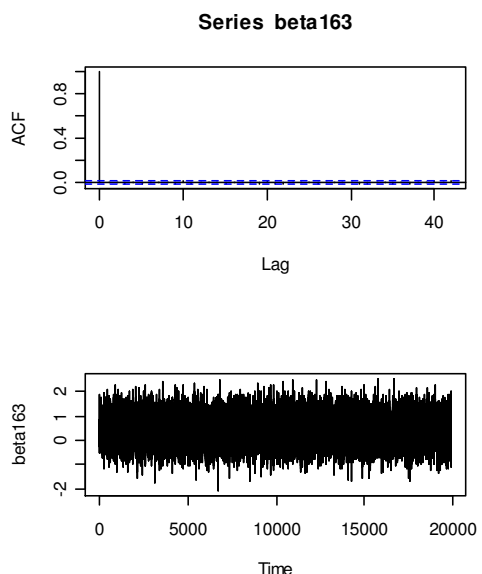


\section{Apêndices}

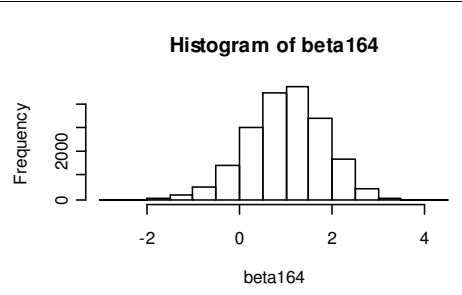

Series beta 164
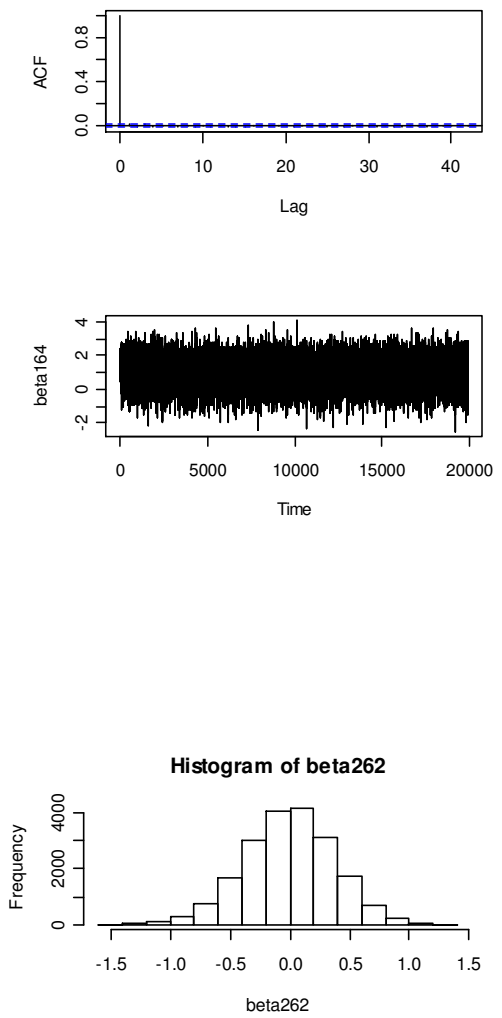

Series beta262
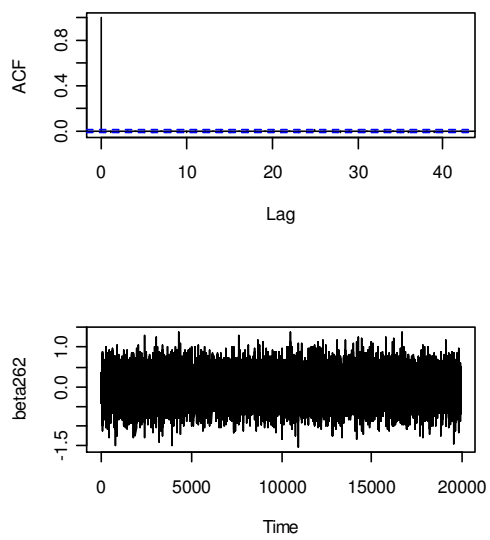

Histogram of beta 182

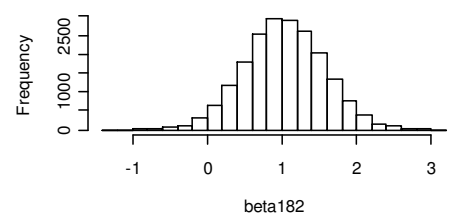

Series beta182
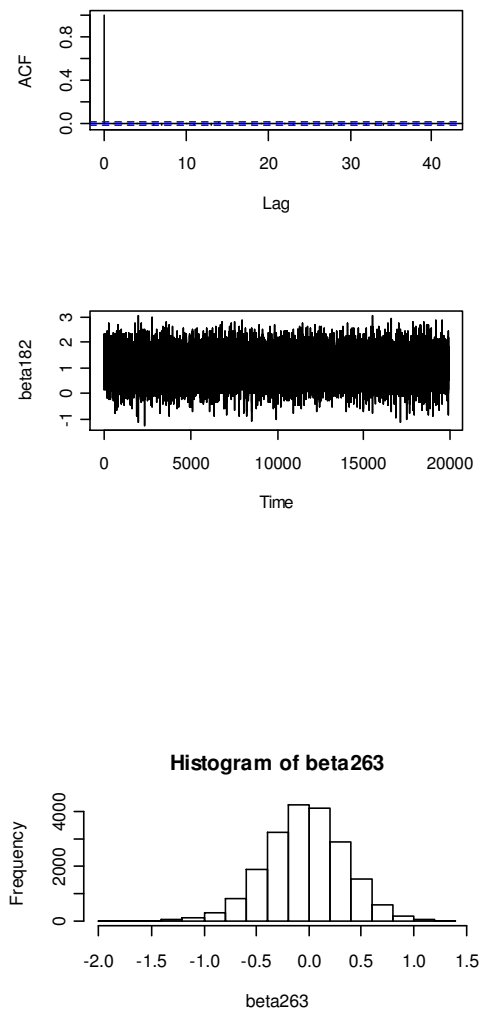

Series beta263
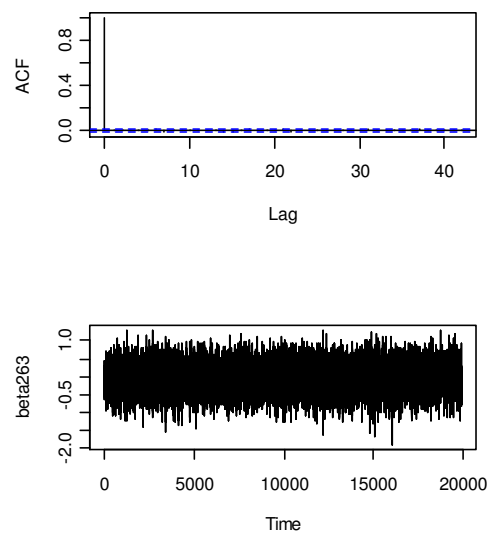

Histogram of beta221

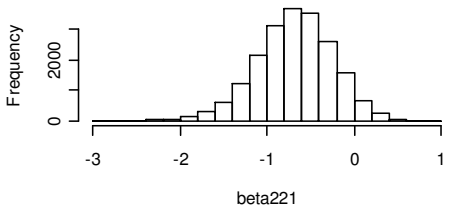

Series beta221
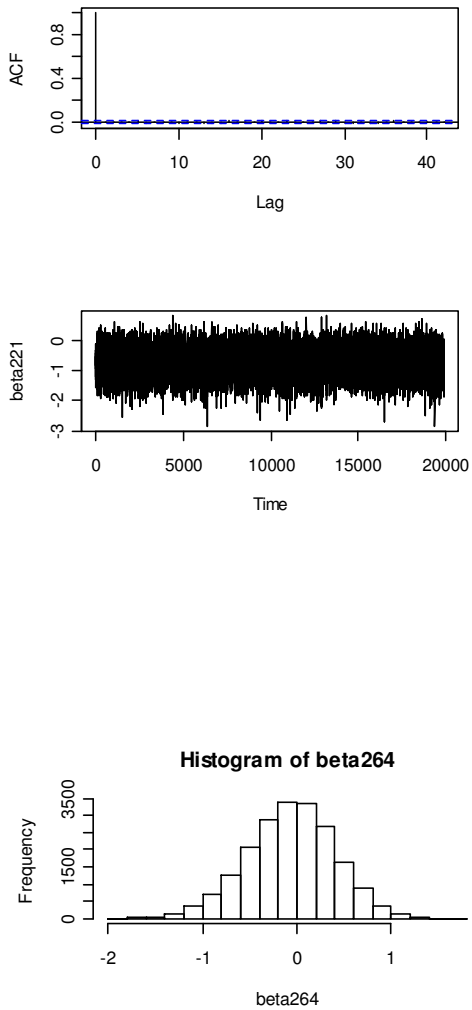

Series beta264
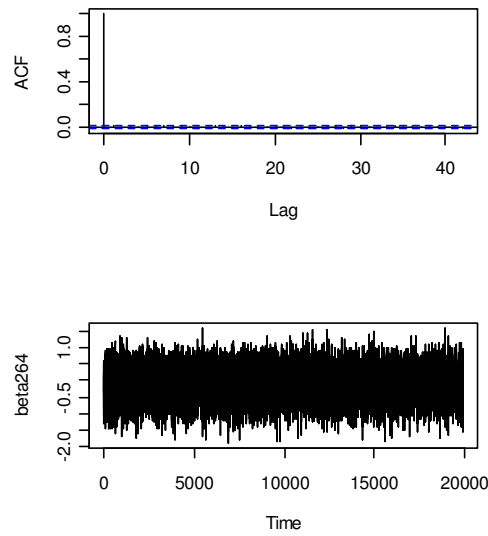

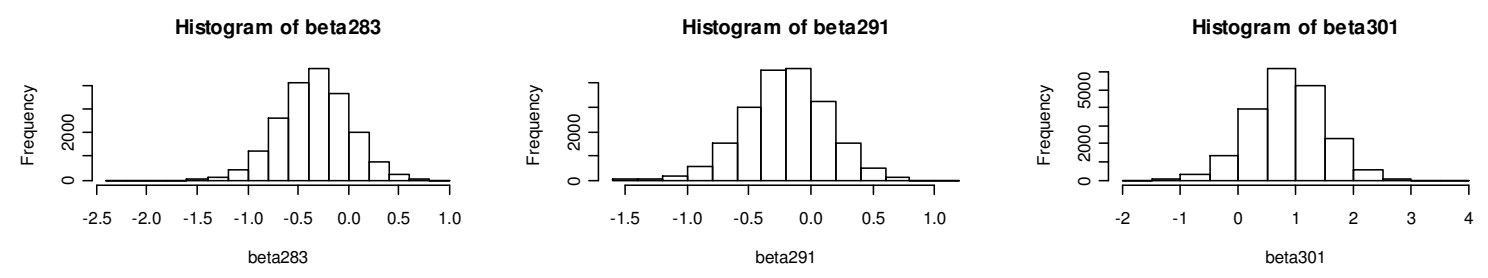

Series beta283

Series beta291
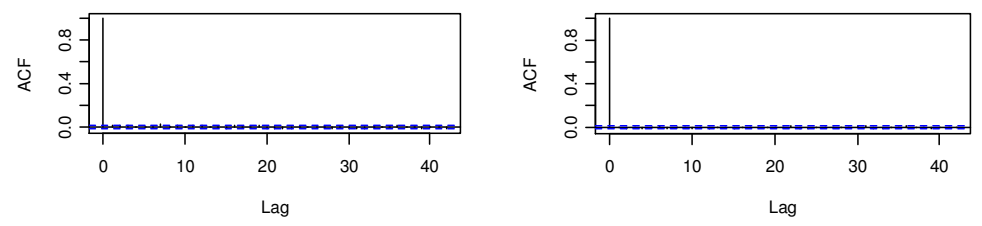

Series beta301
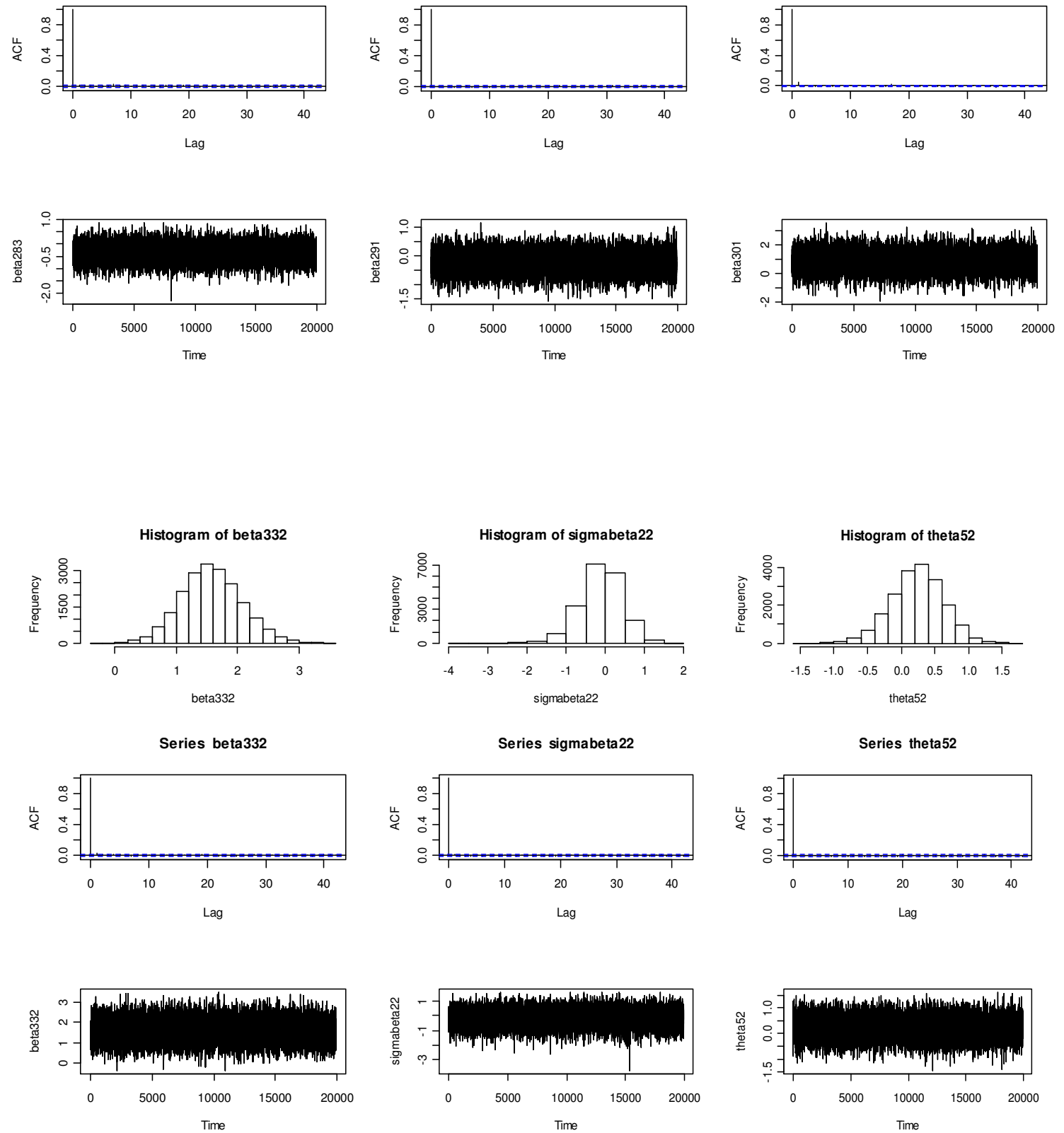


\section{Apêndices}

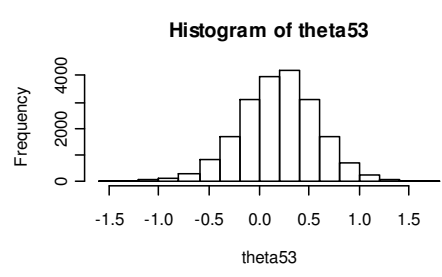

Series theta53
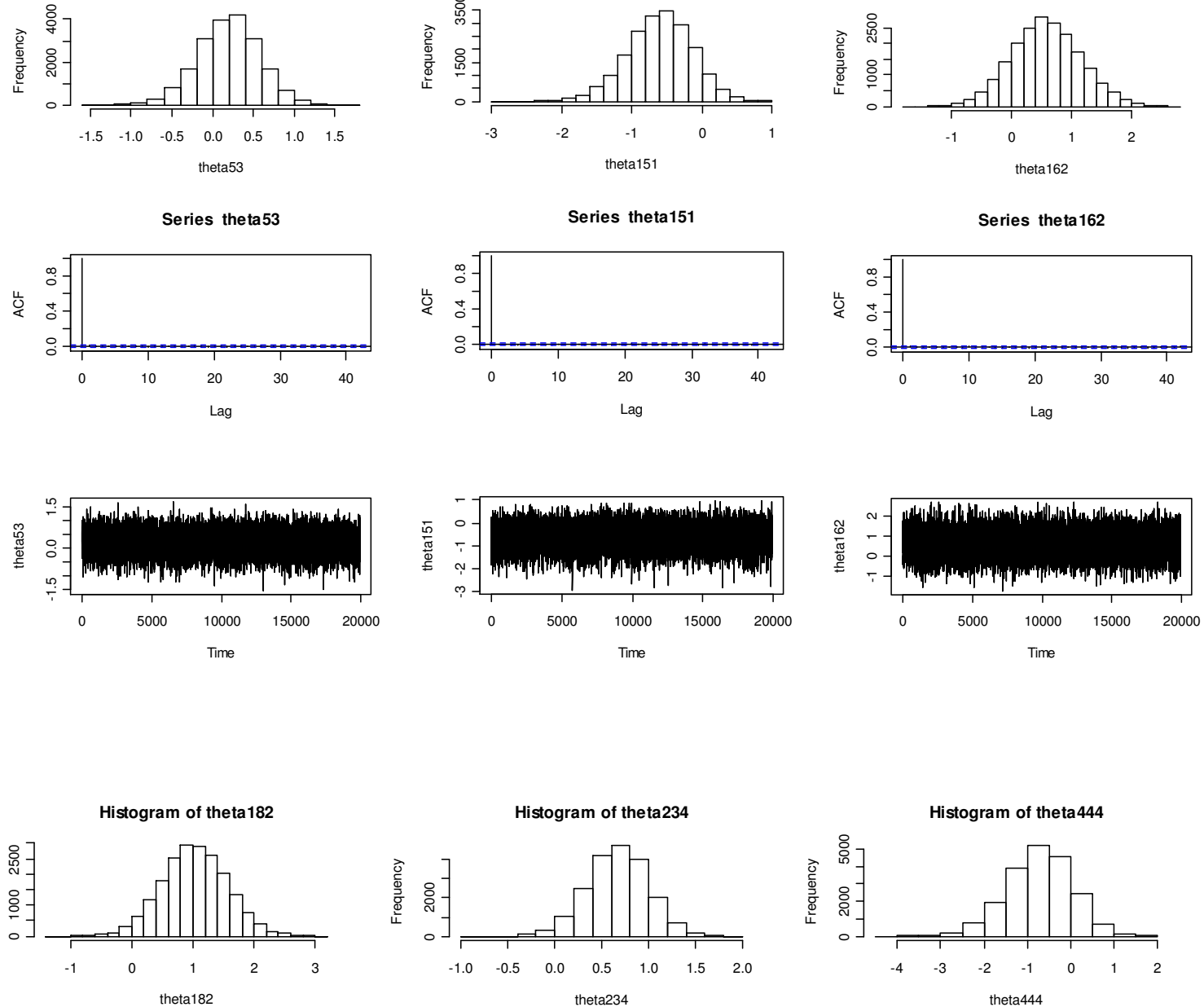

Series theta234

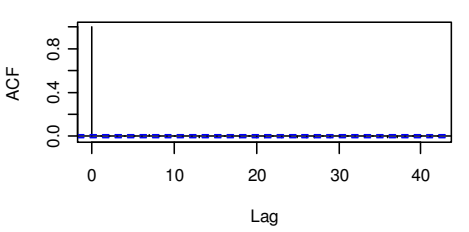

Series theta444
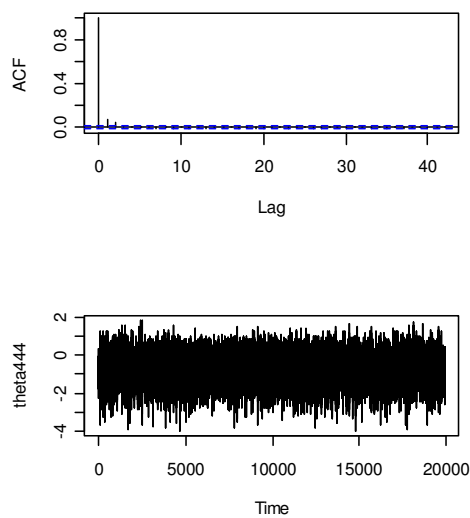


\section{APÊNDICE B}

\section{CÓDIGO WInBUGS PARA O MODELO 1}

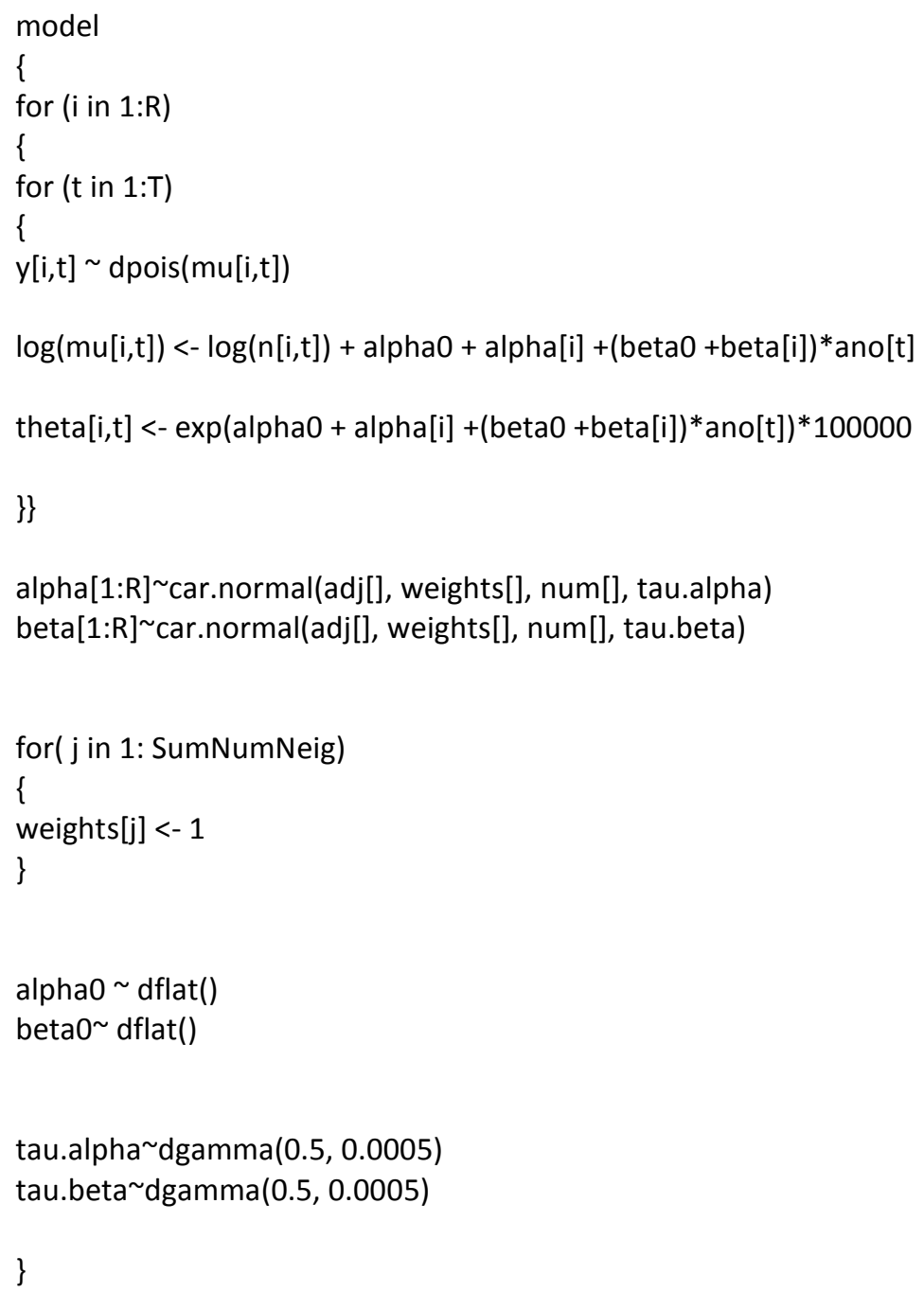

Neste e nos demais códigos WinBUGS utilizados nesta dissertação, car.normal(adj[], weights[], num[], tau.alpha) refere-se à distribuição condicional auto-regressiva (CAR) normal, onde adj[] é a matriz de vizinhanças, contendo a informação das áreas que são adjacentes a cada uma das áreas consideradas no modelo, weights[] é um vetor que permite ponderações na estrutura de vizinhança (no presente estudo, utilizamos pesos iguais em todas as adjacências), num[] é um vetor que contém o número de áreas adjacentes a cada uma das áreas, e tau.alpha é o inverso da variância da distribuição. A constante SumNumNeig refere-se à soma do número de vizinhanças de todas as 44 áreas consideradas no modelo. 
APÊNDICE C

CÓDIGO WIIBUGS PARA O MODELO 2

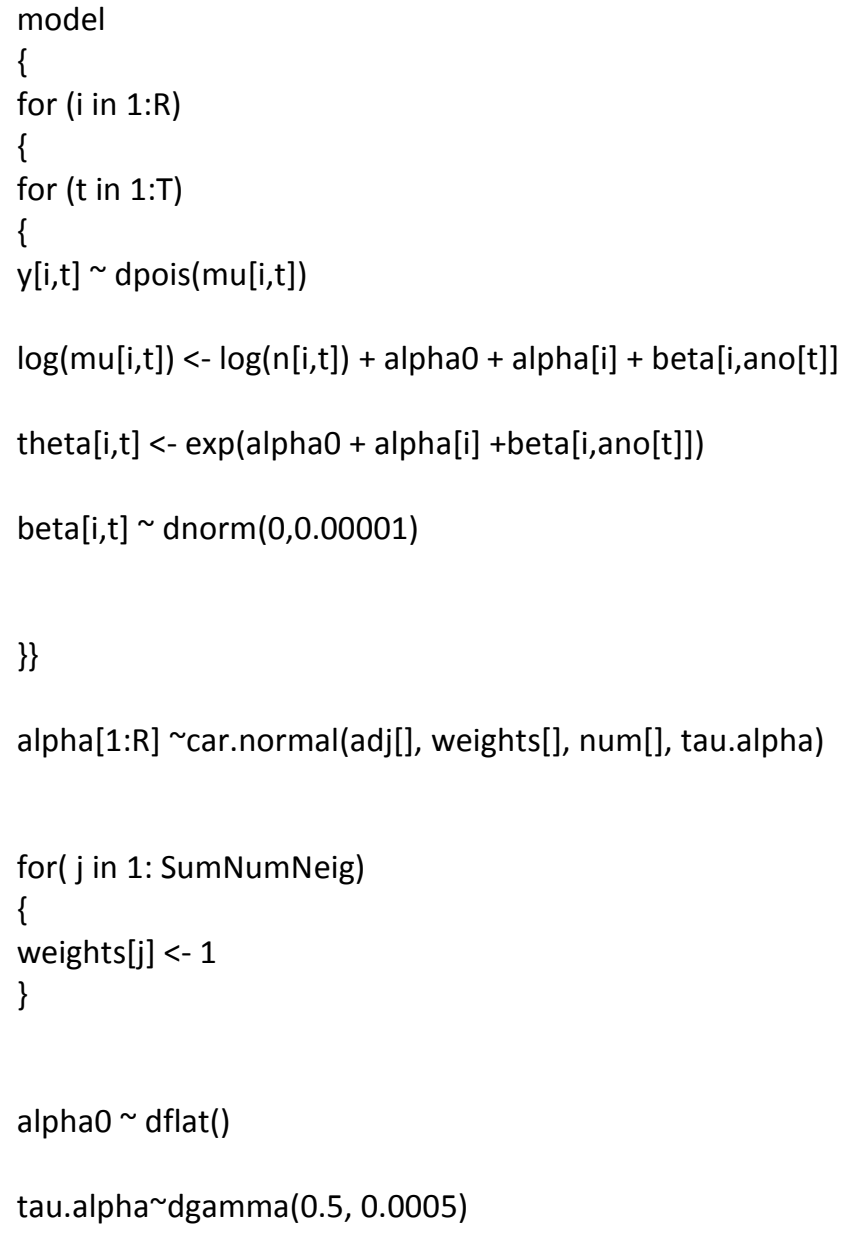




\section{APÊNDICE D}

\section{CÓDIGO WinBUGS PARA OS MODELOS 3.1 e 3.2}

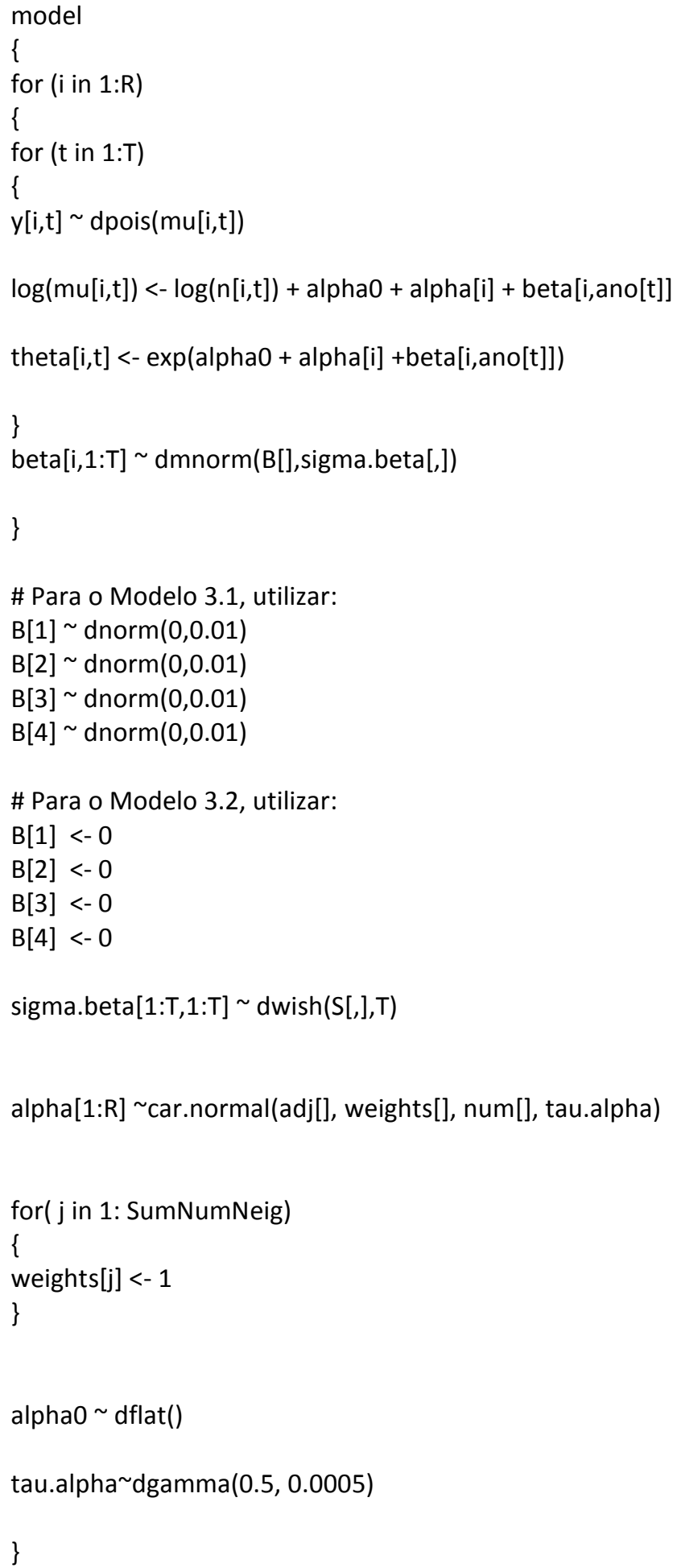




\section{APÊNDICE E \\ CÓDIGO WIIBUGS PARA OS MODELOS 4.1 a 4.4}

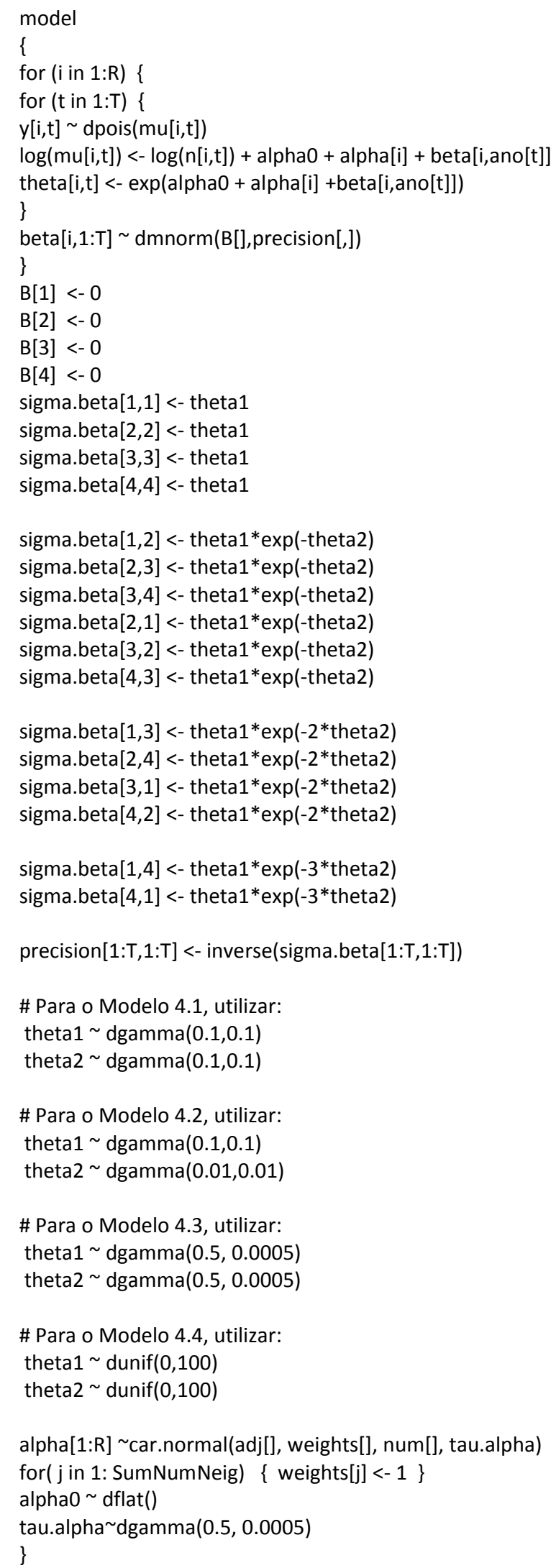




\section{APÊNDICE F}

\section{CÓDIGO WInBUGS PARA O MODELO 5}

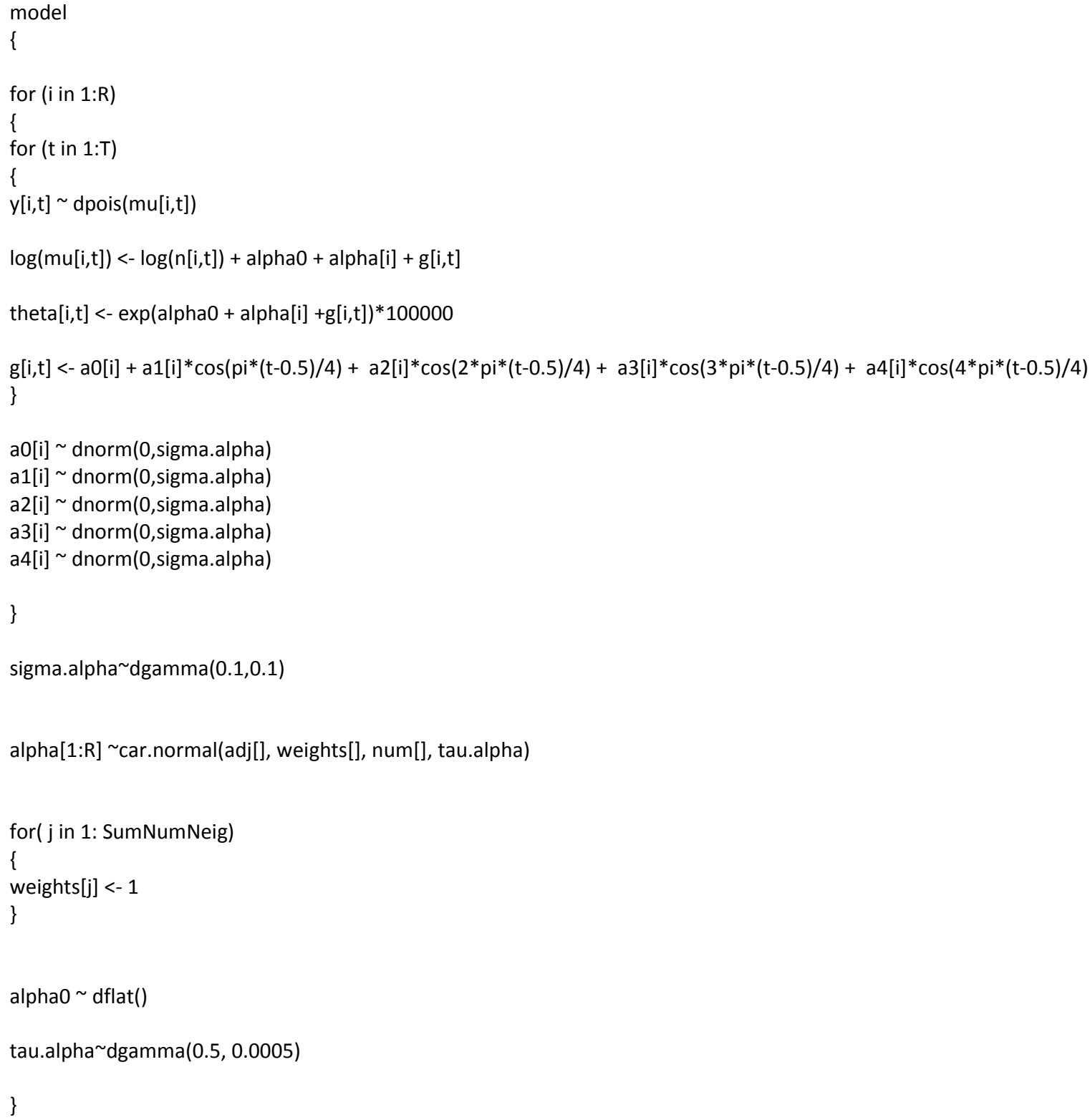




\section{APÊNDICE G}

TABELA DA INCIDÊNCIA DE CASOS DE TB EM RIBEIRÃO PRETO NOS ANOS DE 2006 a 2009

\begin{tabular}{|c|c|c|c|c|c|}
\hline Área & Responsabilidade Sanitária & 2006 & 2007 & 2008 & 2009 \\
\hline 1. Heitor Rigon & UBS Heitor Rigon & 16,65 & 51,08 & 16,70 & 82,76 \\
\hline 2. Geraldo Correia de Carvalho & USF Geraldo C. de Carvalho & 49,67 & 0 & 49,80 & 49,35 \\
\hline 3. Marincek & UBS Marincek & 12,55 & 32,08 & 25,17 & 18,71 \\
\hline 4. Valentina Figueiredo & UBS Valentina Figueiredo & 0 & 82,30 & 40,37 & 40,01 \\
\hline 5. Adelino Simioni & UBS Adelino Simioni & 27,77 & 42,58 & 41,77 & 69,00 \\
\hline 6. Estação do Alto & USF Estação do Alto & 67,52 & 69,03 & 50,77 & 67,10 \\
\hline 7. Quintino II & UBDS Quintino II & 13,02 & 26,62 & 26,11 & 25,87 \\
\hline 8. Avelino Palma & UBS Avelino Palma & 22,36 & 38,10 & 37,37 & 29,63 \\
\hline 9. Quintino I & UBS Quintino I & 46,24 & 18,91 & 74,19 & 64,34 \\
\hline 10. Vila Mariana & UBS Vila Mariana & 16,63 & 42,52 & 33,36 & 8,26 \\
\hline 11. Jardim Aeroporto & UBS Jardim Aeroporto & 55,68 & 56,93 & 63,81 & 39,53 \\
\hline 12. Ribeirão Verde & UBS Ribeirão Verde & 50,92 & 34,71 & 68,08 & 50,61 \\
\hline 13. Dom Mielle & UBS Dom Mielle & 26,09 & 0 & 17,44 & 8,64 \\
\hline 14. José Sampaio & UBS José Sampaio & 26,94 & 27,54 & 20,26 & 26,77 \\
\hline 15. Maria Casagrande & UBS Maria Casagrande & 11,66 & 47,68 & 70,15 & 23,17 \\
\hline 16. Eugênio Mendes Lopes & USF Eugênio Mendes Lopes & 304,87 & 311,52 & 0 & 303,03 \\
\hline 17. Portal do Alto & USF Portal do Alto & 0 & 0 & 0 & 0 \\
\hline 18. Jardim Paiva & UBS Jardim Paiva & 405,67 & 207,46 & 813,00 & 403,22 \\
\hline 19. Campus da USP & UBDS Sumarezinho & 0 & 0 & 0 & 0 \\
\hline 20. Vila Lobato & UBS Vila Lobato & 12,87 & 32,78 & 19,29 & 38,24 \\
\hline 21. Sumarezinho & UBDS Sumarezinho & 84,79 & 28,89 & 63,77 & 84,27 \\
\hline 22. Ipiranga & UBS Ipiranga & 8,94 & 27,41 & 31,37 & 8,88 \\
\hline 23. Vila Recreio & UBS Vila Recreio & 72,39 & 19,73 & 38,71 & 71,95 \\
\hline 24. Dutra & UBS Dutra & 27,78 & 21,30 & 55,71 & 27,61 \\
\hline 25. Vila Albertina & UBS Vila Albertina & 28,19 & 69,16 & 73,49 & 44,82 \\
\hline 26. Vila Tibério I & UBS Vila Tibério I & 21,85 & 29,78 & 29,21 & 28,95 \\
\hline 27. Vila Tibério II & UBS Vila Tibério II & 0 & 50,70 & 0 & 0 \\
\hline
\end{tabular}


Apêndices

\begin{tabular}{|c|c|c|c|c|c|}
\hline 28. Central & UBDS Central & 16,51 & 16,88 & 19,87 & 16,41 \\
\hline 29. Campos Elíseos & UBS Campos Elíseos & 19,50 & 45,57 & 41,90 & 33,22 \\
\hline 30. Campus Moura Lacerda & UBS Campos Elíseos & 0 & 0 & 0 & 364,63 \\
\hline 31. João Rossi & UBS João Rossi & 34,49 & 15,11 & 14,82 & 14,69 \\
\hline 32. Jardim Recreio & UBDS Vila Virgínia & 62,57 & 63,97 & 0 & 373,13 \\
\hline 33. Jardim Itaú & UBDS Vila Virgínia & 0 & 1170,56 & 656,81 & 1951,22 \\
\hline 34. Adão do Carmo & UBS Adão do Carmo & 234,19 & 53,20 & 52,19 & 129,99 \\
\hline 35. Vila Virgínia & UBDS Vila Virgínia & 32,42 & 40,80 & 25,01 & 24,78 \\
\hline 36. Maria das Graças & UBS Maria das Graças & 247,27 & 303,33 & 0 & 245,70 \\
\hline 37. Parque Ribeirão & UBS Parque Ribeirão & 20,08 & 30,80 & 40,27 & 23,28 \\
\hline 38. Santa Cruz & UBS Santa Cruz & 14,84 & 15,18 & 7,44 & 0 \\
\hline 39. Castelo Branco & UBDS Castelo Branco & 12,18 & 8,30 & 6,10 & 8,07 \\
\hline 40. Jardim Zara & USF Jardim Zara & 10,39 & 63,73 & 10,41 & 61,95 \\
\hline 41. Vila Abranches & UBS Vila Abranches & 28,28 & 0 & 21,27 & 7,02 \\
\hline 42. Jardim Juliana & UBS Jardim Juliana & 123,15 & 27,97 & 54,87 & 27,19 \\
\hline 43. São José & UBS São José & 9,56 & 9,77 & 28,76 & 0 \\
\hline 44. Bonfim Paulista & UBS Bonfim Paulista & 34,62 & 0 & 11,57 & 0 \\
\hline
\end{tabular}




\section{APÊNDICE H}

TABELA DA MÉDIA AJUSTADA DA INCIDÊNCIA DE CASOS DE TB PELO MELHOR MODELO PARA RIBEIRÃO PRETO NOS ANOS DE 2006 a 2009

\begin{tabular}{|c|c|c|c|c|c|}
\hline Área & Responsabilidade Sanitária & 2006 & 2007 & 2008 & 2009 \\
\hline 1. Heitor Rigon & UBS Heitor Rigon & 34,85 & 47,90 & 36,60 & 58,31 \\
\hline 2. Geraldo Correia de Carvalho & USF Geraldo C. de Carvalho & 40,75 & 33,78 & 38,23 & 41,01 \\
\hline 3. Marincek & UBS Marincek & 19,95 & 28,17 & 25,13 & 19,96 \\
\hline 4. Valentina Figueiredo & UBS Valentina Figueiredo & 32,14 & 47,81 & 39,45 & 42,62 \\
\hline 5. Adelino Simioni & UBS Adelino Simioni & 38,48 & 45,65 & 43,24 & 56,25 \\
\hline 6. Estação do Alto & USF Estação do Alto & 57,71 & 59,72 & 53,29 & 69,05 \\
\hline 7. Quintino II & UBDS Quintino II & 23,71 & 27,37 & 26,81 & 23,71 \\
\hline 8. Avelino Palma & UBS Avelino Palma & 28,14 & 35,59 & 34,43 & 30,73 \\
\hline 9. Quintino I & UBS Quintino I & 48,44 & 37,09 & 57,33 & 58,37 \\
\hline 10. Vila Mariana & UBS Vila Mariana & 22,06 & 31,75 & 28,47 & 18,79 \\
\hline 11. Jardim Aeroporto & UBS Jardim Aeroporto & 50,31 & 51,69 & 54,53 & 48,82 \\
\hline 12. Ribeirão Verde & UBS Ribeirão Verde & 47,96 & 43,30 & 51,38 & 52,28 \\
\hline 13. Dom Mielle & UBS Dom Mielle & 21,89 & 12,79 & 17,38 & 11,14 \\
\hline 14. José Sampaio & UBS José Sampaio & 27,90 & 27,61 & 25,42 & 25,35 \\
\hline 15. Maria Casagrande & UBS Maria Casagrande & 27,20 & 41,86 & 46,56 & 32,55 \\
\hline 16. Eugênio Mendes Lopes & USF Eugênio Mendes Lopes & 107,50 & 120,20 & 95,29 & 198,10 \\
\hline 17. Portal do Alto & USF Portal do Alto & 36,86 & 37,05 & 36,00 & 40,42 \\
\hline 18. Jardim Paiva & UBS Jardim Paiva & 212,00 & 214,20 & 270,90 & 464,40 \\
\hline 19. Campus da USP & UBDS Sumarezinho & 25,85 & 24,71 & 24,87 & 22,12 \\
\hline 20. Vila Lobato & UBS Vila Lobato & 22,94 & 32,17 & 26,09 & 30,58 \\
\hline 21. Sumarezinho & UBDS Sumarezinho & 75,46 & 42,49 & 59,36 & 79,25 \\
\hline 22. Ipiranga & UBS Ipiranga & 15,89 & 24,32 & 25,43 & 13,68 \\
\hline 23. Vila Recreio & UBS Vila Recreio & 65,46 & 31,61 & 41,73 & 64,56 \\
\hline 24. Dutra & UBS Dutra & 31,41 & 28,84 & 41,74 & 29,84 \\
\hline 25. Vila Albertina & UBS Vila Albertina & 35,18 & 62,15 & 61,65 & 50,38 \\
\hline 26. Vila Tibério I & UBS Vila Tibério I & 26,73 & 30,09 & 29,52 & 27,52 \\
\hline
\end{tabular}


Apêndices

\begin{tabular}{|c|c|c|c|c|c|}
\hline 27. Vila Tibério II & UBS Vila Tibério II & 12,38 & 25,08 & 14,40 & 10,16 \\
\hline 28. Central & UBDS Central & 19,09 & 18,81 & 20,29 & 15,62 \\
\hline 29. Campos Elíseos & UBS Campos Elíseos & 24,43 & 43,00 & 39,17 & 33,78 \\
\hline 30. Campus Moura Lacerda & UBS Campos Elíseos & 66,75 & 74,90 & 66,54 & 159,40 \\
\hline 31. João Rossi & UBS João Rossi & 28,68 & 18,03 & 19,41 & 16,22 \\
\hline 32. Jardim Recreio & UBDS Vila Virgínia & 87,87 & 98,22 & 78,63 & 221,70 \\
\hline 33. Jardim Itaú & UBDS Vila Virgínia & 239,20 & 767,20 & 457,80 & 1731,0 \\
\hline 34. Adão do Carmo & UBS Adão do Carmo & 148,80 & 68,81 & 73,19 & 131,10 \\
\hline 35. Vila Virgínia & UBDS Vila Virgínia & 31,36 & 36,93 & 27,73 & 26,81 \\
\hline 36. Maria das Graças & UBS Maria das Graças & 151,40 & 181,90 & 97,87 & 251,70 \\
\hline 37. Parque Ribeirão & UBS Parque Ribeirão & 24,15 & 30,89 & 35,36 & 24,78 \\
\hline 38. Santa Cruz & UBS Santa Cruz & 13,39 & 12,14 & 10,97 & 5,64 \\
\hline 39. Castelo Branco & UBDS Castelo Branco & 12,89 & 9,96 & 9,80 & 7,11 \\
\hline 40. Jardim Zara & USF Jardim Zara & 26,99 & 50,35 & 30,18 & 47,94 \\
\hline 41. Vila Abranches & UBS Vila Abranches & 22,79 & 12,06 & 18,15 & 10,75 \\
\hline 42. Jardim Juliana & UBS Jardim Juliana & 80,77 & 36,47 & 47,96 & 45,66 \\
\hline 43. São José & UBS São José & 15,34 & 14,40 & 18,51 & 9,20 \\
\hline 44. Bonfim Paulista & UBS Bonfim Paulista & 21,76 & 11,77 & 15,05 & 9,21 \\
\hline
\end{tabular}


ANEXO

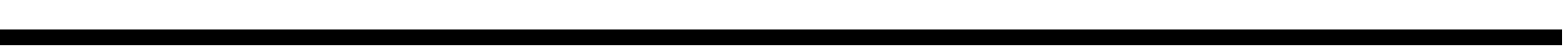





\section{ANEXO A}

Aprovação do Comitê de Ética em Pesquisa

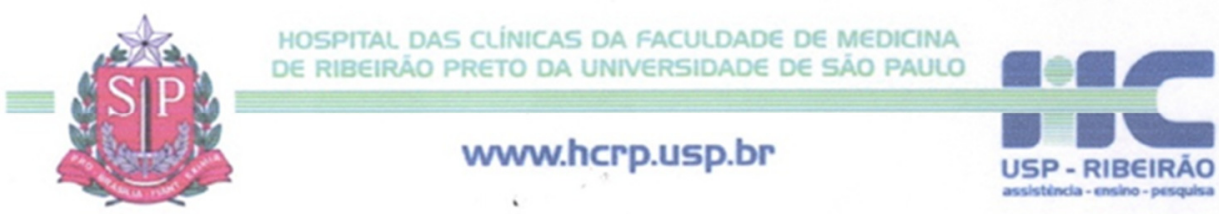

Ribeirão Preto, 08 de dezembro de 2009

Oficio $n^{\circ} 4095 / 2009$

$\mathrm{CEP} / \mathrm{MGV}$

Prezados Senhores,

O trabalho intitulado "TÉCNICAS ESTATÍSTICAS E ANÁLISE ESPACIAL APLICADAS EM DADOS DE TUBERCULOSE: USO DE UM MODELO BAYESIANO AUTO-REGRESSIVO CONDICIONAL E OUTRAS TÉCNICAS TRADICIONAIS" foi analisado pelo Comitê de Ética em Pesquisa, em sua $300^{\alpha}$ Reunião Ordinária realizada em 07/12/2009 e enquadrado na categoria: APROVADO, de acordo com o Processo HCRP n ${ }^{\circ}$ $11304 / 2009$.

Este Comitê segue integralmente a Conferência Internacional de Harmonizaçāo de Boas Práticas Clínicas (IGH-GCP), bem como a Resoluçāo no 196/96 CNS/MS.

Lembramos que devem ser apresentados a este CEP, 0 Relatório Parcial e o Relatório Final da pesquisa.

Atenciosamente.

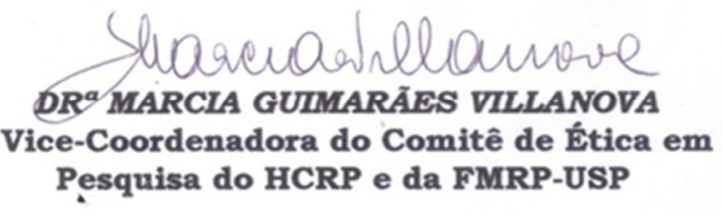

Ilustríssimos Senhores

DAIANE LEITE DA ROZA

PROF. DR. EDSON ZANGIACOMI MARTINEZ

Depto. de Medicina Social

Comitê de Ética em Pesquisa HCRP e FMRP-USP - Campus Universitário

FWA - 0000 2733; IRB - 00002186 e Registro SISNEPICONEP n ${ }^{\circ} 4$

Fone (16) 3602-2228 - E-mail : cep@hcrp.usp.br

Monte Alegre 14048-900 Ribeirăo Preto SP 